\title{
Going to the Mines to Look for Diamonds \\ Experimenting with \\ Military Recruiting Stations in Malls
}

Ronald D. Fricker, Jr.

C. Christine Fair

Prepared for the Office of the Secretary of Defense

RAND

National Defense Research Institute 
The research described in this report was sponsored by the Office of the Secretary of Defense (OSD). The research was conducted in RAND's National Defense Research Institute, a federally funded research and development center supported by the OSD, the Joint Staff, the unified commands, and the defense agencies under Contract DASW01-01-C-0004.

\section{Library of Congress Cataloging-in-Publication Data}

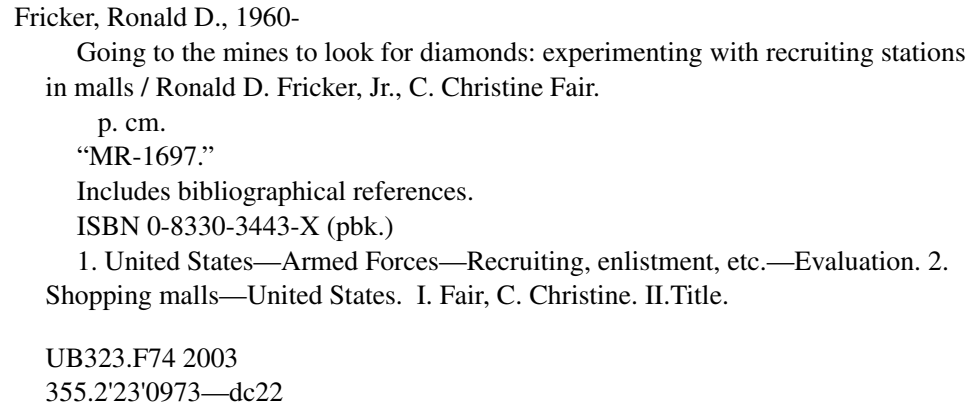

2003015007

Cover photograph courtesy of Ronald D. Fricker, Jr.

RAND is a nonprofit institution that helps improve policy and decisionmaking through research and analysis. RAND ${ }^{\circledR}$ is a registered trademark. RAND's publications do not necessarily reflect the opinions or policies of its research sponsors.

Cover design by Barbara Angell Caslon

(C) Copyright 2003 RAND

All rights reserved. No part of this book may be reproduced in any form by any electronic or mechanical means (including photocopying, recording, or information storage and retrieval) without permission in writing from RAND.

Published 2003 by RAND

1700 Main Street, P.O. Box 2138, Santa Monica, CA 90407-2138 1200 South Hayes Street, Arlington, VA 22202-5050

201 North Craig Street, Suite 202, Pittsburgh, PA 15213-1516

RAND URL: http://www.rand.org/

To order RAND documents or to obtain additional information, contact Distribution Services: Telephone: (310) 451-7002;

Fax: (310) 451-6915; Email: order@rand.org 


\section{PREFACE}

In 1999, with the intention of improving the process by which the United States armed forces recruit youth to join the military services, the Joint Recruiting Facilities Committee recommended the development and establishment of a new type of recruiting station: the marketing-enhanced recruiting station (MERS). The goal was to employ the MERS in support of actual recruiting operations while also using it to raise awareness in the general public of the military services as employment and career opportunities. To accomplish this goal, the marketing-enhanced recruiting stations concept combines both marketing and recruiting operations in a single facility, to be located in high-foot-traffic locations, such as large regional malls.

The MERS was envisioned to be an upgraded recruiting station, complete with special "marketing enhancements"-television and video monitors for playing U.S. armed forces' advertisements, a computer kiosk enabling access to military web sites, and other "high-tech" features-that would present an inviting image of the military to youth and the adults who may influence their enlistment decisions ("influencers"). It would entice the youth and their influencers to enter the facility, expose them to the positive aspects of military service, and facilitate their exploration of the available opportunities.

In early 2000, the Under Secretary of Defense for Personnel and Readiness authorized the construction of a prototype marketingenhanced recruiting station in the Potomac Mills Mall located in northern Virginia. That MERS began operation in December 2000 with the expectation that 30 additional MERS would be opened 
subsequently throughout the country. However, before proceeding further, the Department of Defense decided first to formally evaluate the Potomac Mills station's performance. RAND was asked to conduct the evaluation.

This report summarizes the results of that evaluation. It includes (1) statistical information about the performance of the Potomac Mills station; (2) information about how the services used the station, including employment of civilian administrators; (3) conclusions about the potential of the MERS concept in general, as well as ways in which this particular station might be improved; (4) case studies of standard recruiting stations located in other retail malls; and (5) recommendations about how the services and the Office of the Secretary of Defense might utilize this prototype station to experiment further with and learn about the effectiveness of various recruiting practices and techniques.

Because this evaluation is based on only one station, the results are not predictive of the overall success or failure of the general MERS concept, since it cannot account for how other marketing-enhanced recruiting stations would perform in other parts of the country or under other conditions. Instead, these results indicate how one MERS performed under one set of operating conditions and recruiting policies. However, this report is able to provide some insight into how the MERS concept could be modified in the future for improved performance.

This research should be of interest to the Office of the Secretary of Defense, particularly the Office of the Under Secretary of Defense (Personnel and Readiness); the services' recruiting commands and commanders; the various committees and joint councils that oversee, coordinate, and manage military recruiting (including the Joint Recruiting Facilities Committee, the Midlevel Interservice Recruitment Committee, the Accession Oversight Council, and the Joint Accession Group); and individual recruiters and researchers interested in recruiting issues and initiatives.

This research was originally sponsored by the Assistant Secretary of Defense (Force Management Policy) and was conducted within the Forces and Resources Policy Center of RAND's National Defense Research Institute (NDRI). NDRI is a federally funded research and de- 
velopment center sponsored by the Office of the Secretary of Defense, the Joint Staff, the unified commands, and the defense agencies.

Comments on this research are welcome and may be addressed to Ron Fricker, ron_fricker@rand.org. For more information on RAND's Forces and Resources Policy Center, contact the director, Susan Everingham, susan_everingham@rand.org, 310-393-0411, extension 7654 . 



\section{CONTENTS}

Preface $\ldots \ldots \ldots \ldots \ldots \ldots \ldots \ldots \ldots \ldots \ldots \ldots \ldots$ iii

Figures $\ldots \ldots \ldots \ldots \ldots \ldots \ldots \ldots \ldots \ldots \ldots \ldots \ldots \ldots \ldots \ldots \ldots$

Tables...................... xiii

Summary ......................... Xv

Acknowledgments ..................... Xxv

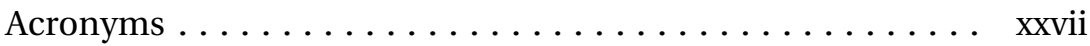

Chapter One

INTRODUCTION .................. 1

Recruiting Stations and the Recruiting Process . . . . . . . . . . 3

Marketing-Enhanced Recruiting Stations . . . . . . . . . . . . 7

Recruiters' Opinions About Recruiting Stations ........ 9

Study Design Limitations $\ldots \ldots \ldots \ldots \ldots \ldots$

Organization of This Report . . . . . . . ..... 12

Chapter Two

THE PROTOTYPE MARKETING-ENHANCED

RECRUITING STATION AT POTOMAC MILLS MALL . . . 13

Potomac Mills Mall . . . . . . . . . . . . . . . . . . . . . . . . . 15

Station Location in the Mall . . . . . . . . . . . . . . . . 15

Potomac Mills Recruiting Station Design and Layout . . . 16

Rationale for Choosing This Design ... . . . . . . 19

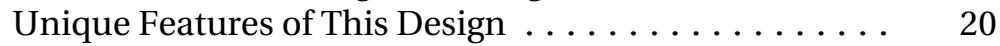

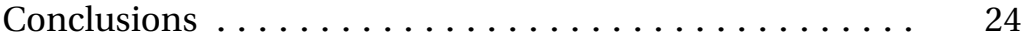


Chapter Three HOW THE POTOMAC MILLS PROTOTYPE MERS

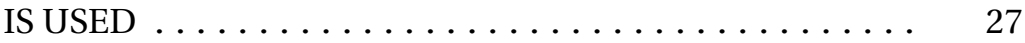

Station Operation and Staffing $\ldots \ldots \ldots \ldots \ldots \ldots .27$

How Did the Services Use the Station? . . . . . . . . . . 29

When Were the Recruiters Present in the Station? . . . . 30

Mall Management ... . . . . . . . . . . . . . . . 31

Who Is Visiting the Potomac Mills Recruiting Station? . . . 32

Demographics .................... 32

How Visitors Used the Station . . . . . . . . . . . . . 35

What Did Visitors Think of the Various Parts of the Station? ....................... 35

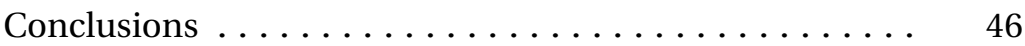

Chapter Four

POTOMAC MILLS RECRUITING STATION PRODUCTION AND COST-EFFECTIVENESS . . . . . . . . . . . . . . 51

Contract-Generation Performance $\ldots \ldots \ldots \ldots \ldots \ldots . \ldots 52$

Lead-Generation Performance . . . . . . . . . . 57

Potomac Mills Construction and Operating Costs . . . . 57

Enlistment Contract Production Cost-Effectiveness .... . 58

Approaches to Improving Contract-Production Cost-

Effectiveness .................. 60

Considering Advertising and Marketing as Part of Station

Cost-Effectiveness . . . . . . . . . . . . 63

Conclusions . . . . . . . . . . . . . . . . 67

Chapter Five

QUALITATIVE COMPARISONS WITH SIMILAR

RECRUITING STATIONS . . . . . . . . . . . . . . . . . 69

Eagle Ridge Mall . . . . . . . . . . . . . . . 70

Description of the Recruiting Station . . . . . . . . 70

Evaluating the Recruiters' Experience . . . . . . . . . . 71

Mall Management . . . . . . . . . . . . . . . . . 72

Mall of America . . . . . . . . . . . . . . . . . 73

Description of the Recruiting Station . . . . . . . . . . 74

Evaluating the Recruiters' Experience . . . . . . . . . . . 74

Mall Management . . . . . . . . . . . . . . . . 76

Westmoreland Mall . . . . . . . . . . . . . . . 76

Description of the Recruiting Station . . . . . . . . . 77

Evaluating the Recruiters' Experience . . . . . . . . 77 
Mall Management . . . . . . . . . . . . . . 78

Galleria Mall . . . . . . . . . . . . . . . . 78

Description of the Recruiting Station . . . . . . . . 79

Evaluating the Recruiters' Experience . . . . . . . . . . 79

Mall Management . . . . . . . . . . . . . . . 81

Times Square . . . . . . . . . . . . . . . . 81

Description of the Recruiting Station . . . . . . . 81

Evaluating the Recruiters' Experience . . . . . . . . . . 82

Conclusions ........................ 83

Chapter Six

DISCUSSION AND RECOMMENDATIONS $\ldots \ldots \ldots \ldots \quad 87$

What Have We Learned from the Prototype MarketingEnhanced Recruiting Station? . . . . . . . . . . 87

Discussion of the Recruiting Process's Role in Evaluating MERS . . ................... 90

“Made Mission, Gone Fishin'” . . . . . . . . . . . . 90

Improvement Requires More Than New Hardware . . . . 92

Recommendations ................. 93

Mining for Diamonds $\ldots \ldots \ldots \ldots \ldots \ldots \ldots \ldots \ldots$

Appendix: RAND Military Career Center Evaluation . . . . . . 99

Bibliography . . . . . . . . . . . . . . . . . . 103 

1.1. A Standard Joint Recruiting Facility (Corner of Santa Monica Boulevard and 14th Street, Santa Monica, Calif., April 2002) . . . . . . . . . . . . . . 5

1.2. A Standard Coast Guard Recruiting Station (Santa Monica Boulevard, Santa Monica, Calif., April 2002) . . 6

2.1. Station Location Within the Potomac Mills Mall,

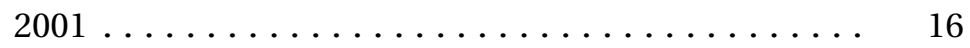

2.2. The Entrance and Lobby of the Potomac Mills Station .................... 17

2.3. Plan View of Station First Floor . . . . . . . . . 18

2.4. Plan View of Station Second Floor . . . . . . . . . 18

3.1. Average Potomac Mills MERS Recruiter Presence by Day for Each Hour During the Month of May 2001 . . $\quad 30$

3.2. Average Potomac Mills MERS Recruiter Presence by Day for Each Hour During the Month of December

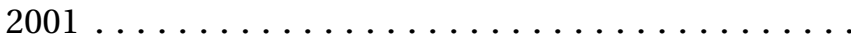

3.3. Total Number of Visitors to the Potomac Mills Station in the Year After the Station Opened, January Through December 2001 . . . . . . . . . . . . . . . . . . 34

3.4. Map of Virginia Zip Codes, Shaded by Fraction of Station Visitors ................. 36

3.5. Potomac Mills MERS Visitors, by Day of the Week ... 37

3.6. Time of the Day for Visitors, for Monday, Tuesday, and Wednesday ................. 38

3.7. Time of the Day for Visitors, for Thursday and Friday .................... 38

3.8. Time of the Day for Visitors, for Saturday and Sunday .................... 39 
3.9. Answers to the Prompt "I found the Military Career Center ...' (check all that apply)" . . . . . . . . . . . .

3.10. Answers to the Prompt "The Military Career Center Was ...' (pick one)" ... . . . . . . . . . . . . . .

3.11. Answers to the Prompt "The Military Career Center was useful for ...' (check all that apply)" . . . . . . . 42

3.12. Answers to the Question "What brought you into the Military Career Center?' (check all that apply)" . . . . . .

3.13. Answers to the Question "How did you hear about the Military Career Center?' (check all that apply)” . . . 44 Photo Plates . . . . . . . . . . . . . . . B Before 45

3.14. Answers to the Prompt "The best feature of the Military Career Center was ...' (pick one)" . . . . . . . 45

3.15. Answers to the Prompt "After visiting the Career Center, I am ...' (pick one)" . . . . . . . . . . . . 45

4.1. Average Contract Production for Potomac Mills Recruiters, per Recruiter per Quarter by Service . . . . . 


\section{TABLES}

1.1. "To what extent do you agree or disagree with the following statements about your office?" . . . . . . . .

1.2. "DoD is evaluating putting recruiting stations in large enclosed malls ... How much do you agree or disagree with the following statements?" . . . . . . .

3.1. Recruiter Staffing by Service for the First Year (2001) of Station Operation . . . . . . . . . . . . . . . .

3.2. Comparison of Demographics Among MERS Visitors, Potomac Mills Mall Visitors, and the Surrounding Counties......................

What Visitors Do in the Potomac Mills Prototype MERS . . . . . . . . . . . . . . . . . . . 39

3.4. Demographics of Survey Participants . . . . . . . . 40

3.5. Survey Participant Write-In Suggestions for Station Improvement . . . . . . . . . . . . . 47

4.1. Potomac Mills Station Contract-Generation Performance, by Month, December 2000 Through December 2001 . . . . . . . . . . . . . . . .

4.2. Potomac Mills Accession Rates Versus Each Service's Average. . . . . . . . . . . . . . 56

4.3. Potomac Mills Construction and Annual Operating Costs ....................... 59

4.4. Advertising Costs for Traditional Media .... . . . . . 64

4.5. Advertising Costs for Marketing-Enhanced Recruiting Stations ..................... 65 

In December 2000, the Under Secretary of Defense for Personnel and Readiness (USD[P\&R]) presided over the opening ceremony of a prototype "marketing-enhanced recruiting station" (MERS) in the Potomac Mills Mall located in northern Virginia, about 15 miles south of Washington, D.C. The purpose of the prototype recruiting station was to explore the use of recruiting stations as tools for marketing the military services to the public.

Intended to present an inviting image of the military to youth and the adults that influence their decisions ("influencers"), a marketingenhanced station is designed and located to entice visitors to the facility. Placed in high-foot-traffic areas, such as large commercial malls, these stations are intended to expose prospective recruits and their adult influencers to the positive aspects of military service and to facilitate their exploration of military career opportunities. (See Figures PM.1 through PM.8 in the color-photograph insert section for pictures of the Potomac Mills station.)

To put this type of station in the appropriate context, it is important to understand the status quo. Historically, two factors have driven how traditional recruiting stations are located and designed. First, minimizing the cost of leasing the storefront has been a major factor in station location. That the least costly spaces may also be less effective in drawing recruits has generally been a lesser consideration. Second, stations have been designed as office space for recruiters to conduct traditional recruiting activities, such as telephone coldcalling to identify prospective recruits ("prospecting"), conducting follow-up calls to interested youth, and meeting potential recruits. 
That recruiting stations also could serve a marketing function (by exposing the general public, for example, to advertisements) has generally not been exploited.

The original intention was to construct 30 MERS throughout the country and conduct a formal evaluation of their performance. The purpose of this evaluation was to determine whether the marketingenhanced recruiting station concept is effective for attracting potential recruits, promoting the image of the United States military to youth as well as to adult influencers, and providing a cost-effective means of advertising and recruit-contract production. However, before proceeding further, the Department of Defense decided to first evaluate Potomac Mills' performance. RAND was asked to conduct the evaluation.

This report summarizes the results of that evaluation. It includes (1) statistical information about the performance of the Potomac Mills station; (2) information about how the services used the station, including employment of civilian administrators; (3) conclusions about the potential of the MERS concept in general, as well as ways in which this particular station might be improved; (4) case studies of standard recruiting stations located in other retail malls; and (5) recommendations about how the services and the Office of the Secretary of Defense might utilize this prototype station to experiment with and learn about the effectiveness of various recruiting practices and techniques.

\section{WHAT WE LEARNED FROM THE EVALUATION}

Our observations, both those from the prototype MERS at Potomac Mills and from the other mall-based stations, as well as the quantitative data we collected at Potomac Mills, led us to a number of conclusions about marketing-enhanced recruiting stations. We focus here on the major conclusions, listing more-detailed conclusions at the end of each chapter.

\section{Major Conclusions}

- The marketing-enhanced recruiting station concept, appropriately implemented, has the potential to be a cost-effective alter- 
native for some recruiting stations and for some types of advertising, when the station's potential recruiting and advertising benefits are fully exploited. Furthermore, by reducing construction costs and by mitigating operating costs, the Department of Defense (DoD) can implement follow-on marketing-enhanced stations for significantly less cost than Potomac Mills' cost.

- To date, the Potomac Mills station has not demonstrated increased enlistment-contract production, which is probably attributable to two factors:

- Potomac Mills station recruiters were required to operate under the standard mission/quota system, a practice that may have driven station contract production toward the norm ${ }^{1}$ and that probably stifled station operational innovation.

- The existing Woodbridge recruiting station, located essentially just across the mall parking lot, was not closed. For most of the services, that station maintained responsibility for most or all of the existing surrounding territory.

- Potomac Mills station recruiters performed similarly to their peers in a standard recruiting station, making the station seem less cost-effective for recruit contract generation than standard recruiting stations. However, this conclusion ignores the marketing and advertising aspects of the station, which have the potential to make the MERS medium a cost-effective combined recruiting-and-advertising venue.

- Because recruiters and recruiting commands did not experiment with adapting their recruiting or operational procedures to the new mall and the MERS environment, we were not able to evaluate what drives station performance or whether alternative operating procedures would have attracted more or higher-quality walk-ins or increased contract production. For example:

\footnotetext{
${ }^{1}$ The Army was the exception, operating the station as a lead-generating facility initially. It has since reverted to staffing and operating Potomac Mills as a standard contract-production facility.
} 
- Recruiters generally kept standard weekday working hours, even though most station visitors came on the weekends and Thursday and Friday nights.

- The services did not hold any special events at the station, nor did they otherwise provide any type of marketing or advertising to exploit the station location.

- The data we collected indicated that the prototype MERS is effective at attracting local recruit-age youth and adult influencers. This success comes in spite of less-than-optimal use of the enhanced station features and no innovation by the services in furnishing marketing materials or events. For example:

- The station attracted over 8,000 visitors in its first year of operation, or an average of 10 recruit-age visitors and 10 adult influencers per day. Approximately half of the visitors were recruit-age.

- Recruiters judged that about 10 percent of the youth visitors resulted in quality leads, or an average of about one lead per day.

- It is not known whether the station could have achieved better performance under other operating conditions and recruiter incentives.

- Our survey (see the Appendix) indicated that the visitors were favorably impressed by the station and that they found it useful for learning about military careers. A significant number (about half) said the station increased their interest in joining the military.

- Finally, an overwhelming majority of active-duty recruiters believe that placing recruiting stations in large, enclosed malls would help recruiting. In the 2000 Military Recruiter Survey (Wilson et al., 2002), 93 percent of active-duty recruiters felt that well-designed recruiting stations in malls would reflect positively on the military, generate new leads, and help them recruit. Almost 70 percent of active-duty recruiters said they would prefer a recruiting station in a large mall to their current station location. And more than 80 percent of active-duty recruiters believed that teenagers would visit such a station and that it would positively impress key influencers. 
Summary xix

\section{Recommendations}

A fundamental recommendation of this study is that the Potomac Mills marketing-enhanced recruiting station should be converted from operation as a standard production recruiting station into an experimental facility for learning how to market and recruit today's youth in a commercial environment. It is a unique facility in which DoD has invested almost $\$ 1$ million and which, thus far, has not been employed to its full potential.

Simply put, as a standard recruiting station, Potomac Mills is untenably expensive. As a combined advertising-and-recruiting platform, the Potomac Mills MERS has the potential to be cost-effective. But the Potomac Mills station is invaluable as a test bed for new marketing, promotional, and recruiting procedures and techniques.

With such a test bed in mind, we offer four recommendations:

Recommendation No. 1: Use the Potomac Mills Station for Experimentation. The Potomac Mills marketing-enhanced recruiting station is unique among stations. It is in a commercial location with high foot traffic. It has facilities for displaying commercials and web sites to a broad cross section of the public. Furthermore, it has the built-in capability to remotely study station visitors and passersby to determine the effectiveness of the various marketing, promotional, and recruiting techniques.

Potomac Mills should be thought of as an ongoing experiment and a platform for testing and evaluating new recruiting methods, rather than as the final manifestation of a specific type of marketingenhanced recruiting station. Such a conversion will require additional resources, both financial and managerial. However, the resulting experimentation can serve as a means for learning how the strengths of the MERS can be exploited, thus maximizing MERS production; and perhaps as a means for discovering new ways of recruiting that are more widely applicable.

In the course of this research, we approached various recruiting commands about using the station to perform marketing and recruiting tests. We were interested in understanding what aspects 
of the station attracted visitors and affected station performance. For example, which types of special promotions and marketing techniques would attract various types of station visitors; how variants of staffing and recruiting methods would affect station production; how visitors would use the station under various conditions; and, most important, how all these factors would relate to the conversion of casual visitors into serious prospects and, ultimately, recruits. To date, no service or recruiting command has used the station for this purpose (hence, we were not able to do such an evaluation).

Examples of the types of experiments we had in mind include the following:

- Evaluating whether displays of military equipment attract visitors.

- Determining whether staffing the station lobby with active-duty personnel (instead of civilian administrators) helps attract and/or convert youth.

- Understanding whether new types of promotions, such as the military-related video games currently being distributed and played on the Web, might attract visitors.

- Learning how changes in the ambience of the station, such as lighting changes, music type and volume changes, and changes to the promotions on the monitors, would or would not attract various visitor demographics.

- Evaluating how hosting unique special events, such as a reception in the lobby for local school counselors, teachers, principals, etc., could contribute to the long-term marketing and recruiting success of the station.

These types of experiments and evaluations are commonplace in the commercial world. The military now has a facility in place to conduct such evaluations and should take advantage of it.

Recommendation No. 2: Use Potomac Mills to Determine How to Operationalize the MERS Concept. In addition to using the facility 
to test individual marketing and recruiting techniques, the services should use Potomac Mills station to learn how to operationalize the marketing-enhanced recruiting station concept. Results of this research indicate that making hardware changes, in the way a station is designed and sited, without making corresponding changes in recruiter incentives or the way the station is operated, is not likely to translate into increased contract production. Various operational changes should be implemented and tested at Potomac Mills to learn how to optimally run such a station. Examples of possible operational changes include the following:

- Varying the use of civilian administrators to learn how they are best employed.

- Evaluating changes in the way recruiters use the station and operate from it.

- Understanding how station design and operation contribute to converting casual visitors to military recruits.

- Modifying station operation to make it more efficient at collecting leads and helping walk-ins self-screen.

- Upgrading certain parts of the facility, such as the computer kiosk, to optimize their attractiveness to youth. ${ }^{2}$

Recommendation No. 3: Consider Giving the Station to One Service to Experiment with and Operate. As this report describes, some of the complexity in operating Potomac Mills stems from the colocation of multiple services in a joint facility. The services share common facilities (such as a lobby) and recruiters of different services are expected to cooperate in the operation of the station.

The experience to date in the Potomac Mills station is that recruiters prefer to forgo the use of certain station amenities rather than risk being perceived as unfairly using/exploiting those facilities to the detriment of the other services. For example, recruiters do not take advantage of the lobby area, which has become a sort of "no-man's-

2 The Army Corps of Engineers is working to upgrade the kiosks; however, as of this writing, no upgrades have been implemented. 
land," largely unused and unexploited. In a similar vein, the "jointness" of the station means that there is no one station commander, such as a standard station would have. Hence, no one is truly in charge of the station on either a day-to-day or a long-term basis.

Thus, one approach to facilitating innovation and experimentation within Potomac Mills is to turn the station over completely to one service for an extended period of time. Given that the Woodbridge station was never closed, this change can be made in such a way that the effect on the other services' recruiting efforts is minimized. That one service would then have free rein to experiment with the staffing, operation, and management of the station, with the goal of figuring out how to maximize the use of a MERS in a large commercial mall.

Recommendation No. 4: Once the MERS Concept Has Been Refined, Conduct Broader, Formal Experiments to Ensure Its Widespread Applicability. The marketing-enhanced recruiting station concept was originally conceived of as an experimental test of a concept. DoD envisioned constructing 30 MERS around the country, then using a formal, statistical methodology to evaluate their performance. Such testing has been used and continues to be used. For example, in the early 1980s, the Army and DoD conducted the Enlistment Bonus Experiment to assess the effects of expanded cash bonuses for attracting high-quality enlistees (Polich, Dertouzos, and Press, 1986). Other examples include the Educational Assistance Test Program in 1981, which examined the effect of varying educational benefits on enlistments (Fernandez, 1982); and the Advertising Mix Test, which estimated the effects of service and joint-service advertising (Carroll, 1987).

Once sufficient experimentation at Potomac Mills has been conducted and the MERS' performance has been optimized in that one location, per Recommendation No. 3, a larger set of stations should be constructed and evaluated formally. Such an evaluation will provide more-definitive evidence of whether the MERS concept works in all locations and under all conditions. In particular, it would be possible to evaluate a number of station variants at the same time to 
determine which combinations of features are widely applicable and are most effective.

\section{MINING FOR DIAMONDS}

A recommendation to put recruiting stations in malls should be like telling prospectors to go into mines to look for diamonds. And such a mining metaphor is particularly apt for military recruiting; it is not an accident that recruiters refer to the process of looking for new recruits as prospecting.

Using the mining metaphor, we set out to answer the question, Is the additional yield in these retail "mines," compared with the yield of existing strip mall-based "mining," worth the increased cost of operations? What we have found is that, although the mine shows distinct promise, the operators have not yet learned how to maximize the quantity of diamonds extracted. Hence, before deciding to abandon the new mine, the operators should first learn to optimize their mining operation. It is only through experimentation and innovation that the mine will achieve its greatest yield. 

ACKNOWLEDGMENTS

The authors gratefully acknowledge the aid of many individuals, too numerous to mention by name, who assisted in the research. Both active-duty and civilian personnel, they are members of the various commands and agencies that conduct and support military recruiting, including the Office of the Under Secretary of Defense (Personnel and Readiness), the U.S. Army Corps of Engineers, the various national and local recruiting commands of the services, the Military Entrance Processing Command, and the various joint committees and councils managing military recruiting-the Accession Oversight Council, the Midlevel Interservice Recruiting Council, the Joint Accession Group, and the Joint Recruiting Facilities Committee.

In particular, this research would not have been possible without the assistance of CDR Yvette Brownwahler, USN, Col Dave Kopanski, USAF, and Capt Gwen Rutherford, USAF, of the Office of Accession Policy in the Office of the Secretary of Defense; W. Steve Sellman, the former Director of the Office of Accession Policy; Curtis Gilroy, the current Director of the Office of Accession Policy; Rodger Reynolds, Mike D'Agosta, Carol Petersen, and Jamie Stuhr of the U.S. Army Corps of Engineers; Rick Hoke of the U.S. Army Corps of Engineers and the Chairman of the Joint Recruiting Facilities Committee; Col Darrell Greer, USAF, Col Jim Holaday, USAF, and George Gonzales, Headquarters, Air Force Recruiting Service; Col. Glenn Cunningham, USMC, and Maj. Frank Rosa, USMC, of Headquarters, U.S. Marine Corps Recruiting Command; LCDR Cedric Hughes, USCG, U.S. Coast Guard Recruiting Command; and all of the recruiters and recruiting 
xxvi Going to the Mines to Look for Diamonds

station commanders who provided us with information about and insight into the challenges of military recruiting.

We also thank our colleagues at RAND who assisted in this research, including Jennifer Pace, Gery Ryan, Grant Marshall, and Carolyn Rogers.

This report was significantly improved as a result of thorough reviews by Stephanie Lofgren of the United States Military Academy and Jim Dertouzos of RAND. Of course, any errors or omissions are entirely the responsibility of the authors. 


$\begin{array}{ll}\text { AFQT } & \text { Armed Forces Qualifying Test } \\ \text { AOC } & \text { Accession Oversight Council } \\ \text { AVF } & \text { All-Volunteer Force } \\ \text { DEP } & \text { Delayed Entry Program } \\ \text { DoD } & \text { Department of Defense } \\ \text { DMDC } & \text { Defense Manpower Data Center } \\ \text { FMP } & \text { Force Management Policy } \\ \text { FY } & \text { fiscal year } \\ \text { HMMWV } & \text { high-mobility multipurpose wheeled vehicle } \\ \text { IRC } & \text { Inter-Service Recruiting Council } \\ \text { JAG } & \text { Joint Accession Group } \\ \text { JRFC } & \text { Joint Recruiting Facilities Committee } \\ \text { MEPCOM } & \text { Military Entrance Processing Command } \\ \text { MEPS } & \text { Military Entrance Processing Station } \\ \text { MERS } & \text { marketing-enhanced recruiting station } \\ \text { MIRC } & \text { Midlevel Interservice Recruitment Committee }\end{array}$


xxviii Going to the Mines to Look for Diamonds

$\begin{array}{ll}\text { NDRI } & \text { National Defense Research Institute } \\ \text { OSD } & \text { Office of the Secretary of Defense } \\ \text { RFMIS } & \text { Recruiting Facilities Management Information System } \\ \text { RMIS } & \text { Recruiter Mission Information System } \\ \text { RSLES } & \text { Recruiting Station Location Evaluation System } \\ \text { SOP } & \text { standard operating procedure } \\ \text { TDY } & \text { temporary duty } \\ \text { USA } & \text { United States Army } \\ \text { USACE } & \text { United States Army Corps of Engineers } \\ \text { USAF } & \text { United States Air Force } \\ \text { USAREC } & \text { U.S. Army Recruiting Command } \\ \text { USCG } & \text { United States Coast Guard } \\ \text { USD(P\&R) } & \text { Under Secretary of Defense for Personnel and Readiness } \\ \text { USMC } & \text { United States Marine Corps } \\ \text { USN } & \text { United States Navy }\end{array}$


With the establishment of the All-Volunteer Force (AVF), the services committed to filling their ranks by encouraging young men and women to choose military service over other options, such as private-sector employment. Finding potential recruits, exposing them to their military options, and enlisting them into military service, especially if other options are attractive, can be complicated, laborious, and expensive. Thus, the process of recruiting personnel requires a large, recurring investment of resources by the Department of Defense (DoD). Such resources include recruiters; recruiting stations; advertising; other recruiting infrastructure (i.e., other kinds of facilities and organizational structures); and enlistment incentives, such as cash bonuses and educational benefits.

In recent years, the services have faced a particularly challenging recruiting environment. In some cases, they have been unable to meet their annual recruiting goals, which is striking because it has happened so rarely in the 25 years of the AVF.

A number of factors affect the success of the military in drawing recruits to its enlisted forces. They include external forces, such as the robustness of the U.S. economy, the employment opportunities the economy presents, and the growing college enrollment rates; and internal factors, such as the level of resources devoted to recruiting by the services and the recruiting practices the services employ.

One particular concern is that youth and the adults who influence them ("influencers") are less familiar today with the military services and with military careers. Such lack of familiarity is due, in part, to the decrease in personal military experience throughout many seg- 
ments of society, especially as the World War II generation ages. Many people are thus less inclined to consider military career options. For example, Dahlman (unpublished), in interviews with Army recruiters, found that recruiters universally sense little to no understanding of today's military in the civilian community.

This lack of awareness may be contributing to the observed decline in youth's propensity to enlist (i.e., its likelihood of enlisting). For example, Orvis, Sastry, and McDonald (1996) found a modest, 10percent decline in the propensity to enlist, from 23.3 percent in 1989 to 21 percent in 1995. They concluded that, with increased accession requirements, "we may be adding a supply problem to the conversion problem." They also concluded that "the supply problem may be exacerbated to the extent that propensity worsens...." (1996, p. 19).

The services have taken a number of steps in response to actual and threatened recent recruiting shortfalls, including significantly increasing the number of field recruiters. Previous RAND research has shown that increasing the number of recruiters is a relatively costeffective way to increase the number of recruits (Asch and Orvis, 1994). However, other aspects of the recruiting environment may be less than optimal and improvements in those aspects may also reap significant benefits.

For example, minimizing the cost of leasing a storefront has been a key driver in the process of deciding where to locate recruiting stations (a process managed by the United States Army Corps of Engineers, USACE, the designated DoD executive agent for locating and procuring recruiting facilities). However, since it is possible that the least-costly spaces are also less effective in drawing recruits, changing the location (e.g., to where the volume of foot traffic is greater) of stations might improve the recruiting process (Dahlman, unpublished).

In addition, recruiting stations are usually designed simply to provide a place for recruiters to conduct traditional recruiting activities, such as arranging school activities, making follow-up calls to interested youth, and meeting potential recruits. The possibility that recruiting stations also could serve a marketing function has not been exploited, a fact recognized by some recruiters. For example, 
Dahlman (unpublished) conducted focus groups at 16 different recruiting locations, ensuring that the locations were representative across services, regions, and recruiting performance. He found that recruiters believe that recruiting offices are located in "seedy neighborhoods or unproductive locations." As Dahlman said,

A common refrain criticized the location of recruiting stations. Since locations are chosen by the Army Corps of Engineers as the executive agent for all the services, price per square foot factors heavily in location decisions.

He went on to say that many recruiters felt it was important to have an attractive office in a decent location so that a professional image could be conveyed to new recruits. A preferred location for many of them would be in a visible place in a good-quality mall, where recruit-age youngsters tend to congregate. Focus-group members also said that more advertising should be directed toward providing information for influencers. Regardless of location, recruiters would like to be able to convey in a visible manner via upgrades in their recruiting stations-to parents, school officials, and former military members-what today's military is really like, in the belief that doing so would make access to youth and their adult influencers much easier.

\section{RECRUITING STATIONS AND THE RECRUITING PROCESS}

Attracting youth into the military is a complicated process. That process is defined, governed, and, ultimately, constrained by a system consisting of (1) organizational, operational, and management recruiting policies and procedures, (2) the actual facilities and equipment provided to recruiters, and (3) other operating parameters, such as the number and distribution of recruiters themselves. For example, the operational policy of requiring recruiters to meet monthly goals enormously influences the behavior of both the individual recruiters and entire recruiting commands. Similarly, the design and location of recruiting stations influence how individual recruiters as well as recruiting commands conduct business.

Existing marketing and recruiting operations within each service tend to be organizationally separate, focusing on different but complementary objectives. For example, each service's marketing efforts 
tend to be focused primarily on national advertising designed to raise the awareness of potential enlistees to the military services. Such national advertising campaigns are designed and executed by commercial advertising firms under contract to each service. The services also execute various special-event advertising campaigns, some local advertising, and various print materials and giveaways.

Current recruiting efforts by each of the services rely primarily on thousands of individual recruiters throughout the country, activeduty enlisted personnel who have either volunteered for or been assigned recruiting duty. The recruiters are most often assigned to a recruiting station located in a particular community. The recruiting stations tend to be small, usually nondescript offices located in strip mall-type buildings. Generally one or a few recruiters operate out of these offices (Figures 1.1 and 1.2).

Asch, Kilburn, and Klerman (1999) divide the factors that can affect the success of a recruiting system into two major sets: internal and external. ${ }^{1}$

Internal factors are those that the services can change (or at least affect), including the following:

- Available enlistment-contract attributes (occupations or occupational groups offered, enlistment contract length options, assignment-location opportunities, choice or type of training, etc.).

- Recruiting resources (recruiters, advertising, enlistment incentives, etc.).

- Management of recruiting resources (distribution of recruiting resources, by type and geography [i.e., where the various types of stations are located]; management of recruiters, including quotas and recruiter incentive plans).

\footnotetext{
${ }^{1}$ Asch, Kilburn, and Klerman (1999) used the terminology "demand" for those factors the services can affect and "supply" for those the services cannot affect. We changed the terms to "internal factors" and "external factors" to avoid confusing their use here with their more-traditional economic definitions.
} 


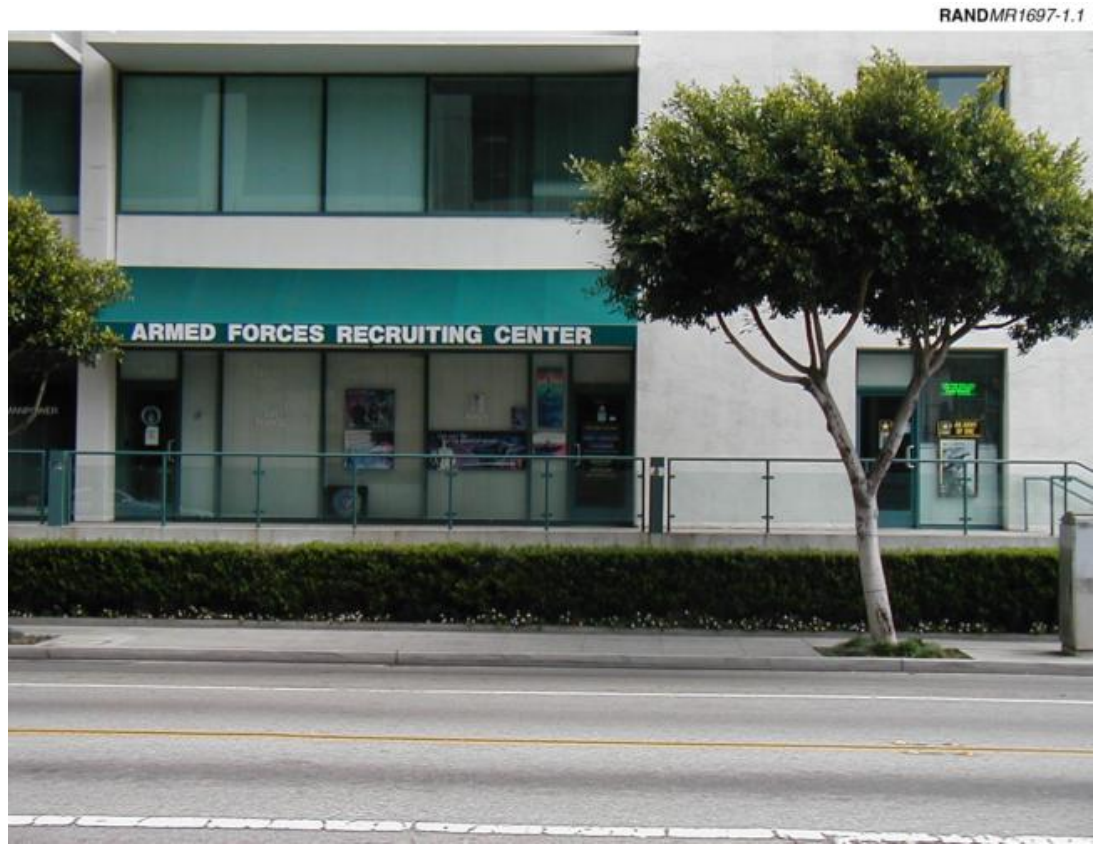

Figure 1.1-A Standard Joint Recruiting Facility (Corner of Santa Monica Boulevard and 14th Street, Santa Monica, Calif., April 2002)

In contrast, external factors are those that the services cannot affect, such as the following:

- Size of youth population.

- Civilian-job-market opportunities (civilian pay compared with military pay, unemployment rate).

- Post-secondary education opportunities (and costs).

Army regulations (USAREC, 1996, as cited in Thomas, 1997) define five specific tasks for recruiters: planning, prospecting, sales, processing, and Delayed Entry Program (DEP) ${ }^{2}$ maintenance. While 2 The Delayed Entry Program is a holding program for those who have signed an en-
listment contract but who have not yet gone to boot camp. 


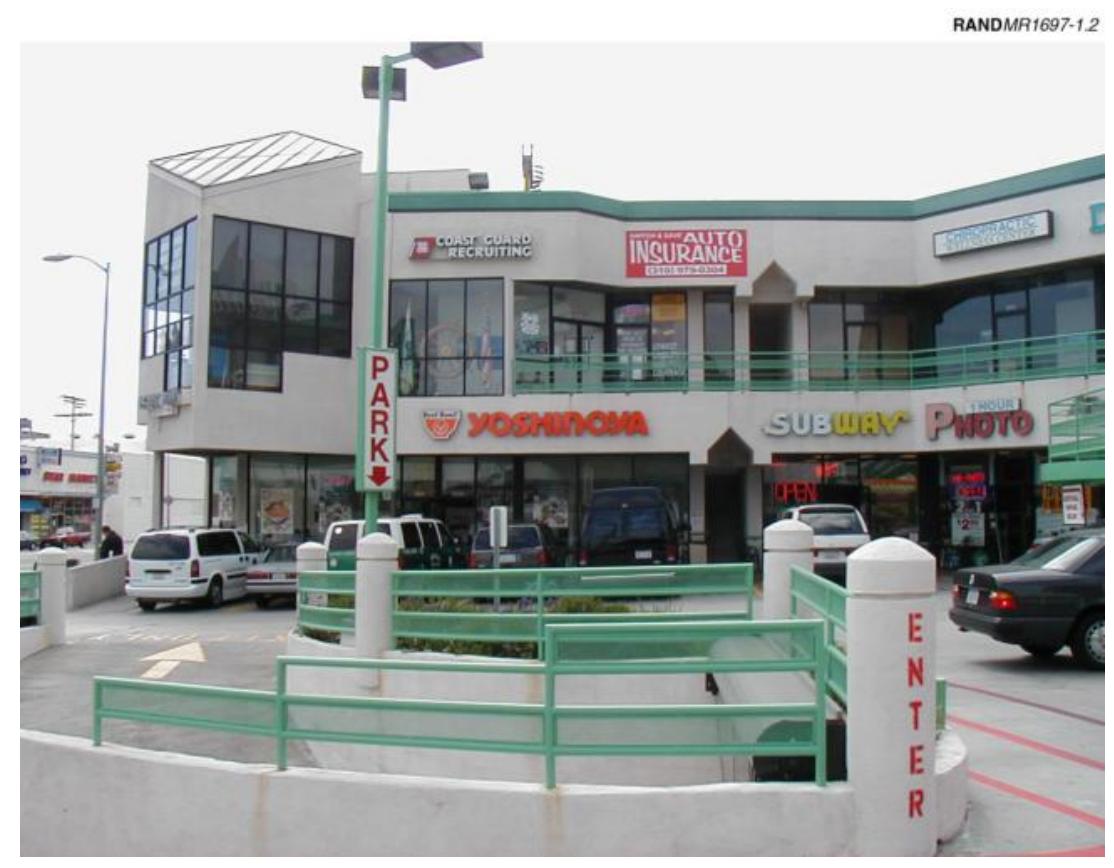

Figure 1.2-A Standard Coast Guard Recruiting Station (Santa Monica Boulevard, Santa Monica, Calif., April 2002)

traditional recruiting stations can be used to attract youth, as described earlier in this chapter, they are used predominantly as general office space for recruiters. Much less frequently, and generally not by design, recruiting stations may also serve to draw potential new recruits to the recruiters. ${ }^{3}$

Traditional recruiting methods may be becoming more difficult. For example, Thomas (1997) argued that DoD's process of generating leads (a primary resource for recruiters under the current operating

\footnotetext{
${ }^{3}$ Perhaps the best example of such a station is the one in Times Square in New York City. Because of its location and historical significance to many veterans, the Times Square station tends to draw potential recruits who specifically come to it in order to join the military at that particular location. The Times Square station is unique because of its nostalgia factor and its physical attributes; there is nothing else like it in the recruiting-station inventory.
} 
paradigm) needs to be reengineered to make the recruiters more efficient. In support of this argument, he cites the following statistics:

- In the early 1990s, the Marine Corps showed that an increasing number of telephone calls are required per contract generated: about 500 calls in 1993, just under 600 calls in 1994, and over 650 calls in 1995.

- Similarly, the 1994 Air Force recruiter survey (cited in Thomas, 1997) showed that the average time a recruiter spent on the telephone had increased 14 percent from 1991 to 1994.

- The 1994 Air Force recruiter survey also showed that recruiters spent 1.7 hours per day on the telephone, prospecting (i.e., coldcalling potential recruits). Thomas concluded from interviews with recruiters that this was common for all services.

- 1994 Marine Corps data (cited in Thomas, 1997) showed that more than half of all enlistment contracts originated from telephone prospecting. However, cold-calling is getting more difficult.

Using a simulation model, Cordeiro et al. (2001) showed that the single greatest effect on contract production is prospecting; that is, increases in prospecting had the greatest effect on increases in contract production. Hence, to the extent that station design and location can assist in prospecting, the station itself can contribute to the success of the recruiting process.

\section{MARKETING-ENHANCED RECRUITING STATIONS}

With the intention of improving the recruiting process, the Joint Recruiting Facilities Committee (JRFC) recommended the development and establishment of a set of "marketing-enhanced recruiting stations" (MERS).

The marketing-enhanced recruiting station concept is intended to bring the marketing and recruiting operations together into a station in a high-foot-traffic location such as a large regional mall. The concept is to use the physical station to support actual recruiting operations, to promote a positive image of the military, to raise awareness 
of the military services as employment and career opportunities, and generally to contribute both to enhanced marketing and recruiting.

This use of retail malls is consistent with how some in the shoppingmall-building industry foresee the use of such commercial space (Johnson, 2001):

A deal announced Friday by real estate developer Mills Corp. and William Morris Agency offers further proof that shopping malls aren't just for shopping anymore. The joint venture promises to make available thousands of new locations where car manufacturers, cruise lines and other companies can market their wares.

"Maybe you open a next-generation auto showroom with a [test track] for SUVs so you can drive one before you buy it," said Mills Executive Vice President Mark Rivers, who will serve as Venue3D's chief executive. "We're not talking about a [kiosk] where someone offers you a free cosmetics sample. And we're not just offering [marketers] nice imagery. We're offering them a business opportunity ... to sell cars or maybe their cruise ship line."

Within the taxonomy of Asch, Kilburn, and Klerman (1999), the design and location of recruiting stations are internal factors. However, the intention of a marketing-enhanced recruiting station is to influence an external factor: the likelihood that youth will walk into a recruiting station to learn about military careers and perhaps even engage a recruiter. Of course, influencing the number of walk-in youth does not necessarily translate into a greater number of contracts without appropriately changing those internal factors that convert the walk-ins into recruits (see Cordeiro et al., 2001).

For example, Polich, Dertouzos, and Press (1986) found that, when a recruiting resource such as advertising is increased, enlistments do not increase to the full market potential. They found that enlistments increased to only about 70 percent of what was expected, unless the recruiter quotas (goals, missions) were increased simultaneously. They concluded that, as the market expands, the recruiter's job is made easier, so the recruiter puts forth less effort. We return to this point in Chapter Six. 


\section{RECRUITERS' OPINIONS ABOUT RECRUITING STATIONS}

The facilities and equipment given the recruiters, one of three parts of the recruiting system, have the potential for both drawing in prospective recruits and conveying a positive message about the military. Recruiters themselves endorse this view, showing approval for a facility such as the MERS.

In the 2000 Military Recruiter Survey (Wilson et al., 2002), recruiters were specifically asked about their recruiting station's appearance and impact on recruiting, as well as their opinion about putting recruiting stations in large malls. Respondents consisted of a representative sample of 4,706 recruiters from all the active components (Army, Air Force, Navy, Marine Corps, and Coast Guard) and the Reserve components. The survey was conducted by the Defense Human Resources Activity of the Department of Defense.

Although survey results show that over three-quarters of active-duty recruiters believe that their current recruiting office presents a professional and pleasant environment for potential applicants (Table 1.1), almost 59 percent of active-duty recruiters "agree" or "strongly agree" that recruiting-station location is in need of improvement. Similarly, over 55 percent of active-duty recruiters "agree" or "strongly agree" that recruiting-station appearance is in need of improvement. Hence, while recruiters are largely satisfied with how their offices appear to potential recruits, the majority of recruiters believe there is room for improvement.

In addition, fully 95 percent of active-duty recruiters rate the location of recruiting stations as "very important" or "important" for recruiting, and 59 percent of active-duty recruiters rate recruiting station walk-ins as "very important" or "important" in attaining non-prior service goals/missions. Yet two-thirds of recruiters say that their office gets very few walk-in potential applicants.

When asked about recruiting stations with the attributes of a marketing-enhanced recruiting station, recruiters answered that they overwhelmingly believed such attributes would be helpful. As shown in Table 1.2, almost all active-duty recruiters believed that placing 
Table 1.1

"To what extent do you agree or disagree with the following statements about your office?"

\begin{tabular}{|c|c|}
\hline Survey Statement & $\begin{array}{l}\text { Percentage of Active-Duty } \\
\text { Recruiters Who Agree or } \\
\text { Strongly Agree }\end{array}$ \\
\hline $\begin{array}{l}\text { My recruiting office presents a professional environ- } \\
\text { ment for potential applicants }\end{array}$ & $78.2 \%$ \\
\hline $\begin{array}{l}\text { My recruiting office presents a pleasant environment } \\
\text { for potential applicants }\end{array}$ & $77.6 \%$ \\
\hline $\begin{array}{l}\text { My recruiting office contributes to my success as a re- } \\
\text { cruiter }\end{array}$ & $43.8 \%$ \\
\hline $\begin{array}{l}\text { My recruiting office gets very few walk-in potential ap- } \\
\text { plicants }\end{array}$ & $67.3 \%$ \\
\hline $\begin{array}{l}\text { I could successfully recruit if my office looked "high- } \\
\text { tech" } \\
\text { My recruiting office is conveniently located }\end{array}$ & $\begin{array}{l}55.8 \% \\
55.2 \%\end{array}$ \\
\hline
\end{tabular}

SOURCES: Question 22 in M. J. Wilson et al., 2000 Military Recruiter Survey: An Overview, Arlington, Va.: Defense Human Resources Activity, JMARS Report No. 2002-001, 2002. Statistics are drawn from Department of Defense, 2000 Military Recruiter Survey, Tabulations of Responses, Volumes 1 and 2, Washington, D.C.: Defense Human Resources Activity, Joint Advertising, Market Research and Studies, August 2002.

recruiting stations in large, enclosed malls would help recruiting: 93 percent felt that well-designed recruiting stations in malls would reflect positively on the military, generate new leads, and help them recruit. Almost 70 percent of active-duty recruiters said they would prefer a recruiting station in a large mall to their current station location. And more than 80 percent of active-duty recruiters believed that teenagers would visit such a station and that such a station would positively impress key influencers.

\section{STUDY DESIGN LIMITATIONS}

The evaluation of the marketing-enhanced recruiting station concept was originally envisioned as an experimental test of 30 MERS around the country using a formal, statistical methodology. Such testing has been used and continues to be used in other areas of military recruiting: the Army's Enlistment Bonus Experiment in the early 1980s (Polich, Dertouzos, and Press, 1986), which, by providing policymakers with rigorous empirical evidence of the performance of each 
Table 1.2

"DoD is evaluating putting recruiting stations in large enclosed malls ... How much do you agree or disagree with the following statements?"

\begin{tabular}{|c|c|}
\hline Survey Statement & $\begin{array}{l}\text { Percentage of Active-Duty } \\
\text { Recruiters Who Agree or } \\
\text { Strongly Agree }\end{array}$ \\
\hline $\begin{array}{l}\text { In the right mall, with a good design, the station } \\
\text { would reflect well on the military and generate new } \\
\text { leads }\end{array}$ & $93.0 \%$ \\
\hline $\begin{array}{l}\text { Locating my station where there are a lot of potential } \\
\text { applicants who could visit the station would help } \\
\text { me recruit }\end{array}$ & $92.8 \%$ \\
\hline $\begin{array}{l}\text { I would prefer working in a station that was easily ac- } \\
\text { cessible to the public }\end{array}$ & $92.2 \%$ \\
\hline $\begin{array}{l}\text { I would prefer a location in a large mall to my current } \\
\text { station location }\end{array}$ & $69.6 \%$ \\
\hline $\begin{array}{l}\text { A mall location would be a hindrance for meeting } \\
\text { with prospects }\end{array}$ & $15.5 \%$ \\
\hline $\begin{array}{l}\text { Teenagers would visit a mall recruiting station if it } \\
\text { looked "high-tech" }\end{array}$ & $83.2 \%$ \\
\hline $\begin{array}{l}\text { Teenagers today are more impressed by appearance } \\
\text { and style } \\
\text { Proper visibility in a mall would positively impress }\end{array}$ & $85.0 \%$ \\
\hline $\begin{array}{l}\text { Proper influencers } \\
\text { key in }\end{array}$ & $82.0 \%$ \\
\hline
\end{tabular}

SOURCES: Question 63 in M. J. Wilson et al., 2000 Military Recruiter Survey: An Overview, Arlington, Va.: Defense Human Resources Activity, JMARS Report No. 2002001, 2002. Statistics are drawn from Department of Defense, 2000 Military Recruiter Survey, Tabulations of Responses, Volumes 1 and 2, Washington, D.C.: Defense Human Resources Activity, Joint Advertising, Market Research and Studies, August 2002.

type of bonus, enabled them to then make solid policy trade-off and implementation decisions; the Educational Assistance Test Program in 1981, which examined the effect of varying educational benefits on enlistments (Fernandez, 1982); and the Advertising Mix Test, which estimated the effects of service and joint-service advertising (Carroll, 1987). For example, the Enlistment Bonus Experiment divided the United States into three "test cells," each of which offered differing enlistment bonuses to qualified individuals. The experiment allowed the effects of the bonuses to be evaluated, including determining whether the bonuses resulted in market expansion, skill channeling, or shifts in terms of enlistment.

Ideally, this evaluation would have been similarly rigorous. However, the scope of the effort was subsequently reduced from a formal 
evaluation of 30 stations to the observation of the operation of a single station, Potomac Mills. Furthermore, by the time RAND was brought in to make the evaluation, the recruiting station layout was designed, the mall was selected, the contract signed, and the station essentially constructed; the mix of services was arranged; and the civilian administrators were hired. RAND provided no hypotheses or input on possible layouts or operational procedures. Our resulting tasks were to observe, interview, and collect statistical information about visitors and their responses to the MERS and relate them to the MERS' cost.

\section{ORGANIZATION OF THIS REPORT}

In Chapter Two, we describe the particular mall in which one variant of a MERS was built, the location of the station in the mall, and the design features of the station. In Chapter Three, we address how the station is being used by both recruiters and visitors. In Chapter Four, we evaluate the cost-effectiveness of the station for recruiting and for advertising, and in Chapter Five we provide case studies of standard (nonmarketing) mall-based recruiting stations for comparison with the MERS. In Chapter Six, we provide a discussion of what we have learned about mall recruiting stations and offer recommendations for the future use of the MERS.

At the end of each chapter, we offer general observations, recommendations, and conclusions specific to the points discussed in that chapter. For simplicity, we refer to them as "Conclusions," set them off in italics, and expand on them (in regular type). 
Chapter Two

THE PROTOTYPE MARKETING-ENHANCED RECRUITING STATION AT POTOMAC MILLS MALL

The motivation behind the marketing-enhanced recruiting station concept was to leverage some or all of thousands of recruiting offices located throughout the country as marketing tools, as well as for their original purpose. However, since most of the existing stations are in low-foot-traffic locations, have generally nondescript appearances, and function mostly as office space for recruiters, a new station was constructed at Potomac Mills to test the marketing-enhanced recruiting station concept in a high-foot-traffic location.

As a recruiting station, Potomac Mills is unique in a number of ways (see Figures PM.1 through PM.8 in the color-photograph insert section for pictures of the station):

- It was designed specifically for marketing as much as for recruiting.

- It is located in a commercial mall and along a high-foot-traffic area.

- It has a large lobby containing high-tech features, such as large video monitors and computers, to attract walk-in visitors.

- Recruiters from all services, including the Coast Guard, are colocated in a single facility.

- The station is staffed by civilian administrators, as well as by active-duty recruiters. 
Potomac Mills was built "from the ground up" to incorporate a variety of marketing tools, including large-screen televisions showing advertising clips, a computer kiosk for station visitors to use to learn more about military careers, and a large lobby. None of these marketing tools had been tested for their marketing effectivenessindeed some did not even exist at the time it was decided to build the Potomac Mills station. Hence, these marketing tools were incorporated without any real research into optimal design, placement, or usage.

Because of this lack of research, it is important to note that the Potomac Mills station is just one possible realization of the MERS concept. In this report, we refer to it as a "prototype MERS" to reflect this status. Success or failure with this particular station does not necessarily imply that the use of recruiting stations for marketing is infeasible or not cost-effective. Similarly, it could be that other station variants may be better or more cost-effective for marketing, either for attracting youth, encouraging youth to explore military careers, providing a positive image of the military to either youth or adult influencers (or both), or for achieving other advertising purposes. ${ }^{1}$ In addition, other station variants may enhance or inhibit the station's capacity to convert casual browsers of the station into serious potential recruits or simply to increase the station's ability to produce a higher volume of contracts.

Note that the MERS does not fit neatly within the current organization of the recruiting commands, which is, generally speaking, divided into two groups: recruiting, which is fundamentally concerned with generating the requisite number of contracts for a given period of time, and advertising, which tends to be concerned with national advertising campaigns and large-scale advertising and public-relations events rather than station-specific events.

The study described here involved numerous site visits over the course of the first year. During the site visits, the researchers would take pictures, interview recruiters, and survey visitors. The RAND team developed a survey (see the Appendix) to collect visitors' opin-

${ }^{1}$ We use the words advertising and marketing interchangeably in the context of the MERS to mean an entire continuum of activities related to promoting the military and attracting youth into the military services. 
ions, observed visitor behavior in the station, enlisted the station administrators to collect other types of data on an ongoing basis, and assembled recruiting data from the services.

With this as background, this chapter describes the particular mall in which this variant of a MERS was built, the location of the station in the mall, and the design features of the station.

\section{POTOMAC MILLS MALL}

The Potomac Mills Recruiting Station is located in the Potomac Mills Mall, a single-story mall that covers an area of approximately $0.5 \times 1$ mile (including parking lots). The mall is anchored by at least a half dozen large stores (such as TJ Maxx, J.C. Penney, Linens 'n Things, and Burlington Coat Factory) and contains a movie theater, food court, and a skateboard park, all of which attract a significant youth population as part of the approximately 24 million people who visited the mall in 2001 (see Chapter Three, Table 3.2).

Potomac Mills Mall is located in Prince William County, Virginia, about 15 miles south of Washington, D.C., on the Interstate 95 corridor. The mall draws 76 percent of its customers from the local area, defined as within a 50-mile radius of the mall (The Mills, 2001). Of the mall's customers, 69 percent reside in Virginia, 14 percent, in Maryland, and 6 percent, in the District of Columbia. Thus, while Potomac Mills is considered a large, regional mall that attracts a significant number of domestic and international tourists, fully 89 percent of the mall's customers reside in the immediately surrounding states and the District of Columbia. ${ }^{2}$

\section{STATION LOCATION IN THE MALL}

As shown in Figure 2.1, the recruiting station is located directly across from The Sports Authority store, a location chosen from among all the locations available at the time of construction to maximize youth foot traffic.

\footnotetext{
${ }^{2}$ Additional demographic information about mall visitors is provided in Chapter Three.
} 


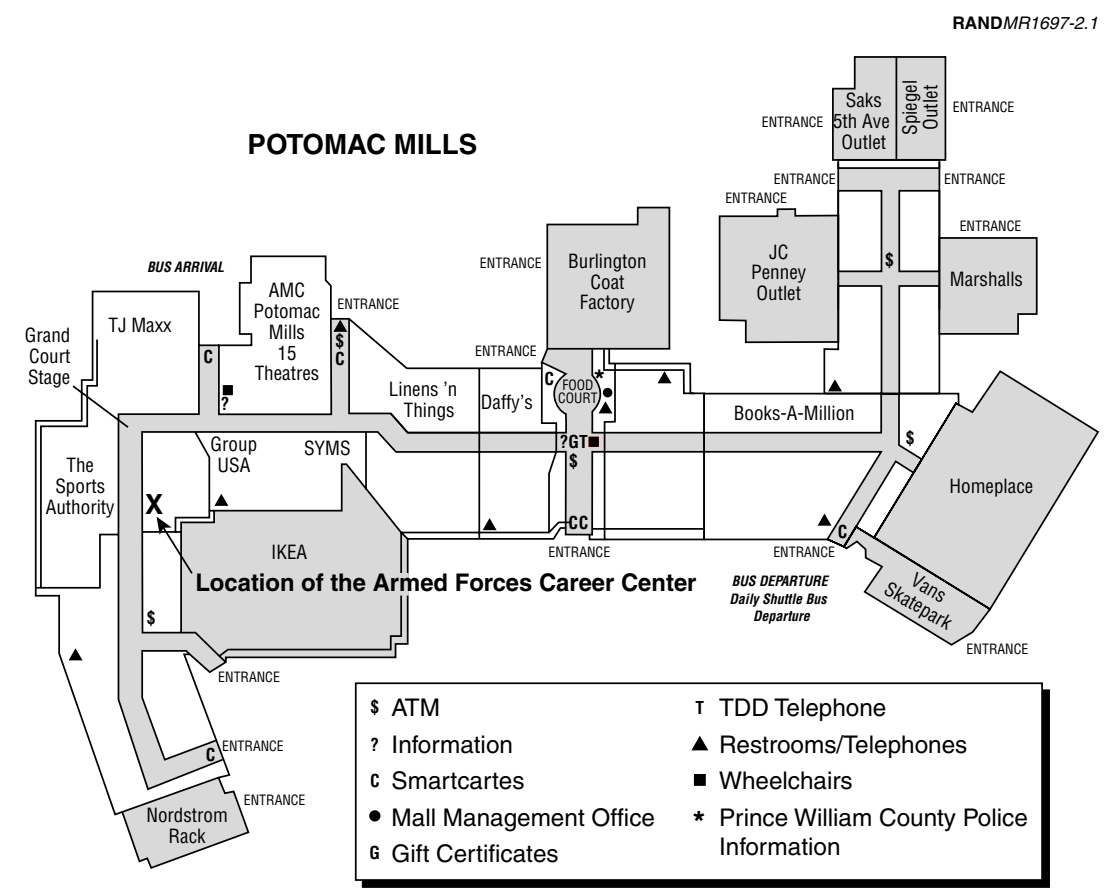

SOURCE: Adapted from Potomac Mills (www.potomacmills.com). Reprinted by permission.

Figure 2.1-Station Location Within the Potomac Mills Mall, 2001

\section{POTOMAC MILLS RECRUITING STATION DESIGN AND LAYOUT}

The Potomac Mills Recruiting Station is a two-level structure. The lower level comprises approximately 3,600 square feet and consists of a lobby area, four recruiting offices, and a public-access restroom.

The lobby, which is immediately off the mall corridor, is approximately $29 \times 27$ feet (i.e., just under 800 square feet). It is two stories high, which gives the space a large, open feeling, and it contains a reception desk and an area for greeting visitors and displaying 
promotional literature; a computer kiosk; two large-screen televisions; a third, large projection television that continuously displays military-recruiting advertisements; and a wall display area (Figure 2.2).

Behind the lobby are four recruiting offices that contain modular furniture for two recruiters apiece. The Army, Navy, and Air Force each have a full office, and the Marine Corps and Coast Guard share an office. The second floor is above some of the recruiting offices and contains two applicant-testing rooms, a combined conference room and small gymnasium facility, and separate men's and women's restroom/shower facilities. Plan views of the floor layouts are shown in Figures 2.3 and 2.4.

In Figure 2.3, the mall is on the right side of the figure ("storefront"). From this vantage point, people in the mall look in on the large lobby, which is dominated by the computer kiosk in the center.

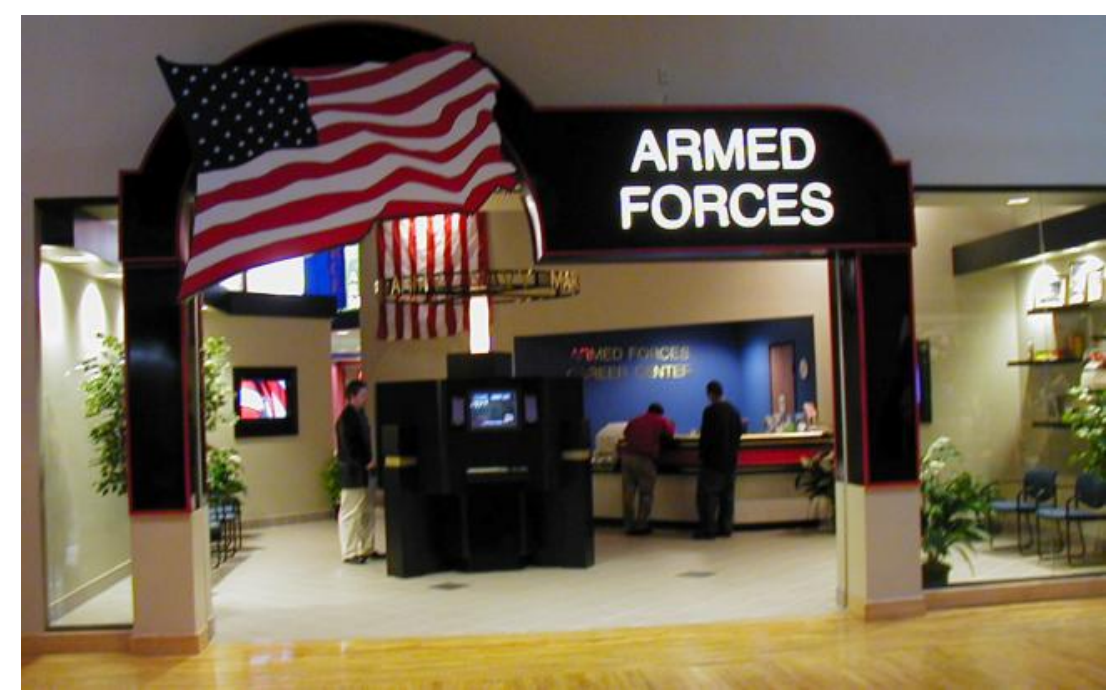

Figure 2.2-The Entrance and Lobby of the Potomac Mills Station ${ }^{3}$

\footnotetext{
${ }^{3}$ See center insert for color pictures of the station.
} 


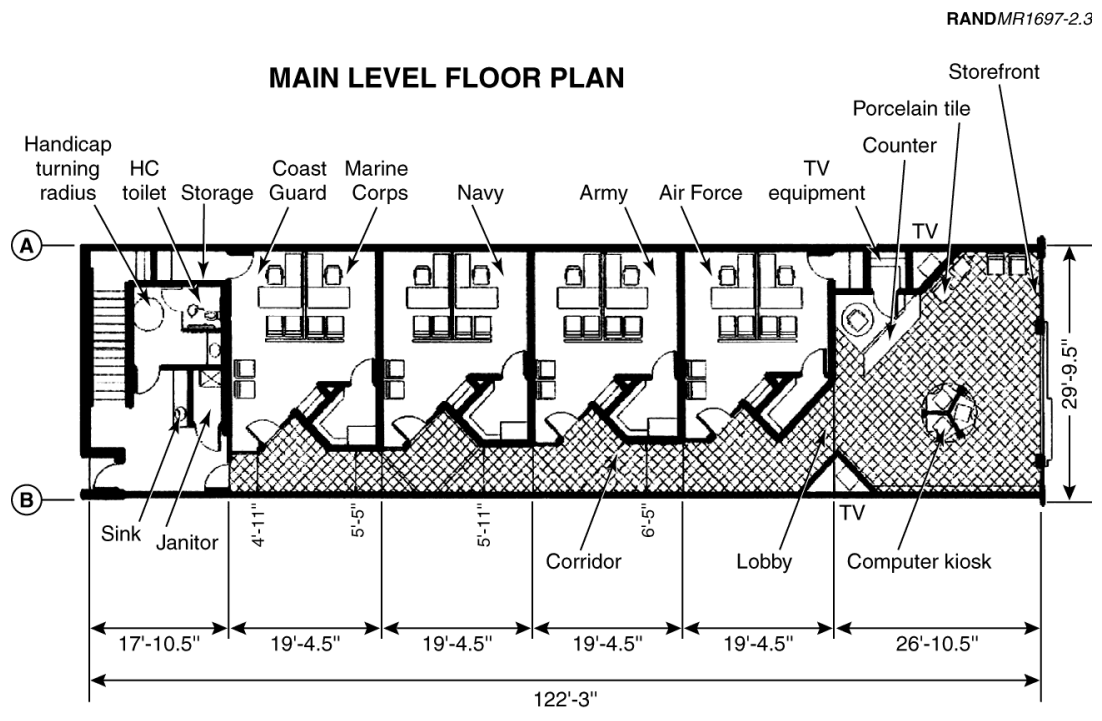

SOURCE: U.S. Army Corps of Engineers.

Figure 2.3-Plan View of Station First Floor

RANDMR1697-2.4

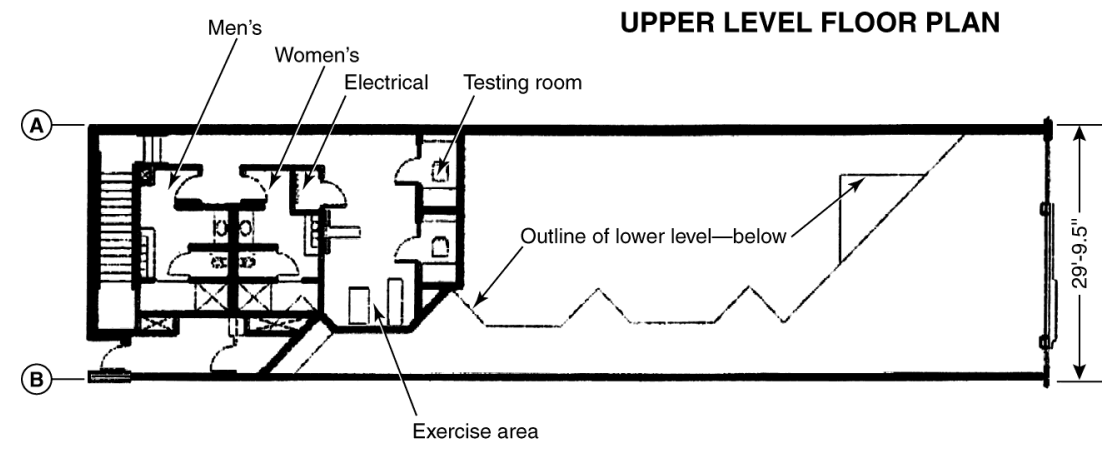

SOURCE: U.S. Army Corps of Engineers.

Figure 2.4-Plan View of Station Second Floor 
Behind and to the right (as one stands at the storefront looking in) is a counter for the station administrators, flanked by two television monitors connected to video equipment (for showing militaryrecruiting commercials and other recruiting-relevant promotional videos). Not shown in this plan view is a large-screen display located on the wall above the civilian administrators; this screen also shows promotional video material.

The recruiters' offices are located down the hallway, in the back of the station. This placement, a purposeful part of the design, effectively ensures that visitors are unaware of the recruiters' offices, unless they ask or wander down the hallway. Throughout the operation of the station during this evaluation, no indicators or signs were used to inform casual lobby visitors of the presence of recruiters or their offices in the station.

Behind the combined Marine Corps/Coast Guard office is a small kitchen area, with a sink, coffee pot, and fold-out table. Behind the kitchen area are stairs to the second floor.

The second level of the station consists of men's and women's bathrooms, complete with shower and locker facilities, a central area that contains some exercise equipment, and two testing rooms. The exercise area was originally envisioned as a place for youth in the Delayed Entry Program ("DEPers") to meet with and work out with their recruiters. This idea was subsequently canceled for liability concerns, although the equipment was still installed for recruiter use. Most recently, additional furniture has been installed in the exercise area so that it can also be used as a conference room.

\section{Rationale for Choosing This Design}

The station design was primarily driven by the configuration of the space available in Potomac Mills Mall. The narrow and very deep space precluded locating the recruiter's offices in the front because there was no feasible way for all four services (subsequently increased to five once the Coast Guard agreed to participate) to equitably share the storefront. Because allowing any one service to dominate the storefront would have given that service an unfair recruiting advantage, it was decided that none of the services' recruiting offices would be visible from the storefront. 
The second floor was added in an effort to maximize the station's square footage. However, that space is used infrequently under the current operating procedures, so it is not clear that the addition of the second floor was necessary. Furthermore, DoD is liable for returning the space to its original condition, which means the second floor will have to be removed if the station is closed, at considerable expense.

\section{Unique Features of This Design}

Compared with a standard recruiting station, the Potomac Mills station is unique in many ways, including that (1) all five services are colocated in a single recruiting-station structure, (2) the station's mission is broader than a standard station's, encompassing both marketing and recruiting, (3) the previously existing station, which has responsibility for the surrounding territory, was not closed, and (4) the new station also incorporated the use of civilian administrators. We discuss each of these features in turn, below.

Collocation of All Services Within a Single Structure. First and most obviously, all five services are colocated in a single, common structure. The services are strongly encouraged to colocate in other locations; however, such colocation is generally manifested as adjacent (but separate) recruiting offices in exterior strip malls (see Figure 1.1 in Chapter One). Potomac Mills, as a single facility that all services share (both physically and contractually), introduces additional coordination, operations, and management challenges. For example, operational expenses (such as utilities) must be jointly managed and prorated among the services. ${ }^{4}$ Similarly, management of Potomac Mills is more complicated than a standard station, for which the senior recruiter in the office is in charge and reports directly to a regional supervisor for the operation of the station. In Potomac Mills, no such "station commander" exists (although each service does have its senior recruiter in charge of that service's personnel and interior office space). Responsibility for the entire station rotates annually among the services. As a result, in many

\footnotetext{
${ }^{4}$ In comparison, in a standard recruiting office, all of the operating expenses are paid by the responsible service.
} 
ways no one is truly in charge of the entire station's operation and management.

Such close colocation in a single facility requires a level of interservice cooperation and professional interaction not necessary in other colocated stations. For example, in a standard station, prospects outside the station are generally considered open to solicitation by any recruiter of any service. And the demarcation between being inside and outside a particular service's station and, hence, whether a potential prospect is "fair game," is clear. ${ }^{5}$

In Potomac Mills, it is less clear how recruiters should treat potential prospects who are inside the station but not in a particular service's office. For example, if a prospect enters the station with an appointment to meet with a specific recruiter or service, then it would be poor form for a recruiter from another service to approach that individual and try to enlist him or her. However, since the Potomac Mills station is supposed to be marketing military service careers, both in general and for each specific service, it would be advantageous to have recruiters present in the lobby talking to visitors. But it is not clear how to balance the conflicting demands. The result is that the lobby and the hallway leading down to the individual offices are generally treated as a sort of "no-mans-land," where little to no recruiting takes place.

For the Marine Corps and Coast Guard, colocation is taken to the extreme: Both services share a single office within the Potomac Mills station, the result of the Coast Guard's late entry into the Potomac Mills project and the Marine Corps' gracious volunteering of space. However, the unintended consequence of such sharing is that the recruiters for these two services do not have any real privacy within the facility. The nature of recruiting is competitive under the best of circumstances; yet, this arrangement places these recruiters in the difficult position of compromising service-proprietary information when both are present in the facility (e.g., each can overhear the other's

${ }^{5}$ Obviously, there are more-subtle conventions and customs than described here. For example, surely one service's recruiting staff would take exception to another service's recruiter standing directly outside its station's door and redirecting visitors away from the station. But, barring extreme examples such as this, the general idea of fair game outside the station and off-limits inside is clear. 
telephone conversations). The result is that the recruiters for these two services, simply due to the design of the facility, are motivated to avoid working within the station, as the frequently empty office during our visits testified.

Station Mission Is More Complicated: It Is Both Marketing and Recruiting. The mission of Potomac Mills is also more complicated, because the station was designed to perform both recruiting and marketing functions. Standard recruiting stations function basically as recruiter office space; any marketing that takes place is a by-product of basic station signage. In comparison, Potomac Mills station placement in a high-foot-traffic location and its high-tech features are intended to attract visitors. Unlike visitors to standard stations who generally are already seriously considering a military career, the visitors here may be less interested in joining the military immediately and more interested in learning about the military and military careers (either for themselves or for sons, daughters, nieces, or nephews, in the case of various adult influencers). As such, many of them are often early in the decisionmaking process-perhaps having only walked in to the station on a whim - and may thus require alternative types of information and attention than what a recruiter normally provides.

Station's Territory and Operation Confounded by Those of an Existing Station. Potomac Mills is also unique in that the existing station, the Woodbridge station, ${ }^{6}$ was not closed when Potomac Mills was opened. Essentially right across the parking lot from Potomac Mills, this station houses additional recruiters and traditional recruiter office space.

The continued existence of the Woodbridge station has both complicated and complemented the operation of the Potomac Mills station, in a number of ways. As a complication, each service has separated or combined the operations of the two stations in different ways. For example, the Navy and Marine Corps, on the one hand, have operated Potomac Mills as an extension of the Woodbridge station, maintaining their senior recruiters in the Woodbridge station and

${ }^{6}$ The "Woodbridge station" is actually a set of stations, one for each service, all located in the immediate vicinity of Potomac Mills. For simplicity, we refer to it in the singular. 
assigning one or more recruiters to the Potomac Mills station. The Army and Air Force, on the other hand, have staffed Potomac Mills as a full-time station, placing the senior recruiter on-site in charge of their portion of the station.

However, because of the existence of the Woodbridge station, all services have had to assign the surrounding territory piecemeal between those recruiters assigned to Potomac Mills and those assigned to Woodbridge. As a result, the Potomac Mills station is not specifically and individually responsible for all of the surrounding territory, which is important: It makes it difficult to separate the effects of the two stations on recruiting performance. The consequence has been perhaps most visible for the Marine Corps. During the first six months of station operation, that service attributed a number of contracts to the Potomac Mills station, without having a recruiter actually present on-site at Potomac Mills. It is difficult to know how to attribute such success, which clearly would not have occurred without the presence of the Woodbridge station.

Use of Civilian Administrators. Another major difference between the Potomac Mills station and standard recruiting stations is the presence of civilian administrators. The Potomac Mills station is required to be open at all times that the mall is open-approximately 80 hours per week. To free the recruiters from having to be present in the station for all of this time, and to provide a "neutral" lobby with respect to military service, civilians are employed to staff the desk in the lobby. They are responsible for ensuring that the station is opened on time (when the mall opens), that it remains open during mall operating hours, and that the equipment in the lobby (lights, video monitors, kiosk, etc.) is operational during business hours.

This use of civilian administrators has also introduced a number of complexities into the Potomac Mills station. From the beginning, the administrator's role in the recruiting process has been limited specifically by the services, which believe that recruiting is best served when a prospect is face to face with an active-duty recruiter. As a result, the civilian administrators are allowed only to answer basic questions about the facility, to take messages, to provide some 
recruiting literature, and then to direct visitors to the recruiters. ${ }^{7}$ Various recruiting commanders and supervisors expressed some concern early-on about avoiding favoritism between the administrators and one or more services and/or recruiters. During the period of this evaluation, the administrators seemed to have successfully remained neutral in this regard.

A major difficulty with respect to the administrators has been supervision. Nominally, the administrators are supposed to be supervised by the service with responsibility for the station (which, as described, alternates annually among the services). In the first year, the Marine Corps was responsible for the station. However, little or no oversight of the administrators occurred, ${ }^{8}$ resulting in conflicting opinions of the administrator's role in the station, as well as early misunderstandings of the administrator's duties and responsibilities.

\section{CONCLUSIONS}

The Potomac Mills station is unique among recruiting stations because of the addition of the marketing enhancements, its placement in a large mall, and the colocation of all five services. Here, we offer conclusions related to the design and operation of this particular station.

Conclusion: It is not clear that colocating more than one service in a facility such as the Potomac Mills station, where the services share common facilities (such as a lobby) and/or recruiters of different services are expected to cooperate in the operation of the station, contributes to optimal station performance.

Our initial impressions based on observing the Potomac Mills station are that recruiters prefer to forgo using the facilities rather than take the chance of being perceived as unfairly using/exploiting those facilities to the detriment of the other services. In Potomac Mills, recruiters did not take advantage of the lobby area (e.g., through special-events displays, advertisements, or manning), and the lobby

\footnotetext{
${ }^{7}$ They were also tasked to collect data for this evaluation.

${ }^{8}$ The Marine Corps was supposed to coordinate the creation of a Station Operations Manual. This did not occur.
} 
became a sort of “no-man's-land," largely unused and unexploited by the recruiters. In a similar vein, as we discuss in the next chapter, the "jointness" of the station meant that there was no station commander, which a standard station would have; hence, no one was truly in charge of the station on either a day-to-day or long-term basis. Unlike almost every other recruiting station, none of the recruiters, recruiting commanders, or recruiting commands seemed to feel any ownership of this station.

Conclusion: If more than one military service is colocated in a joint facility such as the Potomac Mills station, then each service's recruiters must have its own office space for privacy and security.

The Marine Corps and Coast Guard experience in the Potomac Mills station makes this conclusion obvious.

Conclusion: Rotating responsibility for Potomac Mills among the services is less effective than the standard arrangement with a station commander. The result is that Potomac Mills suffers from a lack of integration into existing organizational structures and on-site leadership to make it operate as a cohesive single entity.

Our experience with the station is that, since it is not "owned" by any particular service, it does not have a single chain of command overseeing its operation. The result is a lack of a single point of responsibility for the station. For example, the use and effectiveness of station administrators have suffered from a lack of oversight stemming from the lack of a station commander and chain of command.

Conclusion: Civilian administrators' duties and functions need to be better defined, and the administrators should be more fully utilized in joint marketing-enhanced recruiting stations.

The civilian station administrators have been underutilized since the Potomac Mills station was opened in December 2000. Station administrators were originally incorporated into the operation to reduce the burden on station recruiters, alleviating the need for recruiters to staff and maintain the lobby area, and eliminating the requirement that one or more recruiters stay in the station during all mall business hours. The civilian administrators have conducted these limited duties well. 
In addition, the civilian administrators are not integrated with the recruiters. For example, during the period of this evaluation, recruiters frequently did not inform the administrators of their plans or whereabouts so that the administrators could effectively answer visitors' and callers' (both casual and those with appointments) inquiries. For their part, recruiters were frustrated initially with the civilian administrators' lack of duties. Subsequently, the two groups (recruiters and administrators) tended to ignore one another more than they interacted. Compounding this situation, a set of station standard operating procedures (SOPs) delineating station operation and civilian administrator functions has yet to be promulgated; so, the duties, roles, and responsibilities of administrators and recruiters within the Potomac Mills MERS were never clearly defined.

Conclusion: Civilian administrators should be trained and tasked to implement, emphasize, and promote the marketing aspects of the station.

The services specifically limited the civilian administrators' functions so that the administrator performs no recruiting functions. But this limitation was instituted with such a broad definition of what the recruiting functions are that the civilian administrators could not communicate much useful information to casual station visitors, thereby inhibiting some of their usefulness as station marketers. Furthermore, because the civilian administrators have been purposely restricted in the amount and type of functions they can perform, they often have little to do when station walk-in traffic is slow.

If civilian administrator arrangements similar to those at the Potomac Mills station are pursued in the future by one or more of the services and/or DoD, one suggestion is to provide the administrators with some abbreviated form of recruiter training. Doing so will expand their duties in a meaningful way. For example, training could be tailored so that the administrators could prequalify potential applicants and hence provide mission value to the recruiters. At a minimum, the civilian administrators could be tasked to perform those station marketing duties that would promote the station, increase walk-in traffic, and generally complement the recruiters' duties. 
Chapter Three

HOW THE POTOMAC MILLS PROTOTYPE MERS

IS USED

Station design is the most visible aspect of the implementation of the marketing-enhanced recruiting station concept. Operating and management policies are less visible but equally as important. The obvious analogy is that an army is more than the aggregation of its equipment. Campaigns are won when hardware is optimally integrated with appropriate operational doctrine, training, and leadership. Similarly, major recruiting station design and location changes should be accompanied by appropriate changes in operational doctrine and training to optimize station performance.

In this chapter, we look at various indicators of "optimization" for the MERS: the way the station is operated and staffed by the services and by the recruiters from those services; whether the visitors to the mall fit in with the services' recruit demographics (i.e., does the mall attract the age and quality of person who would make a good recruit?); and whether the station is attractive and informative to those who do visit. We summarize our conclusions on station usage at the end of this chapter.

\section{STATION OPERATION AND STAFFING}

During the period of this evaluation, each military service has staffed the station with its recruiters slightly differently (Table 3.1). Throughout the first year of operation, the Army maintained the largest presence in the station, originally with four recruiters assigned. Although subsequently reduced to three, the Army recruiters, in a departure from normal recruiting practice, were not 
Table 3.1

Recruiter Staffing by Service for the First Year (2001) of Station Operation

\begin{tabular}{lcc}
\hline Service & $\begin{array}{c}\text { Number of Full- } \\
\text { Time Recruiters }\end{array}$ & $\begin{array}{c}\text { Number of Part- } \\
\text { Time Recruiters }\end{array}$ \\
\hline Army & $3^{\mathrm{a}}$ & 0 \\
Navy & 1 & varies \\
Air Force & 2 & 0 \\
Marine Corps & 0 & 1 \\
Coast Guard & 1 & 0 \\
\hline
\end{tabular}

aThe Army started out with four recruiters.

initially given a mission - that is, a goal for the number of youth to be signed up during a specific period (usually one month). ${ }^{1}$ Instead, they were responsible for screening potential recruits visiting the station. The recruiters then forwarded the potential recruit and his or her information to the most appropriate recruiting station for final processing.

In contrast, both the Navy and Air Force assigned full-time production recruiters (recruiters on mission who have to produce a specific number of contracts each month) to the Potomac Mills facility (one Navy recruiter and two Air Force recruiters). These recruiters operated within Potomac Mills in the conventional manner for their service. The Coast Guard also assigned one full-time production recruiter to Potomac Mills. However, that recruiter also maintained an office in the Coast Guard's Alexandria, Virginia, recruiting station and had a multistate recruiting territory. As a result, the Coast Guard recruiter, although a full-time production recruiter, maintained only a partial presence in the Potomac Mills facility. The Marine Corps staffed the station with one part-time recruiter who was not on mission and, as mentioned in Chapter Two, was rarely present in the station.

As described in the preceding chapter, in addition to the assigned recruiters, the station uses civilian station administrators to staff the

${ }^{1}$ The Army operated the station this way for approximately the first six months. We do not know the precise date at which the Army put their recruiters back on mission. 
entrance desk and ensure that the station is opened and closed and that equipment runs.

For the first two years (December 2000 through December 2002), Potomac Mills had four full-time civilian administrators staffing the station. A new contract was subsequently implemented that reduced the staffing to two full-time and two part-time station administrators, at a cost savings of $\$ 80,000$ per year, while still keeping the station fully staffed during all mall hours. The telephone long-distance contract was also renegotiated, saving $\$ 4,000$ while maintaining the same calling volume. Station costs are discussed more fully in the next chapter.

With this information as background, we look more closely at how the different services used the station and what the individual recruiters did while they were at the station.

\section{How Did the Services Use the Station?}

With the exception of the Army, the services operated this station either as a standard recruiting station or as an adjunct to the Woodbridge station. As just mentioned, the Army initially treated the station as a lead-generating facility, staffing it with recruiters not on mission/goal who were tasked to generate leads and then forward those leads to the cognizant production station.

To date, none of the services has attempted to exploit or augment the marketing aspects of the station. Rather, all the services have simply assigned recruiters to the station, without additional resources or guidance, leaving them to operate in the Potomac Mills MERS as they would at any other station.

It was suggested to each recruiting command, to the local recruiting commanders, and to the station recruiters that the station could be used for staging special events and employing additional marketing; however, the station has yet to be used in such a fashion. ${ }^{2}$

\footnotetext{
2 The station would lend itself to various events that would not work with other stations. For example, the lobby of the station could be used for special events (service birthday celebrations, historical displays on, for example, units from the area) and special displays to attract the attention of the mall visitors. Each service has
} 


\section{When Were the Recruiters Present in the Station?}

Figures 3.1 and 3.2 show the average recruiter presence in the Potomac Mills MERS by time of day for each day of the week for May and December 2001, respectively. For example, Figure 3.1 shows that an average of three recruiters were present on Saturdays at $2 \mathrm{pm}$

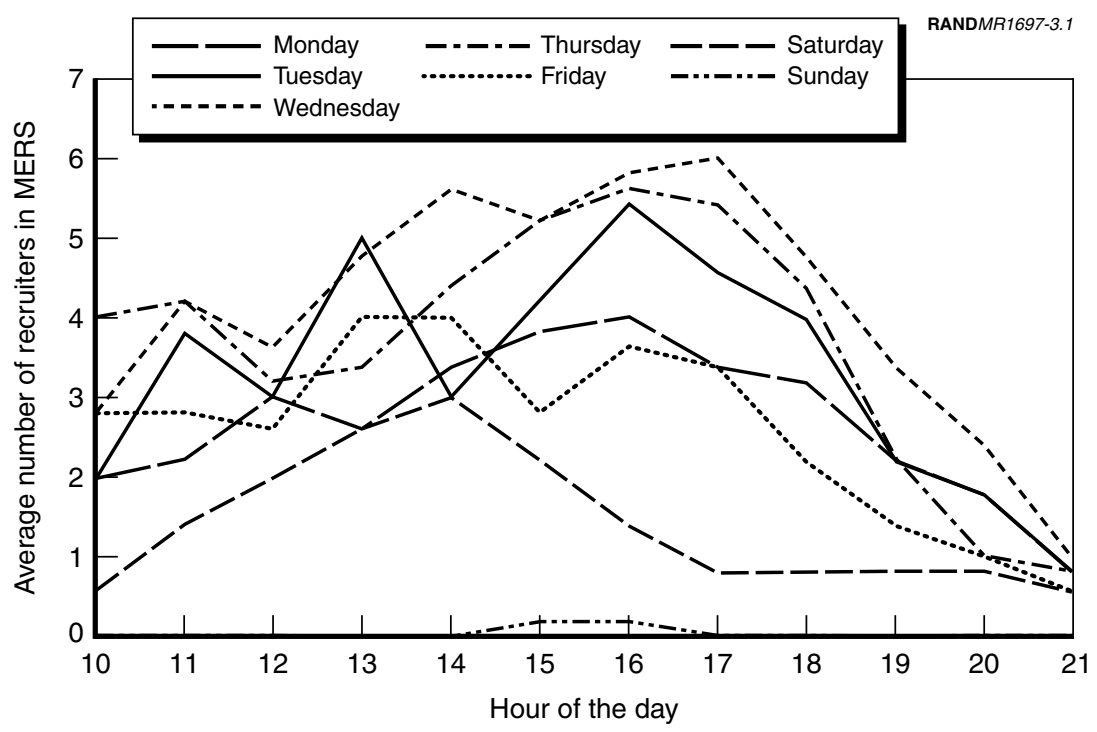

Figure 3.1-Average Potomac Mills MERS Recruiter Presence by Day for Each Hour During the Month of May 2001

various recruiting displays and puts on other special events that could be easily incorporated into the lobby on a rotating basis. Other one-time events (e.g., militaryrelated book signings), could be held there as well.

Similarly, it was suggested that the station host an after-hours social event for local high school principals, guidance counselors, and teachers to introduce them to the station and the military. Such a regular event could build goodwill and provide the station recruiters with greater high school access.

Even simple events, such as a monthly early-morning coffee-and-donuts open house for the mall walkers, could be used to provide a positive introduction to local adult influencers.

All of these ideas were put forward to various recruiters, local recruiting commanders, and recruiting commands. While the ideas were met with enthusiasm and interest, none was ever implemented. 


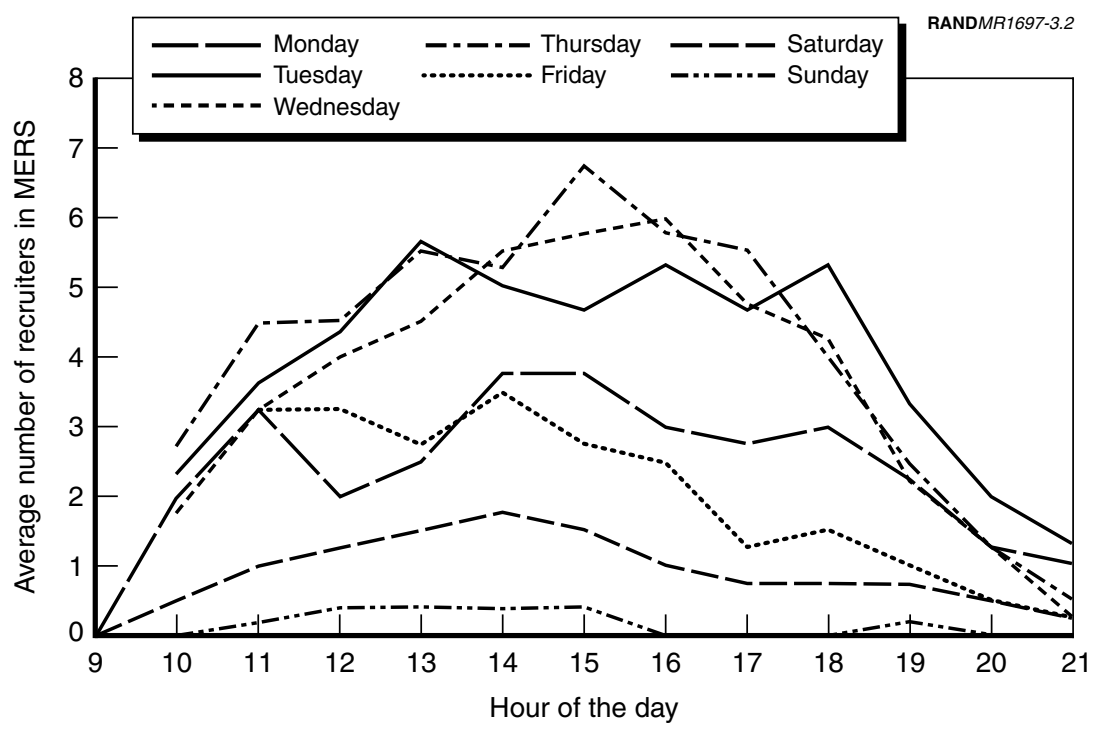

Figure 3.2-Average Potomac Mills MERS Recruiter Presence by Day for Each Hour During the Month of December 2001

( 1400 hours, or " 14 " in the figure). On average, three or more recruiters were present in the MERS during regular working hours on weekdays and sometimes into weekday evenings. Overall, the station tended to have the greatest number of recruiters present on Tuesdays, Wednesdays, and Thursdays in the late afternoon and early evening.

When the Army was using the station for lead generation, it staffed the station on Saturday, as shown in Figure 3.1. However, since placing its recruiters back on mission/goal, the Army recruiters returned to keeping hours more similar to the other services', and the station was virtually unstaffed (with recruiters) on weekends.

\section{MALL MANAGEMENT}

Even if the recruiting officers and commanders had wanted to put on a special event, it is probable that they would have met with some 
resistance from the management of Potomac Mills, as did some of the stations described in Chapter Five. The leasing agreement explicitly requires that the station be open during mall hours, which was accommodated by hiring civilian administrators (an added operating expense), and it specifically limits recruiting, recruiters, and station promotional activity outside the station within the mall. As will be seen in Chapter Five, mall management is an important component of a recruiting station's ability to put itself forward in a given mall, displaying equipment and memorabilia as a way of alerting visitors to the station's presence, advertising special events, and prospecting for recruits.

\section{WHO IS VISITING THE POTOMAC MILLS RECRUITING STATION?}

Walk-in traffic to the station is significant relative to that of standard stations. In the first full year of operation, between January 1 and December 31, 2001, we estimate that the station had almost 8,000 visitors, ${ }^{3}$ which translates into an average of more than 650 visitors per month, or about 20 per day. Over half of the visitors were judged to be of potential recruit age.

In this section, we provide details on the demographics of visitors to the mall overall and visitors to the MERS in particular. We then describe a survey of MERS visitors and their responses. A copy of the survey is in the Appendix.

\section{Demographics}

According to intercept surveys conducted by the Potomac Mills Mall, "the core shopper is a white female, 35-54 years of age, with an average household income of $\$ 50,000$ to $\$ 100,000$. She is likely to be married, have children living at home, and visit the center more than 8 times annually...." (The Mills, 2001). However, as shown in Table 3.2, the Potomac Mills prototype MERS seems to be attracting the

\footnotetext{
${ }^{3}$ A "visitor" was anyone who entered the station. Since the person counting visitors was able neither to distinguish between persons who came in for multiple visits nor to separate those who came in to the station for an appointment with a recruiter versus casual walk-ins, this count likely overstates the number of unique visitors.
} 
Table 3.2

Comparison of Demographics Among MERS Visitors, Potomac Mills Mall Visitors, and the Surrounding Counties

\begin{tabular}{lccc}
\hline $\begin{array}{l}\text { Demographic } \\
\text { Category }\end{array}$ & $\begin{array}{c}\text { MERS } \\
\text { Visitors }\end{array}$ & $\begin{array}{c}\text { Potomac Mills } \\
\text { Mall Visitors }\end{array}$ & $\begin{array}{c}\text { Prince William and } \\
\text { Stafford Countiesc }\end{array}$ \\
\hline Recruit Age & $54 \%$ & $17 \%$ & $11 \%$ \\
Male & $68 \%$ & $39 \%$ & $51 \%$ \\
White & $58 \%$ & - & $77 \%$ \\
Black & $22 \%$ & - & $11 \%$ \\
Hispanic & $9 \%$ & - & $5 \%$ \\
\hline
\end{tabular}

aStatistics compiled from data recorded by station administrators from January 1, 2001, through December 31, 2001.

bThe Mills, Potomac Mills Marketing Program 2000, Prince William, Va., 2000, and The Mills, Potomac Mills Annual Marketing Program 2001, Prince William, Va., 2001.

c1990 Census and Census Bureau 1998 estimates.

$\mathrm{d}$ Recruit age is defined as 18-24 years old for Potomac Mills visitors and Census demographics; MERS visitors were not asked their age, so percentage is based on station administrators' assessment of whether each visitor appeared to be recruit age.

desired youth demographic: More than one out of every two station visitors are of recruit age, ${ }^{4}$ and two out of three are male. The station also seems to attract a larger fraction of minority visitors when compared with the composition of the population in the surrounding counties.

Figure 3.3 shows the total number of visitors to the station from January through November 2001. The pattern follows both the seasonal recruiting pattern and the seasonal shopping pattern. Generally speaking, military recruiters experience an annual cyclical pattern in which the number of interested applicants is lower in the late spring and early summer, when high school students are concerned with graduation and then enjoying the summer prior to beginning job hunting. The number of applicants then peaks in the late summer and early fall as those recent graduates begin assessing their employment prospects in earnest. This pattern is evident in Figure 3.3 between March and September.

\footnotetext{
${ }^{4}$ Station administrators were not able to ask detailed demographic questions of every visitor. Rather, they observed the visitors and recorded whether they looked to be of recruit age.
} 


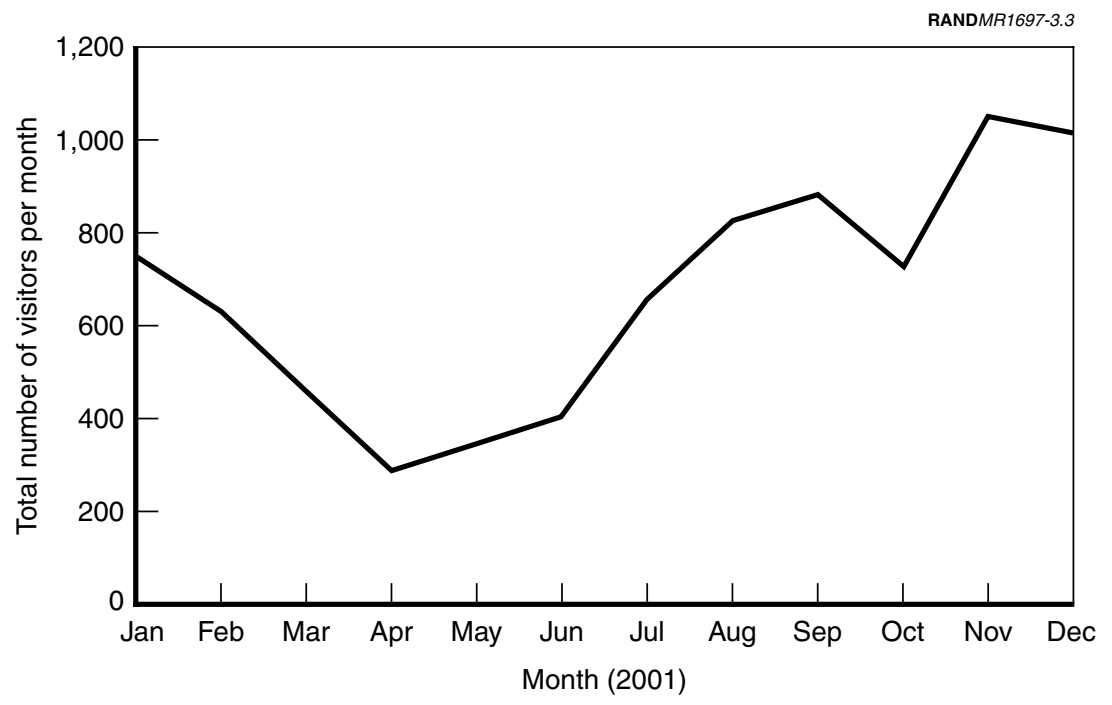

Figure 3.3-Total Number of Visitors to the Potomac Mills Station in the Year After the Station Opened, January Through December 2001

In contrast, the retail seasonal cycle tends to experience its peak during the traditional Thanksgiving-to-Christmas shopping period. Potomac Mills Mall is also said to experience a peak during the summer, when tour buses from Washington, D.C., bring out-of-town tourists down to shop for bargains at the outlet-mall stores. The holiday-shopping peak is evident in Figure 3.3 as the continued upward spike in visitors during November and December, a spike not characteristic in the recruiting cycle. The summer retail spike is not evident in Figure 3.3; however, the absence of a spike may be because visiting tourists are not likely to be interested in a military recruiting station.

From March through December 2001, station administrators also collected station visitors' home zip codes. Of those visitors who supplied their zip codes (88 percent), almost 95 percent indicated that they were from Virginia. Furthermore, most of the Virginia visitors were from areas immediately surrounding Potomac Mills Mall. Hence, the vast majority of station visitors are truly local residents. Of the non-Virginia station visitors, slightly more than 1 percent were 
from Maryland and Washington, D.C., and about 3 percent were from outside the United States.

Figure 3.4 shows the geographic hometown distribution of Potomac Mills Mall Recruiting Station visitors from Virginia by zip code. By far the largest majority of visitors came from zip codes 22191 (28.7 percent), 22192 (31.4 percent), and 22193 (34.3 percent). Potomac Mills Mall is located in zip code 22192. Indeed, almost 95 percent of all Virginia visitors were from these three zip codes. Most of the other zip codes with a nonnegligible fraction of visitors were also in the immediate vicinity of the mall, although the fraction of visitors from these zip codes was substantially smaller-at most a few percent.

As Figure 3.5 shows, one-half of all visitors to the station came on a weekend day. Saturday was by far the most active day of the week. Indeed, fully three-quarters of all visitors came to the station from Thursday through Sunday.

Figures 3.6 though 3.8 show the time of day during which visitors came into the Potomac Mills prototype MERS. The peak visitor time for Monday through Wednesday was during the workday. For Thursday and Friday, it was in the evenings after the workday. For Saturday and Sunday, peak visitor time was in the afternoon.

\section{How Visitors Used the Station}

Table 3.3 shows that just over one in four visitors to the Potomac Mills prototype MERS saw a recruiter and two-thirds of the visitors talked to the station administrators. Almost one-third used the computer kiosk, and one in four took some recruiting literature.

\section{WHAT DID VISITORS THINK OF THE VARIOUS PARTS OF THE STATION?}

To get some insight into what visitors thought of the various aspects of the station, we surveyed 78 walk-ins during the course of the first year. Participation in the survey was entirely voluntary, so the aggregate results may not reflect the larger population of casual station visitors. However, the results of the survey are still very illuminating. 


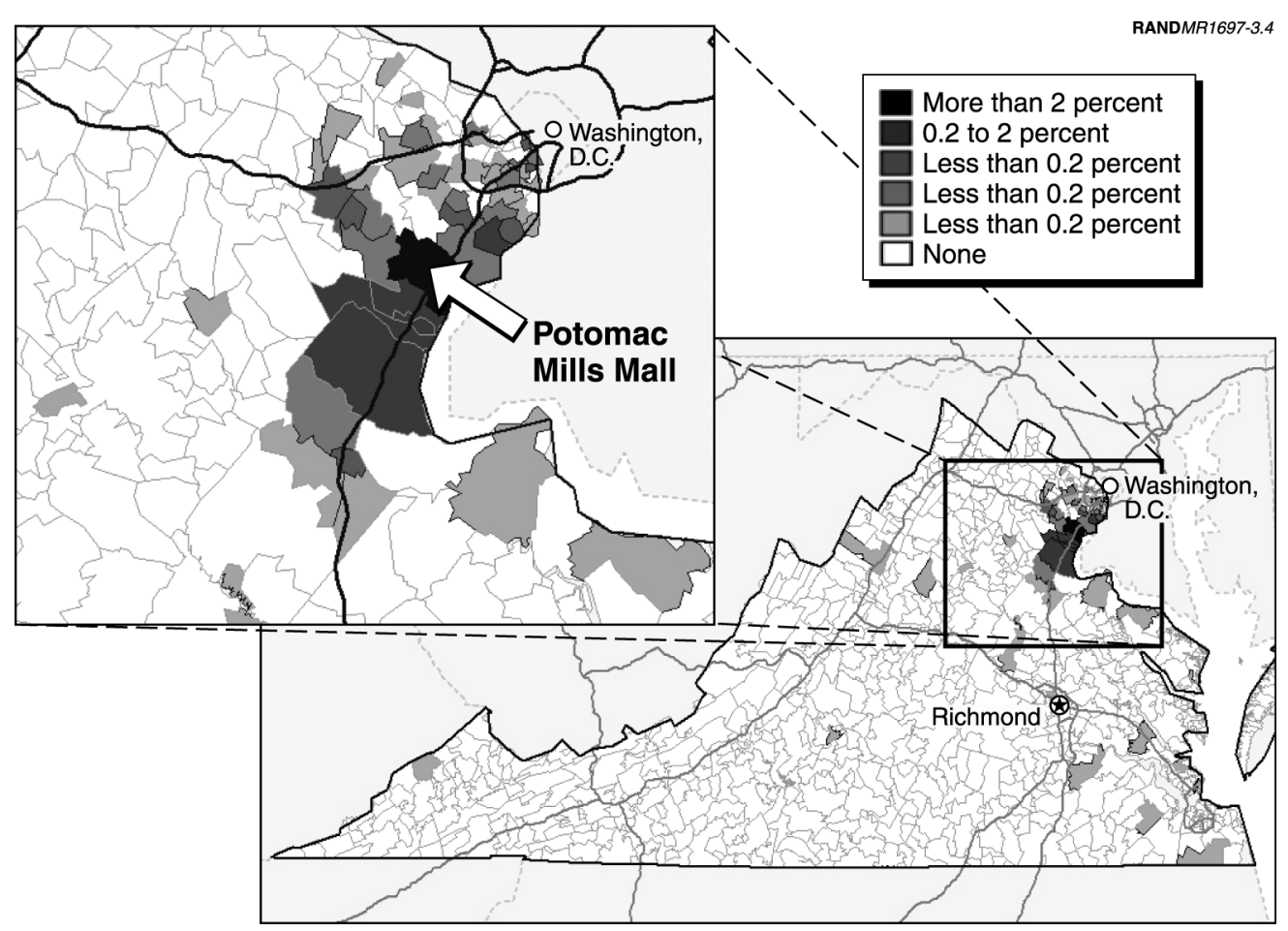

Figure 3.4-Map of Virginia Zip Codes, Shaded by Fraction of Station Visitors 


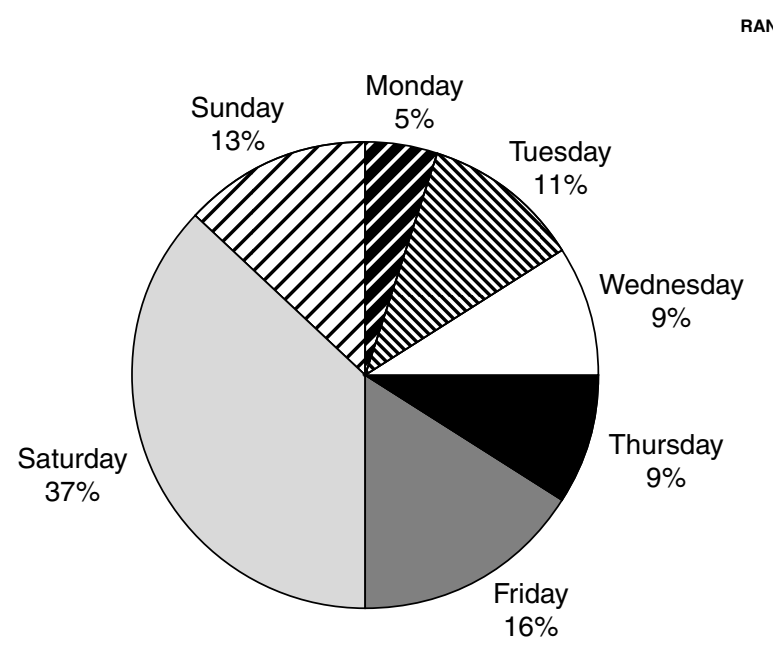

SOURCE: Based on the data collected from January 1 through March 31, 2001, by the station administrators.

Figure 3.5-Potomac Mills MERS Visitors, by Day of the Week

To begin with, Table 3.4 provides the demographics of the survey participants. In comparison with Table 3.2, the survey participants were similar in age, gender, and racial demographics to the general population of station visitors. Half of the survey participants were of recruit age and half were of adult-influencer age. Recruit-age participants were evenly split between male and female; more males than females were the adult-age participants. A larger fraction of the recruit-age participants were minorities, single, and had a high school degree or less than were the adult-influencer participants.

When the respondents were asked to describe the Potomac Mills Recruiting Station ("Military Career Center" in the survey terminology), "welcoming" was the most used adjective (59 percent of both youth and adults ${ }^{5}$ ), followed by "educational" (37 percent), then "hightech" (24 percent). Only 21 percent found it "exciting" (Figure 3.10).

${ }^{5}$ Where youth denotes recruit-age individuals up to 24 years old and adult denotes individuals older than 24 years. 


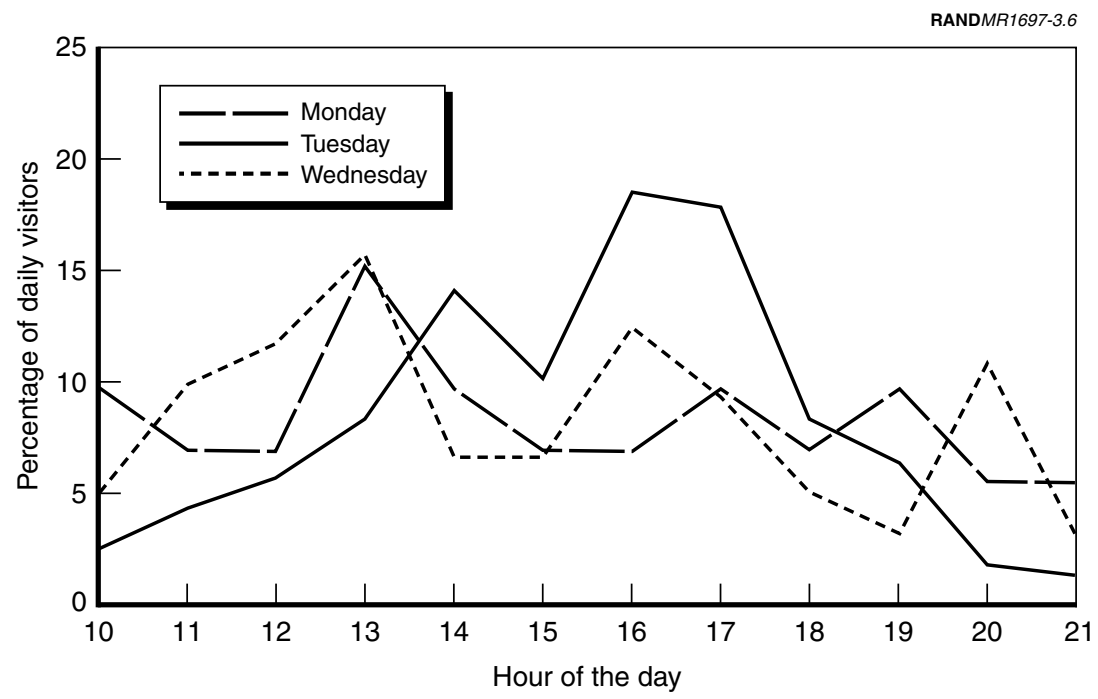

Figure 3.6-Time of the Day for Visitors, for Monday, Tuesday, and Wednesday

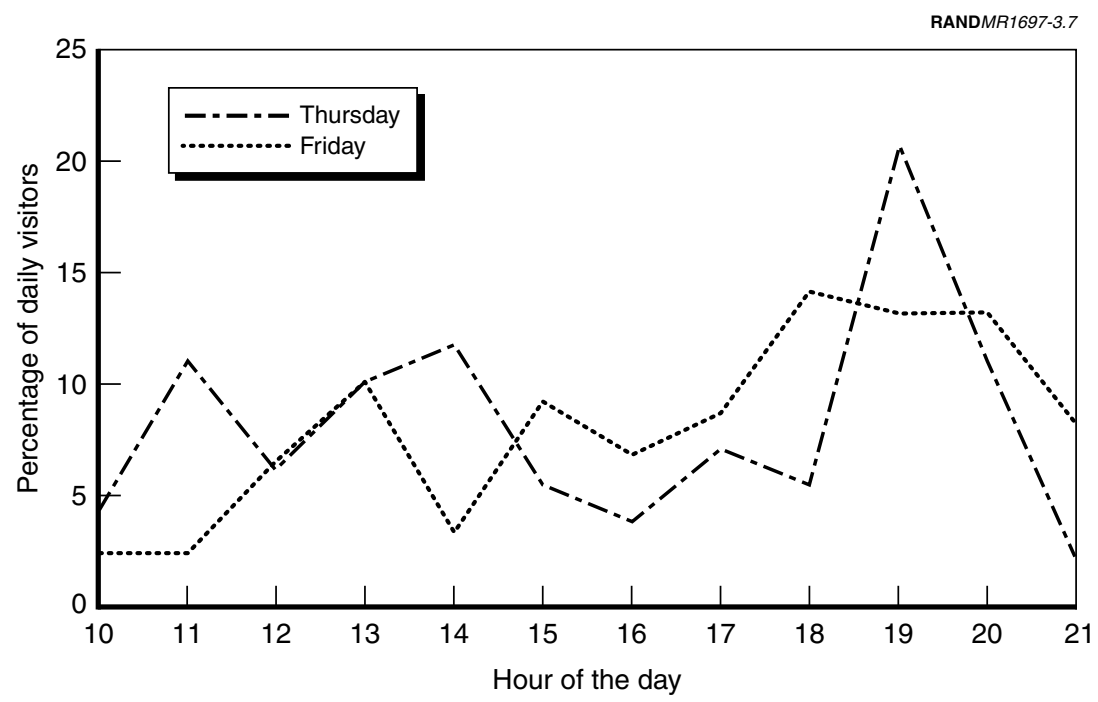

Figure 3.7-Time of the Day for Visitors, for Thursday and Friday 


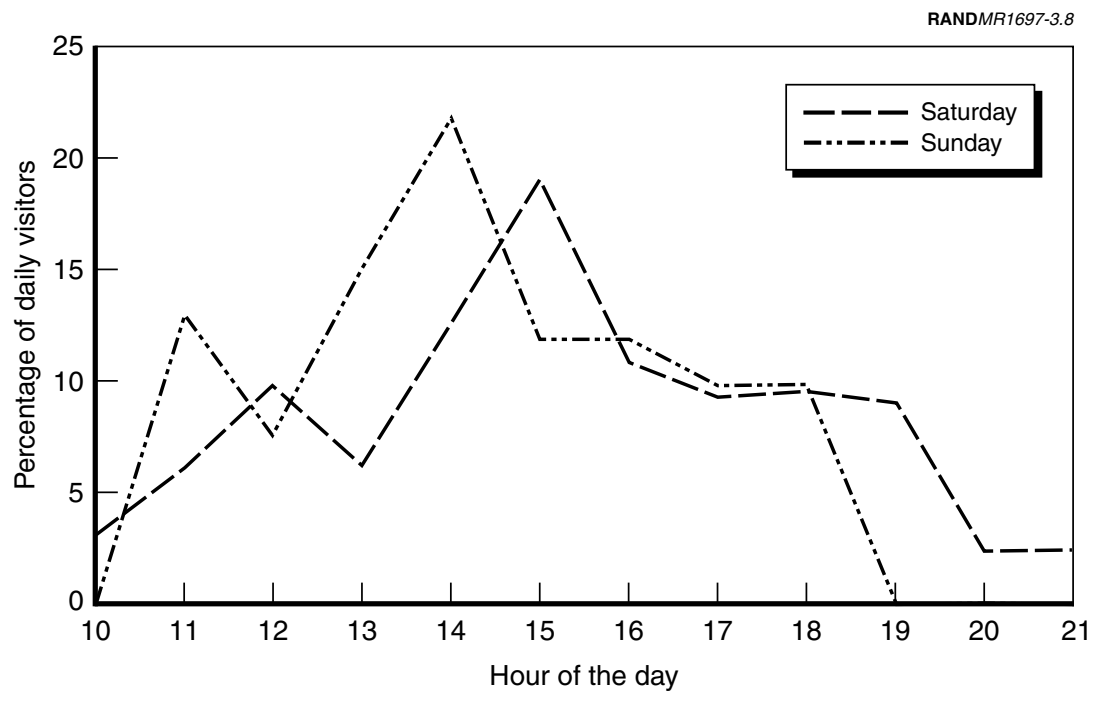

Figure 3.8-Time of the Day for Visitors, for Saturday and Sunday

Table 3.3

What Visitors Do in the Potomac Mills Prototype MERS

\begin{tabular}{lc}
\hline Activity & $\begin{array}{c}\text { Percentage } \\
\text { of Visitors }\end{array}$ \\
\hline Speak to administrators & 67 \\
Use kiosk & 30 \\
See recruiters & 28 \\
Take brochure(s) & 25 \\
Watch videos & 12 \\
\hline SOURCE: Percentages are based on data collected \\
from January 1, 2001, through December 31, 2001, by \\
the station administrators.
\end{tabular}

Notably, fewer youth than adults found the station either high-tech or exciting. However, only 4 percent found the station "boring."

Fully 93 percent of the visitors found the station very interesting (44 percent) or somewhat interesting (49 percent). That is, only 7 percent of the visitors found the station somewhat or very uninteresting (Figure 3.10). Thus, while the station seemingly does not achieve the 
goal of projecting a cutting-edge image for the military-the majority of visitors did not find the station either high-tech or excitingvisitors do find the station interesting.

When asked what the recruiting station was useful for, the predominant answer (76 percent) was "learning about military career opportunities" (Figure 3.11). Of the visitors, 36 percent were also interested in "learning about educational benefits" and 31 percent were

Table 3.4

Demographics of Survey Participants

\begin{tabular}{|c|c|c|c|}
\hline $\begin{array}{l}\text { Demographic } \\
\text { Category }\end{array}$ & $\begin{array}{l}\text { All Participants } \\
\qquad(N=78)\end{array}$ & $\begin{array}{c}\text { Recruit-Age } \\
\text { Participants } \\
(N=39)\end{array}$ & $\begin{array}{c}\text { Adult- } \\
\text { Influencer } \\
\text { Participants } \\
(N=39)\end{array}$ \\
\hline \multicolumn{4}{|l|}{ Age (years) } \\
\hline Under 18 & $12 \%$ & $23 \%$ & $0 \%$ \\
\hline $18-24$ & $38 \%$ & $77 \%$ & $0 \%$ \\
\hline $25-34$ & $26 \%$ & $0 \%$ & $51 \%$ \\
\hline Over 34 & $24 \%$ & $0 \%$ & $49 \%$ \\
\hline \multicolumn{4}{|l|}{ Gender } \\
\hline Male & $58 \%$ & $51 \%$ & $64 \%$ \\
\hline Female & $42 \%$ & $49 \%$ & $36 \%$ \\
\hline \multicolumn{4}{|l|}{ Race } \\
\hline White & $51 \%$ & $46 \%$ & $56 \%$ \\
\hline Black & $21 \%$ & $30 \%$ & $13 \%$ \\
\hline Hispanic & $15 \%$ & $8 \%$ & $21 \%$ \\
\hline Other & $13 \%$ & $16 \%$ & $10 \%$ \\
\hline \multicolumn{4}{|l|}{ Education } \\
\hline less than high school (HS) & $19 \%$ & $37 \%$ & $0 \%$ \\
\hline HS or GED & $27 \%$ & $37 \%$ & $20 \%$ \\
\hline Some college & $23 \%$ & $14 \%$ & $33 \%$ \\
\hline College degree & $31 \%$ & $12 \%$ & $47 \%$ \\
\hline \multicolumn{4}{|l|}{ Marital status } \\
\hline Single & $62 \%$ & $87 \%$ & $36 \%$ \\
\hline Married & $38 \%$ & $13 \%$ & $64 \%$ \\
\hline \multicolumn{4}{|l|}{ Military experience } \\
\hline Never in military & $42 \%$ & $49 \%$ & $36 \%$ \\
\hline \multicolumn{4}{|l|}{ Friends/family in } \\
\hline military & $54 \%$ & $62 \%$ & $46 \%$ \\
\hline Prior military & $15 \%$ & $3 \%$ & $28 \%$ \\
\hline \multicolumn{4}{|l|}{ On active duty or } \\
\hline in Reserves & $18 \%$ & $13 \%$ & $23 \%$ \\
\hline
\end{tabular}




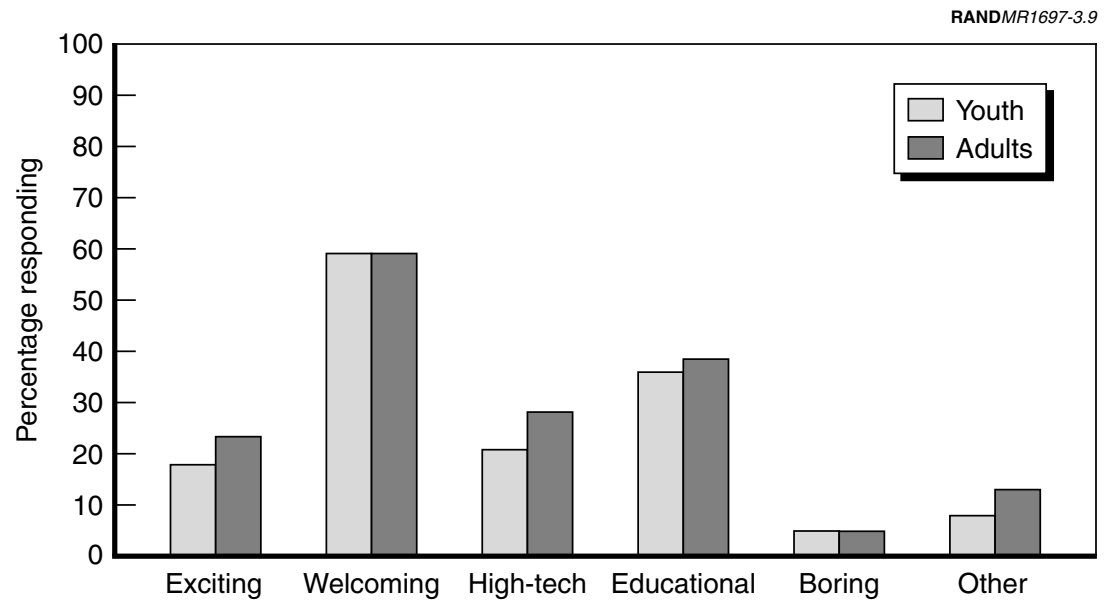

Figure 3.9-Answers to the Prompt "'I found the Military Career Center...' (check all that apply)"

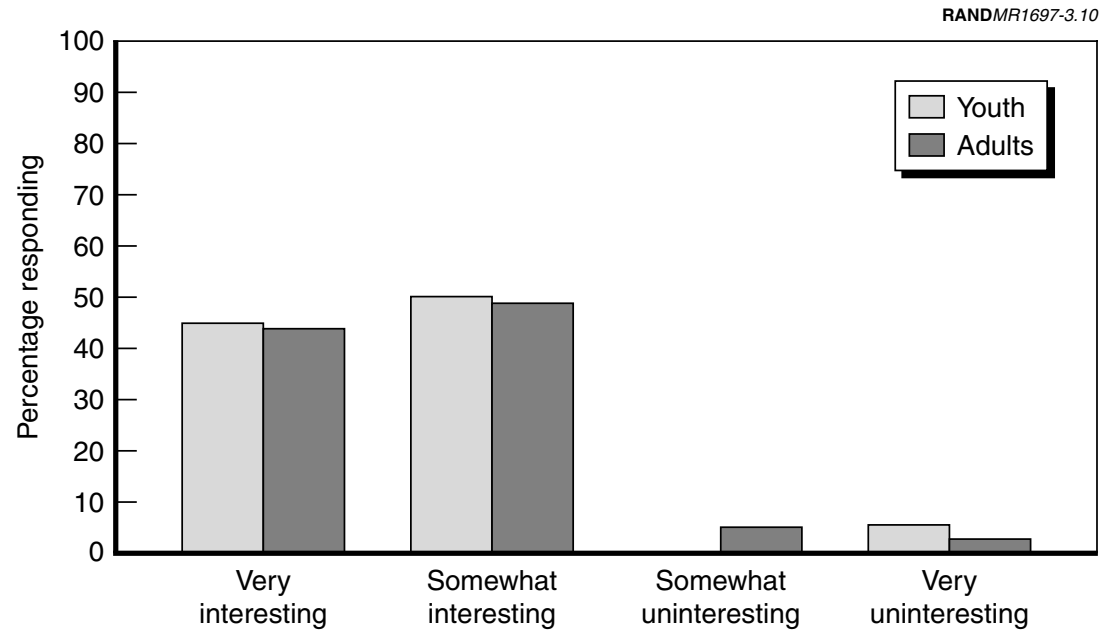

Figure 3.10—Answers to the Prompt "'The Military Career Center Was ...' (pick one)" 


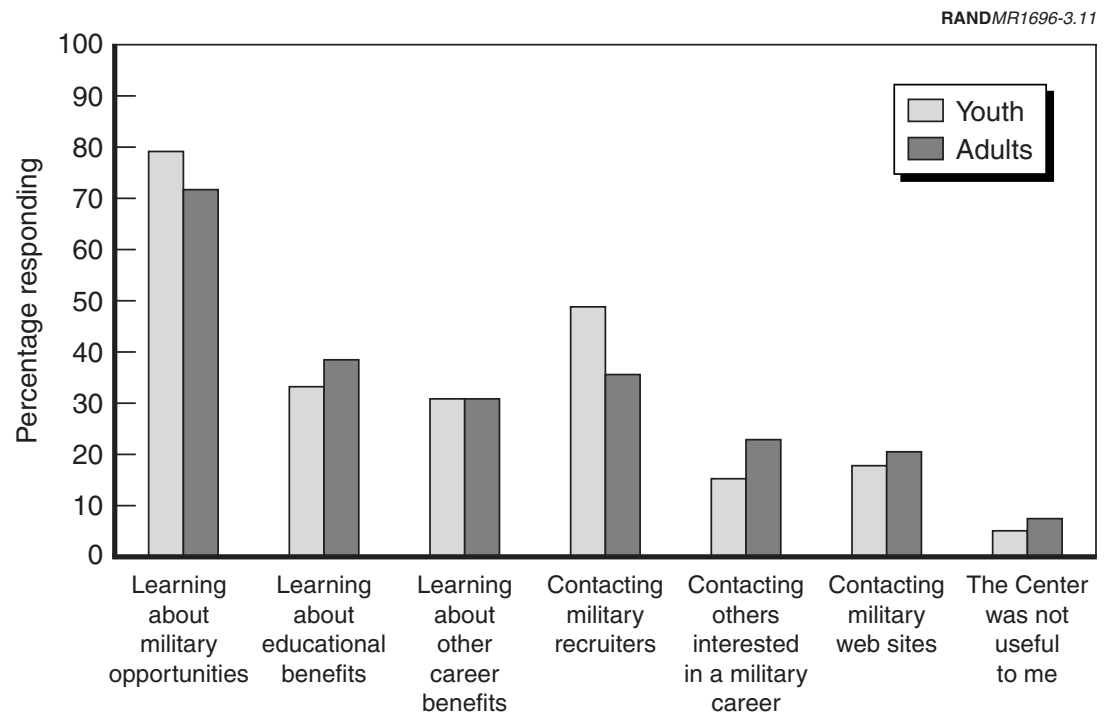

Figure 3.11-Answers to the Prompt “"The Military Career Center was useful for...' (check all that apply)"

interested in "learning about other career benefits." Taken together, fully 86 percent of visitors (all those who answered "yes" to one or more questions in the survey) found the station useful for learning about some aspect of military career opportunities and benefits.

Forty-two percent of the survey respondents (50 percent of youth) said they found the station useful for "contacting military recruiters." For a staffed recruiting station, this is an interesting result, indicating that the majority of visitors were looking for information about the military and military careers, although either not necessarily interested in direct contact with a recruiter or unaware that recruiters were present in the station.

In addition, 19 percent of all respondents found the station useful for "contacting others interested in a military career" and 19 percent found it useful for "contacting military web sites." Perhaps most 
important, only 6 percent of visitors said, "The Center was not useful to me."6

When asked what brought them into the recruiting station (Figure 3.12 ), two out of three respondents (67 percent) said they were "just walking by," and more adults indicated this than did youths. More youths said they were "referred" (by family or a recruiter), presumably reflecting those youths who were specifically referred to the station to see a recruiter. Almost one-third of the youth also said that curiosity about the military brought them into the station. "Other" reasons listed included comments such as "It looked interesting," "looking for facts," and parents visiting the station with their children.

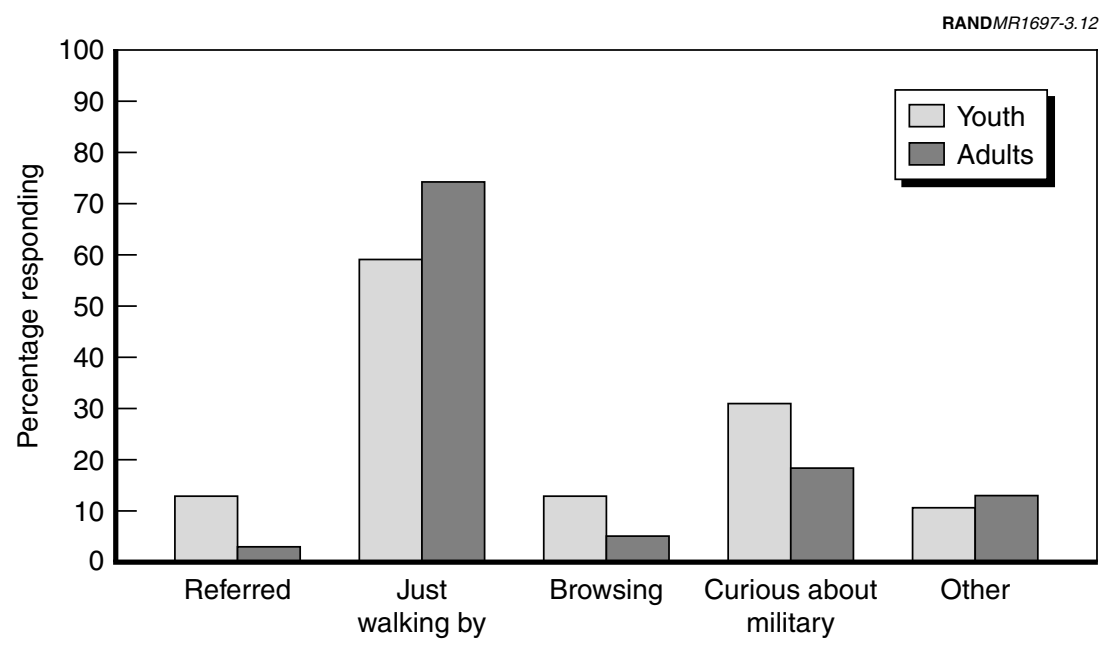

Figure 3.12-Answers to the Question "'What brought you into the Military Career Center?' (check all that apply)”

\footnotetext{
6 It is worth stressing here that the survey respondents are self-selected. Hence, the fraction of those stating that the station was not useful to them is probably an underestimate for the entire population of station visitors, since those filling out the survey form are also more likely to be interested in the station and the military.
} 
In a similar vein, almost all of the respondents (90 percent) said they heard about the recruiting station "just walking by" (Figure 3.13). A much smaller fraction of youth also heard about the station in school, from friends, and from family and relatives. Since the station has not been given any publicity in the media, this result is consistent with the way the station has been operated.

When asked to "pick the best feature of the Military Career Center" (Figure 3.14), visitors gave "computers" as their most popular response (32 percent), followed by "recruiters" ( 23 percent), then "videos" (17 percent). It is notable that the staff appealed to adults more than to youth (17 percent versus 9 percent) as did videos (19 percent versus 14 percent). Conversely, recruiters appealed more to youth ( 26 percent versus 21 percent), as did the computers ( 35 percent versus 29 percent).

Finally, as Figure 3.15 shows, the effect of the recruiting station on the survey respondents was either neutral (48 percent) or positive, with 49 percent of the respondents saying that they are "more interested in joining the military" after visiting the station.

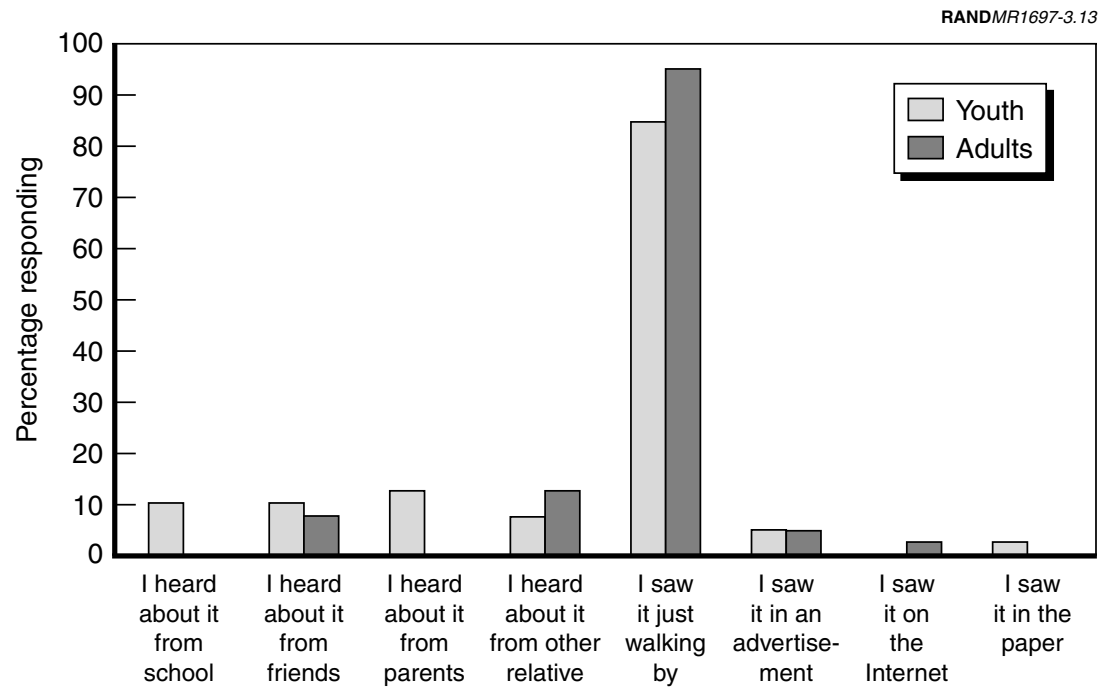

Figure 3.13-Answers to the Question "How did you hear about the Military Career Center?' (check all that apply)" 


\section{MARKETING-ENHANCED RECRUITING STATION AT POTOMAC MILLS MALL, VIRGINIA}

The following photographs, taken January 15,2001 , constitute a virtual tour of the Potomac Mills Mall Marketing-Enhanced Recruiting Station. Chapter Two provides a description of the station and additional details, including plan views of the station layout. The appearance of the station has not changed in any substantial way in the intervening years. 


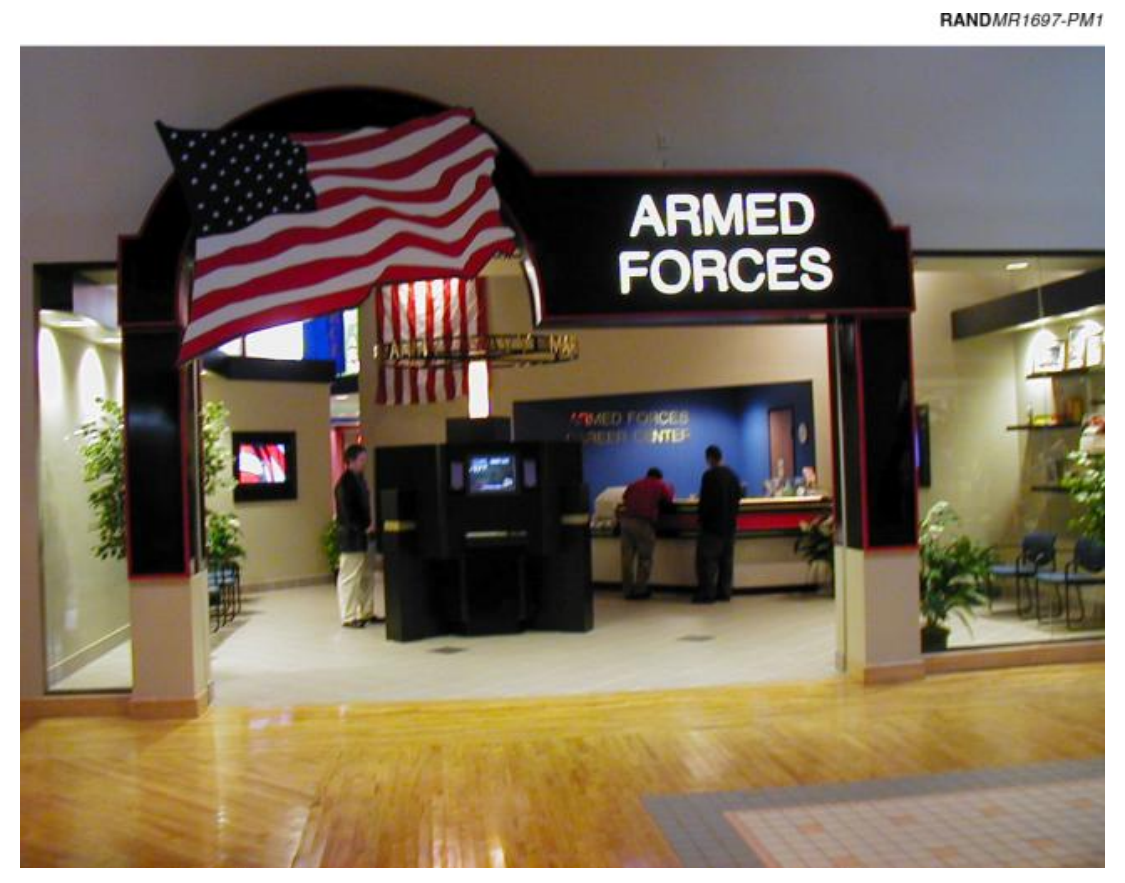

Figure PM.1-Looking into the Station Storefront from the Mall

The entrance to the station is off the main passageway in the mall. People walking through the mall see a large lobby with three television monitors continuously showing video compilations of the services' television commercials; a computer kiosk; and the civilian administrator's desk. Passersby and visitors in the lobby cannot see the recruiters' offices. 


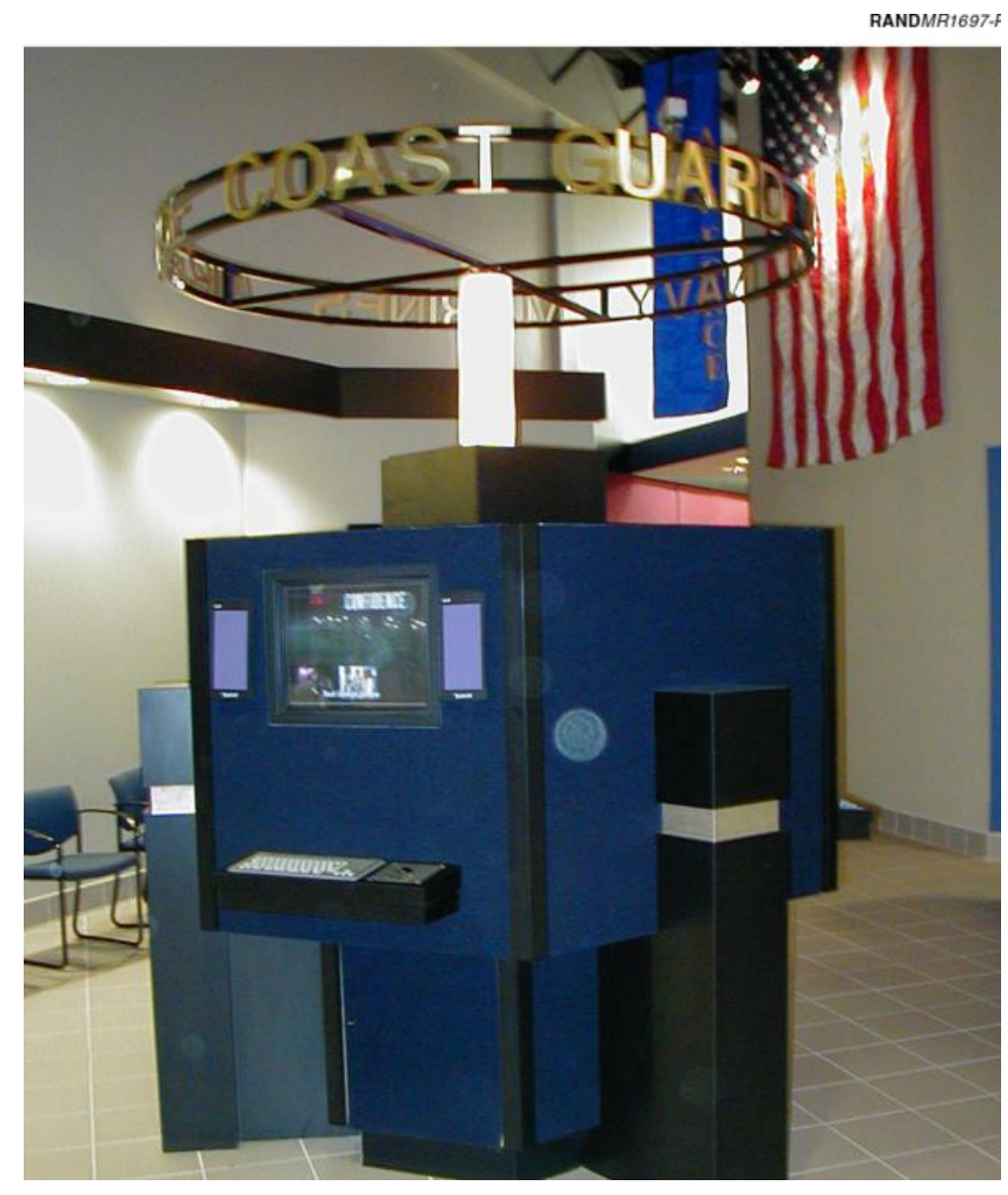

Figure PM.2-The Computer Kiosk

Upon entering the station, a visitor sees a large computer kiosk in the center of the lobby. The kiosk houses three personal computers with a Web interface. By design, Web browsing is restricted to the services' main recruiting web sites, although some visitors have been able to bypass the restrictions.

The signage on the top of the kiosk rotates, displaying each service's name to the lobby and the mall passersby equally. This design was a result of a compromise among the services to ensure that no one service received an unfair recruiting advantage from signage. 


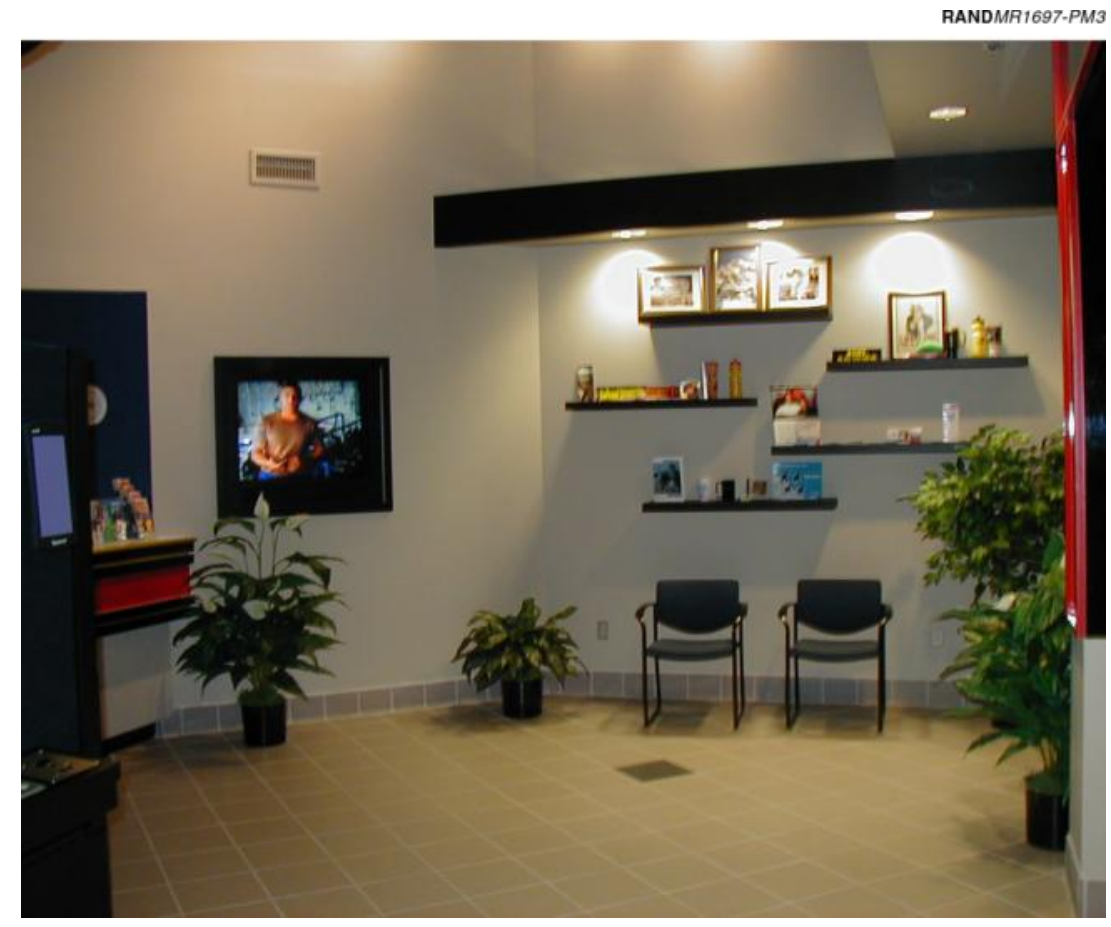

Figure PM.3-Looking to the Right upon Entering the Station

After approaching the kiosk, a visitor who looks to the right sees a display area containing various service recruiting giveaways and one of the smaller video monitors. Note that the chairs in this picture were temporary. They were eventually replaced by larger, plusher chairs. The actual height of the lobby is not visible in this picture. Two stories high, the lobby has a large and open feel.

The civilian administrator's station is just visible to the left in the picture. 


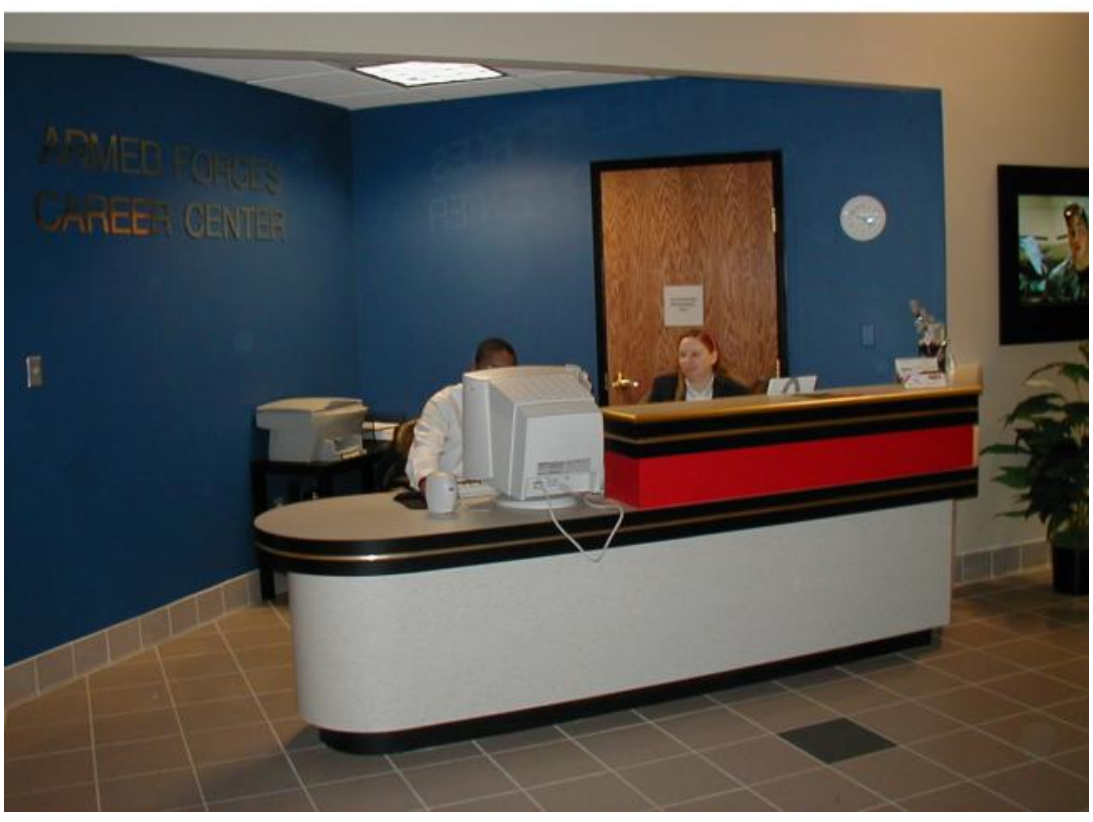

Figure PM.4-The Civilian Administrator's Station

Located at the back of the lobby, the civilian administrator's station provides space for a computer workstation, printer, and a central telephone. The counter has been used routinely for displaying service recruiting literature and recruiter business cards. The door behind the desk is to a closet that contains the video equipment and additional storage space.

The same video monitor from Figure PM. 3 can be seen to the far right in this picture. What cannot be seen is that a large-screen display is mounted on the second story wall above the administrator's station. This monitor plays the same videos as the smaller monitors, but it is more readily visible to mall station passersby. 


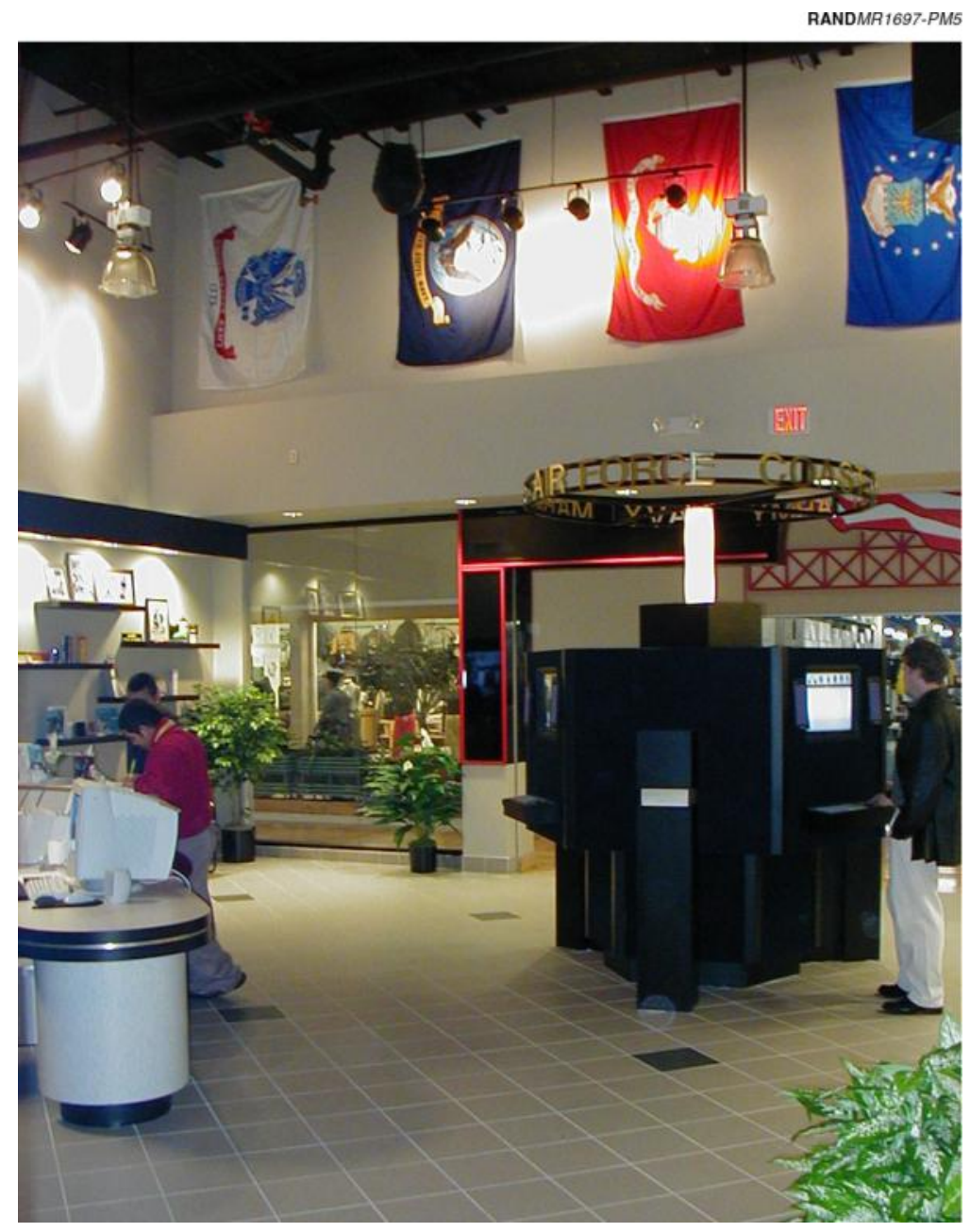

Figure PM.5-Looking out Toward the Mall from the Back of the Lobby

Upon reaching the back of the lobby and turning around, a visitor would be able to see back out into the mall. The actual height of the lobby is visible here, with each of the services' flags displayed on the second-story level of the wall connecting the station to the mall.

In this picture, individuals can be seen at the civilian administrator's station and at the kiosk. 

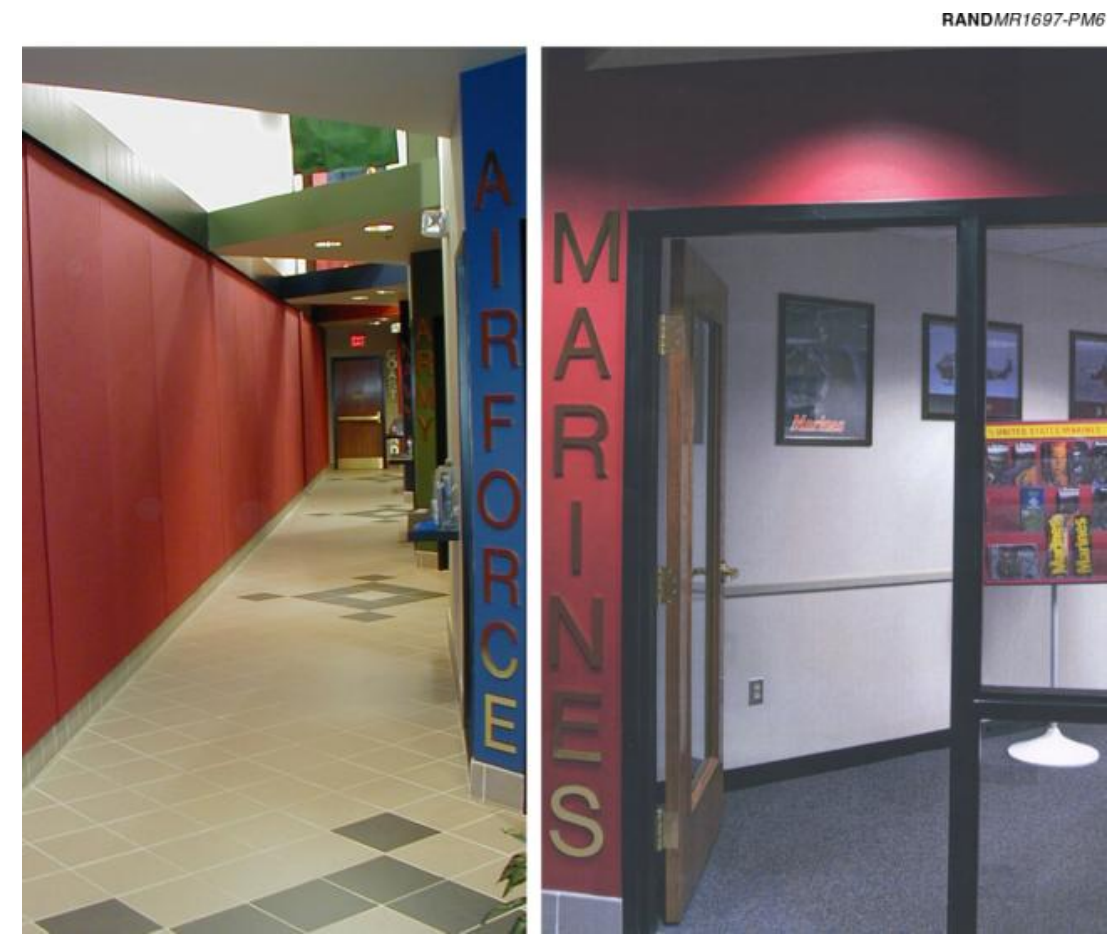

Figure PM.6-The Hall to the Recruiter's Offices (left) and the Entrance to the Marine Corps Office (right)

The hallway to the recruiters' offices begins at the back left of the lobby. The left picture above is what a visitor would see at the head of he hallway. As shown at the right, each office has a glass door; the service's name in large, metallic gold lettering is to the left of the doorway.

The hallway was designed so that all the services' names would be simultaneously visible when a visitor looks down the hallway. Color-coding was employed to distinguish the services. Although not easily visible in the left picture, large banners were also displayed on the second-story level above and outside each office Each recruiting office also has a shelf in the hallway for displaying recruiting literature. 


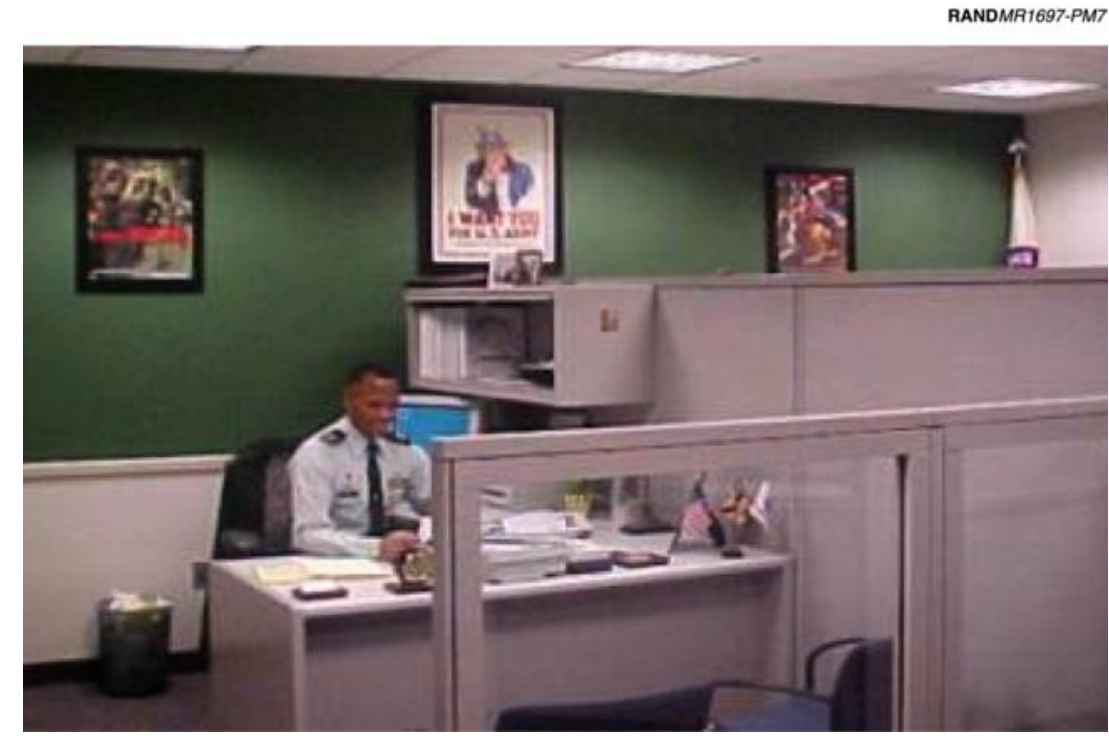

Figure PM.7-The Army Recruiter's Office

Each recruiter office contains desks and modular furniture for two recruiters. Pictured above is the arrangement for one recruiter; the second recruiter has a mirror-image arrangement on the other side of the tall partition. The offices, like the doorways, are color-coded to the services' colors-green in this Army office.

Not shown in the photograph, each office also has a closet for storing recruiting materials. 


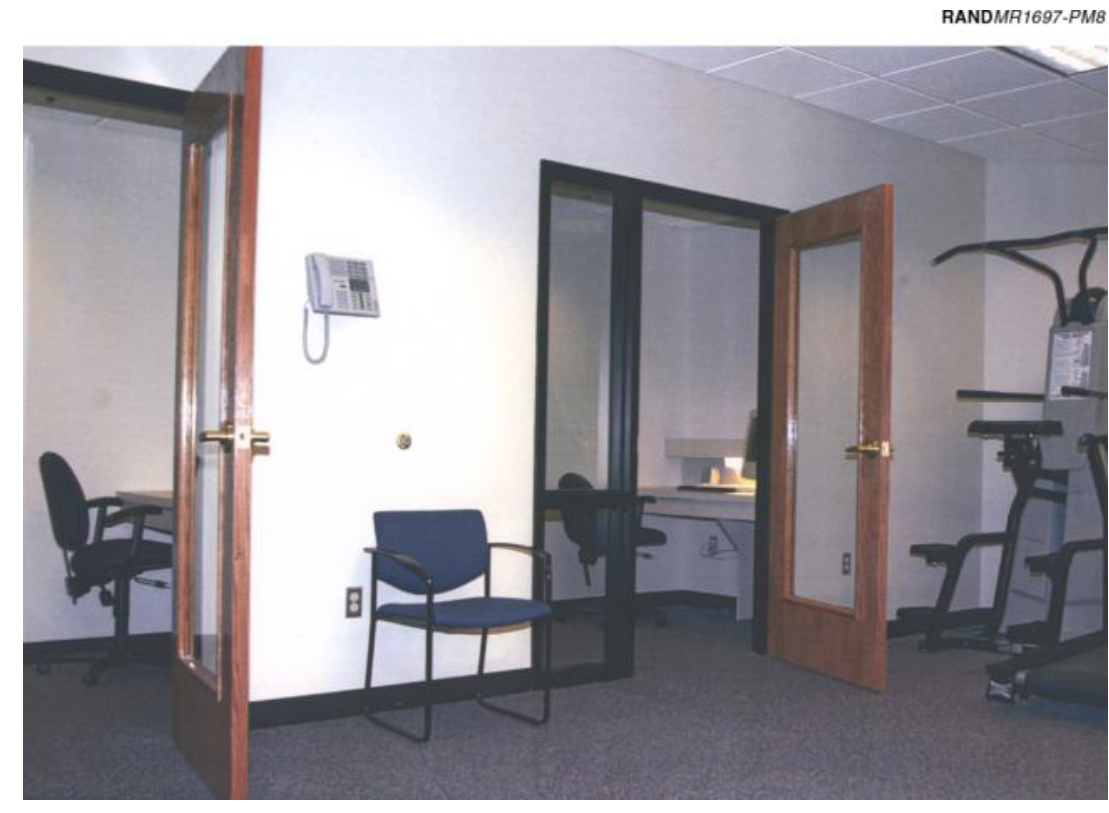

Figure PM.8—Second-Floor Testing Rooms

As described in Chapter Two, the second floor contains men's and women's restrooms, a conference room/exercise area, and two testing rooms. Shown here are the two testing rooms, designed with doors for privacy and facilities for candidates to take practice examinations.

The area outside the testing rooms functions as a conference room (where a large table and chairs were added after this picture was taken) and an exercise space (with the exercise equipment shown to the right). 


\section{QUALITY-ENHANCED RECRUITING STATION IN EAGLE RIDGE MALL, FLORIDA}

The following photographs, taken in June 2001, constitute a virtual tour of the Army's Quality-Enhanced Recruiting Station in Eagle Ridge Mall, Florida. Chapter Five provides additional descriptive details of the Eagle Ridge Mall and the recruiting station. 


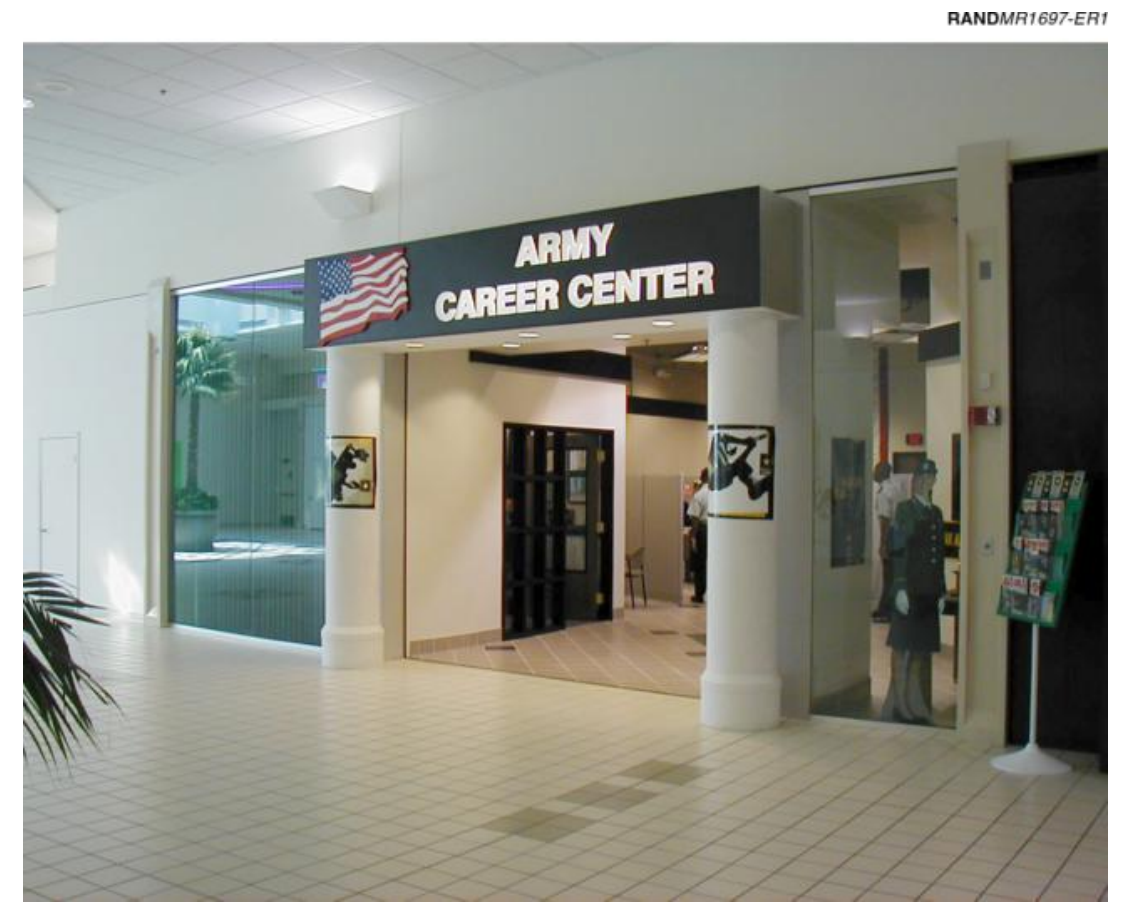

Figure ER.1-Looking into the Station Storefront from the Mall

The entrance to the station is on a secondary passageway that branches off the main passageway through the mall, in the vicinity of the food court. People walking past the station can see into the station commander's office (to the left) and into the main part of the station, which contains cubicles for the recruiters (see Figure ER.2). 


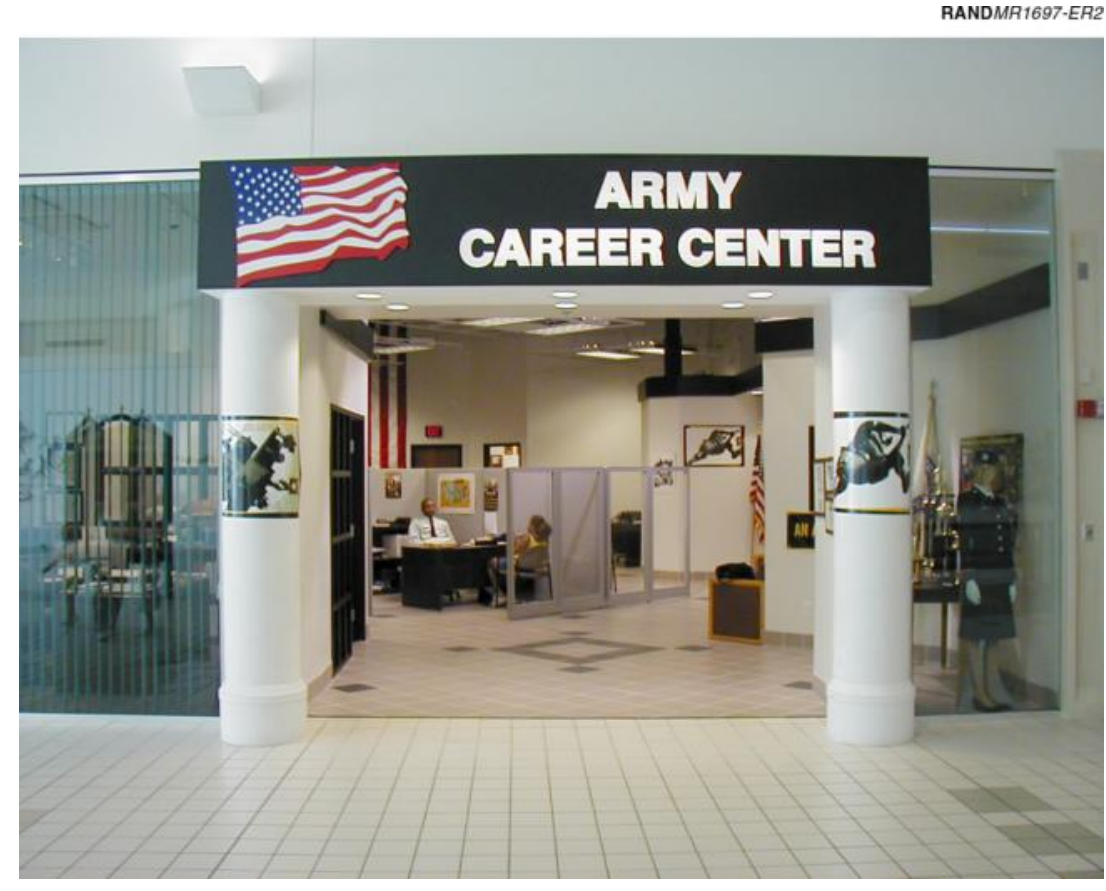

Figure ER.2-Looking Directly into the Station Storefront

The signage at the entrance to this station uses the same flag logo as at the Potomac Mills station. The station commander's office is situated so that he or she can see both into the mall and, via a window on the back wall of the office, into the recruiting station itself.

Not visible in this photograph, a television is mounted in the wall on the opposite side of the entrance from the station commander's office and is visible to passersby. It is similar in size to the two smaller video monitors in Potomac Mills and was installed to play the same types of advertising videos. 


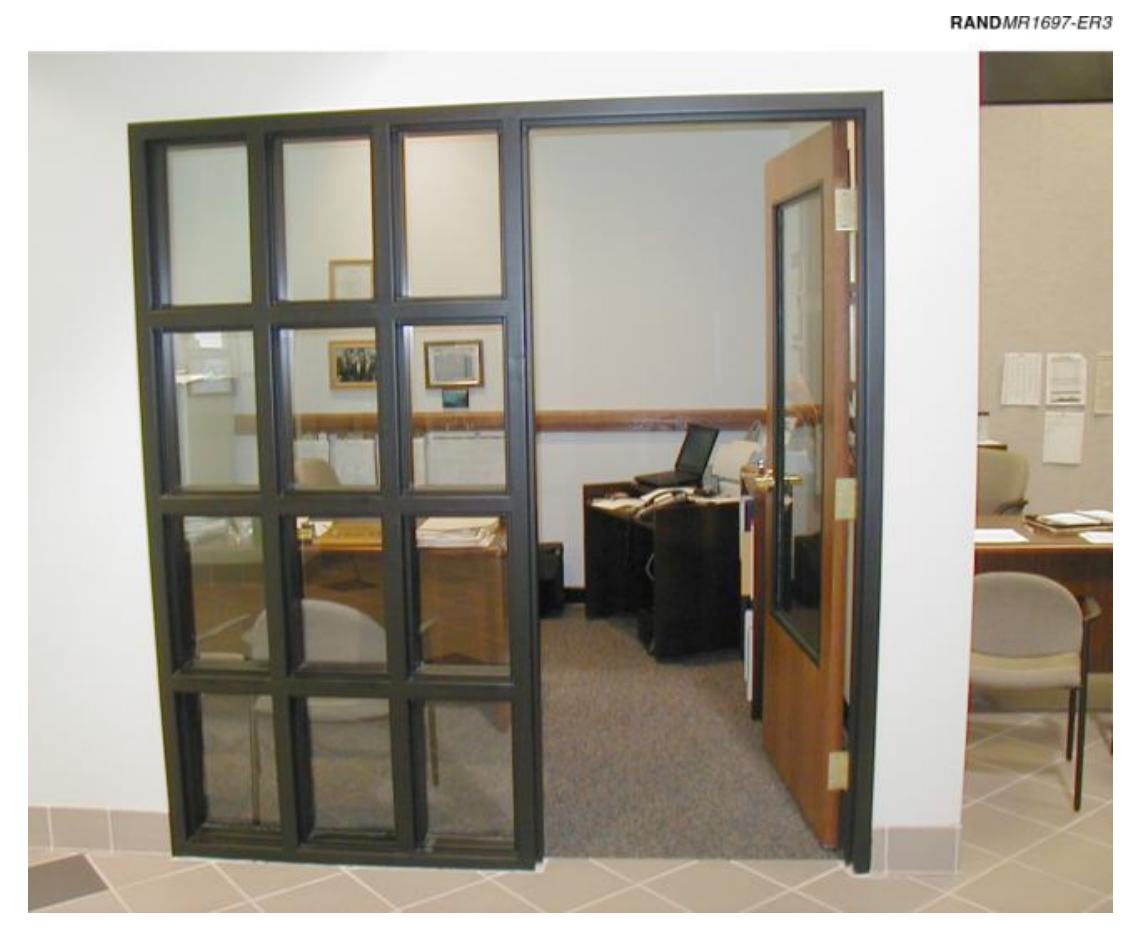

Figure ER.3-Looking into the Station Commander's Office upon Entering the Station

Stepping into the entrance to the station and looking to the left provides another view into the station commander's office (shown in Figure ER.2 from the mall). By design, those entering the station are visible to the station commander from his or her office.

Immediately to the right in this picture is the open bay in the station, where all of the recruiters' cubicles are located. Part of one cubicle is just visible at the far right. 


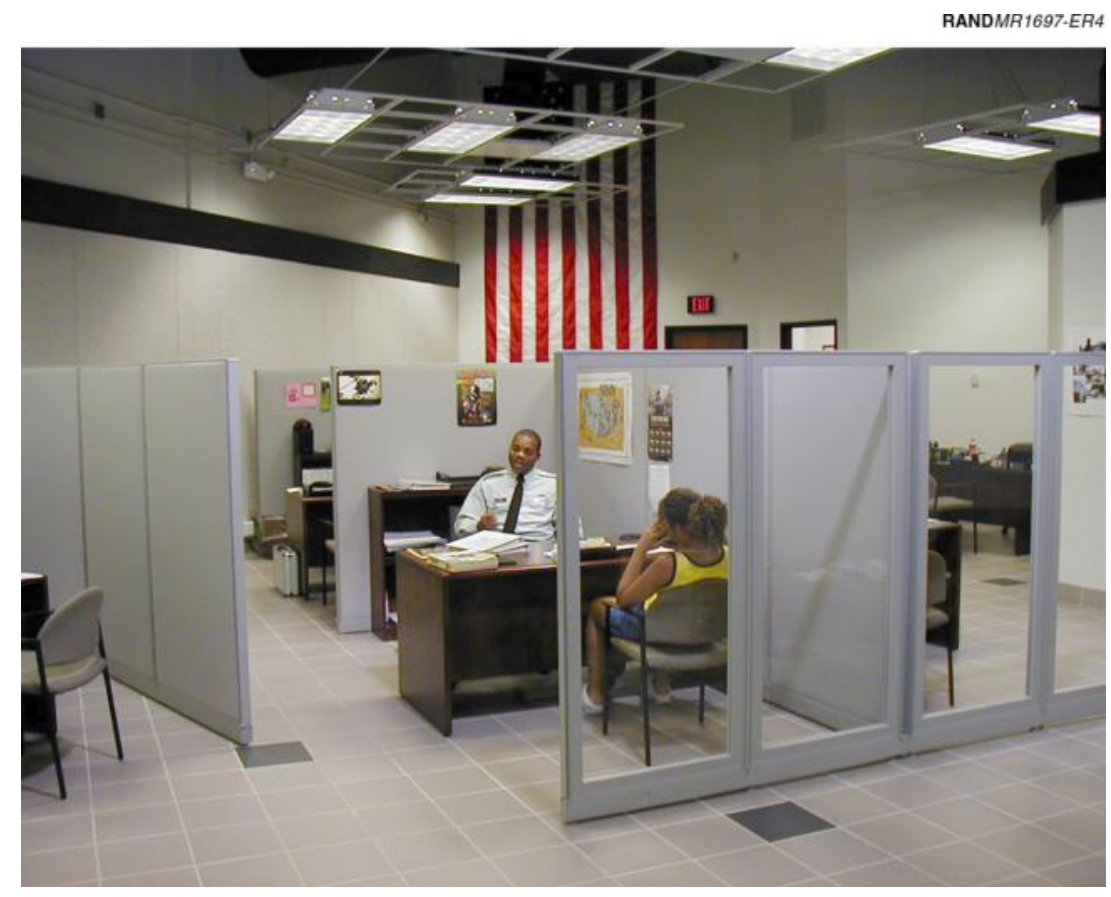

Figure ER.4-Recruiters' Cubicles

Turning to the right at the entrance and looking into the station, a visitor can see cubicles for six or seven recruiters in a common bay area. As the photograph shows, the materials used in the station are the same as or very similar to those used in the Potomac Mills station. 


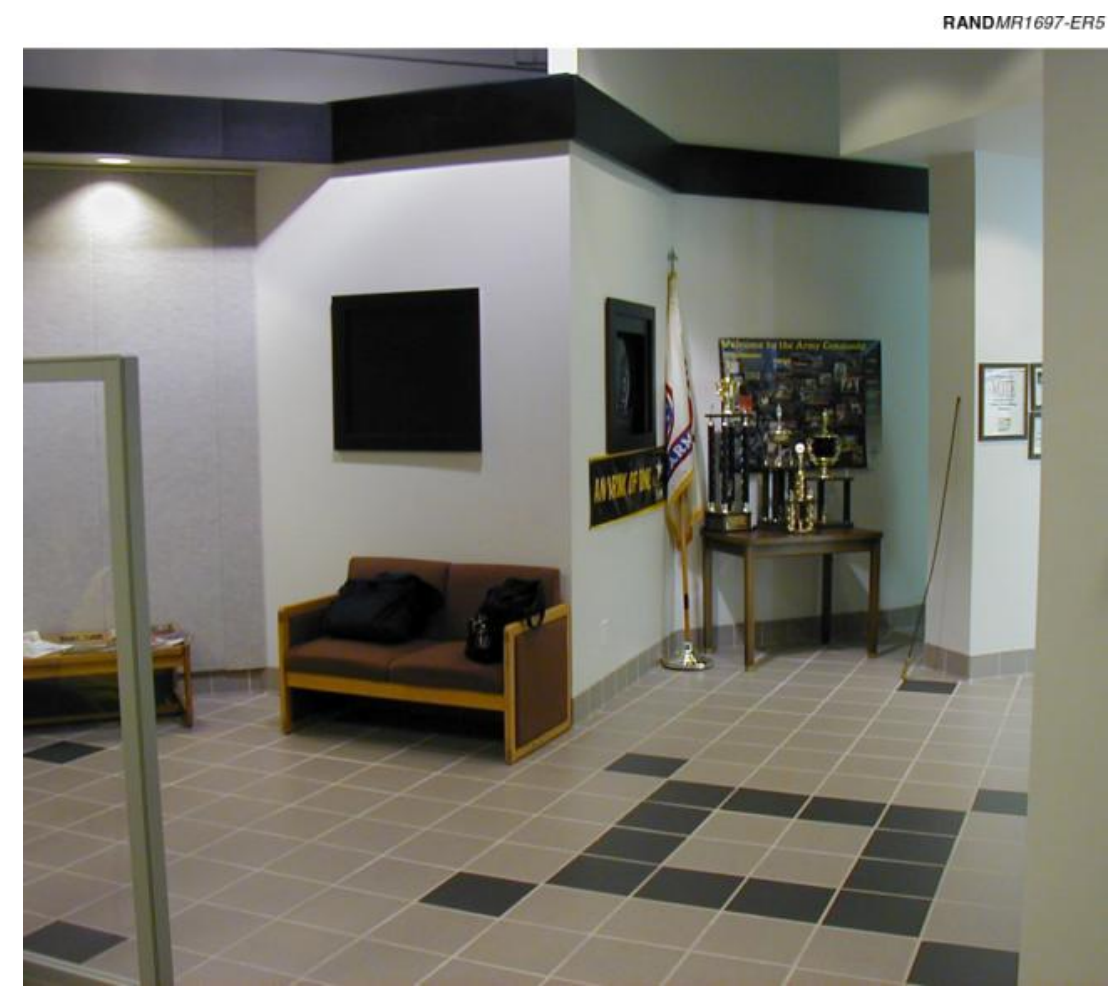

Figure ER.5-Looking Out in the Direction of the Mall from the Center of the Station

This is the view upon turning at the recruiting bay (shown in Figure ER.4) and looking out of the station. The entrance to the mall and the station commander's office are just to the right. To the left is a small waiting area for visitors. In the center of the picture is a television screen that can be used to show promotional videos, much as at Potomac Mills. However, the angle of the wall is such that the videos are not readily visible to those walking by the station in the mall. When this visit was made, the television was not in use. 


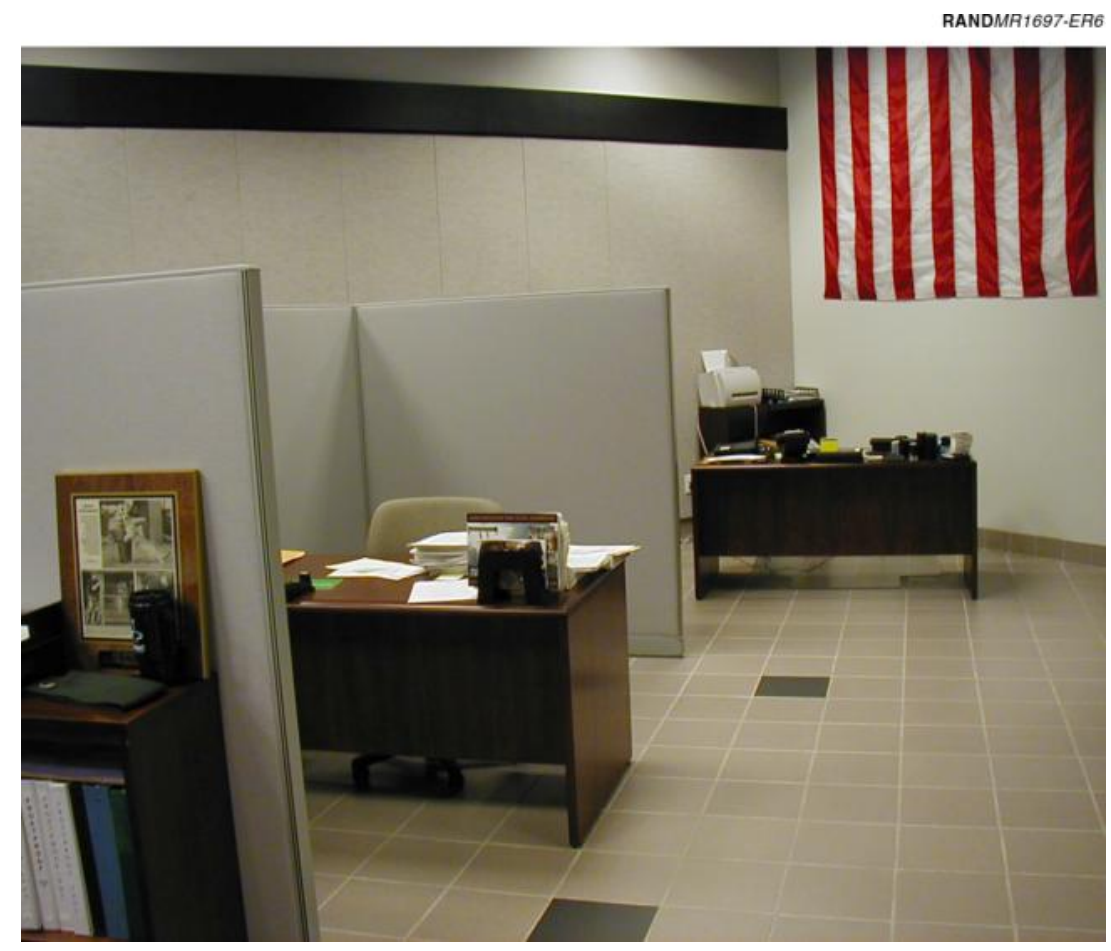

Figure ER.6-Additional Recruiters' Cubicles

This is another view of recruiters' cubicles when one walks farther into the station. The cubicles themselves match those in the Potomac Mills station; the furniture does not. 


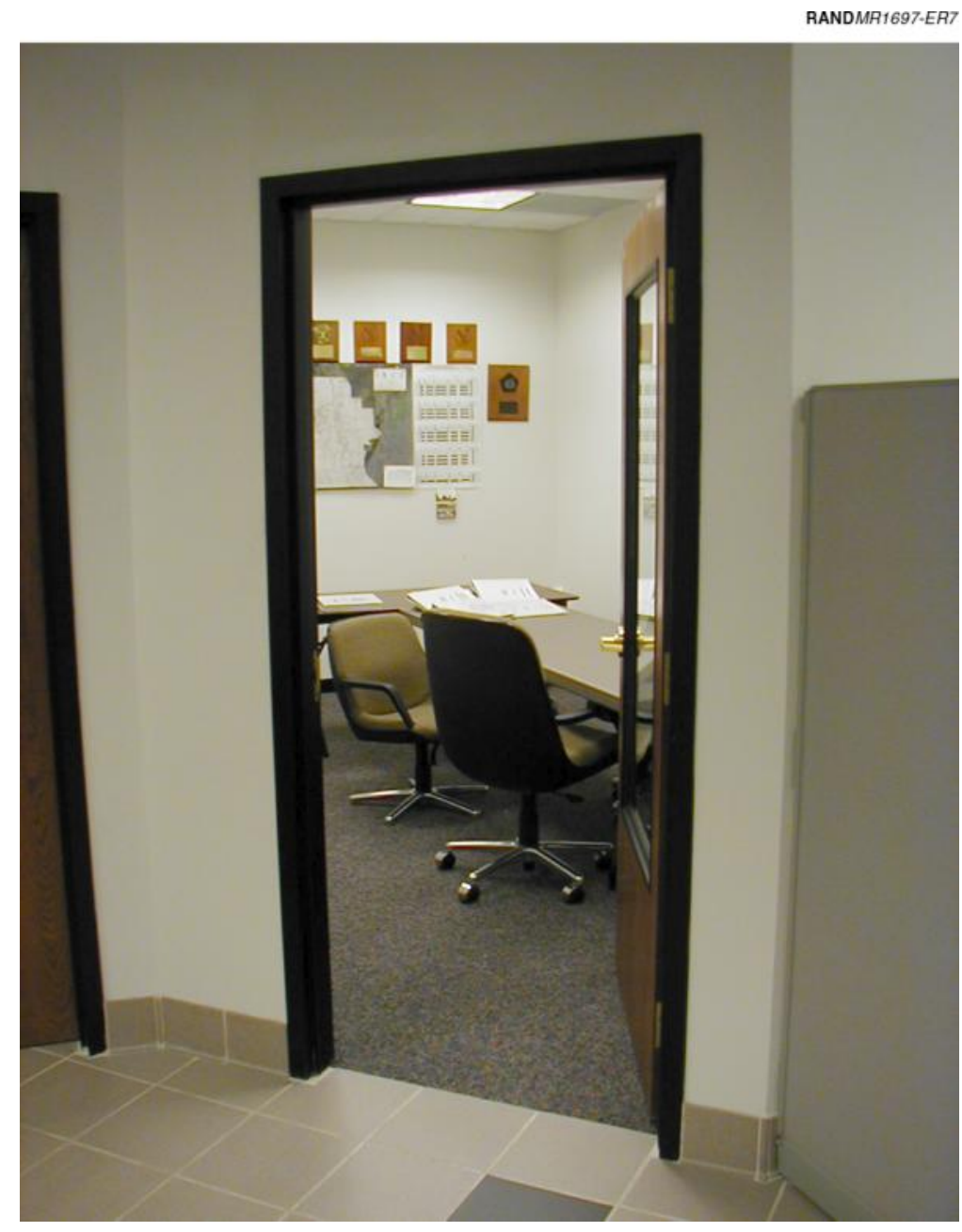

Figure ER.7-Conference Room at the Rear of the Station

At the back of the station is a conference room that can seat six to eight individuals. 


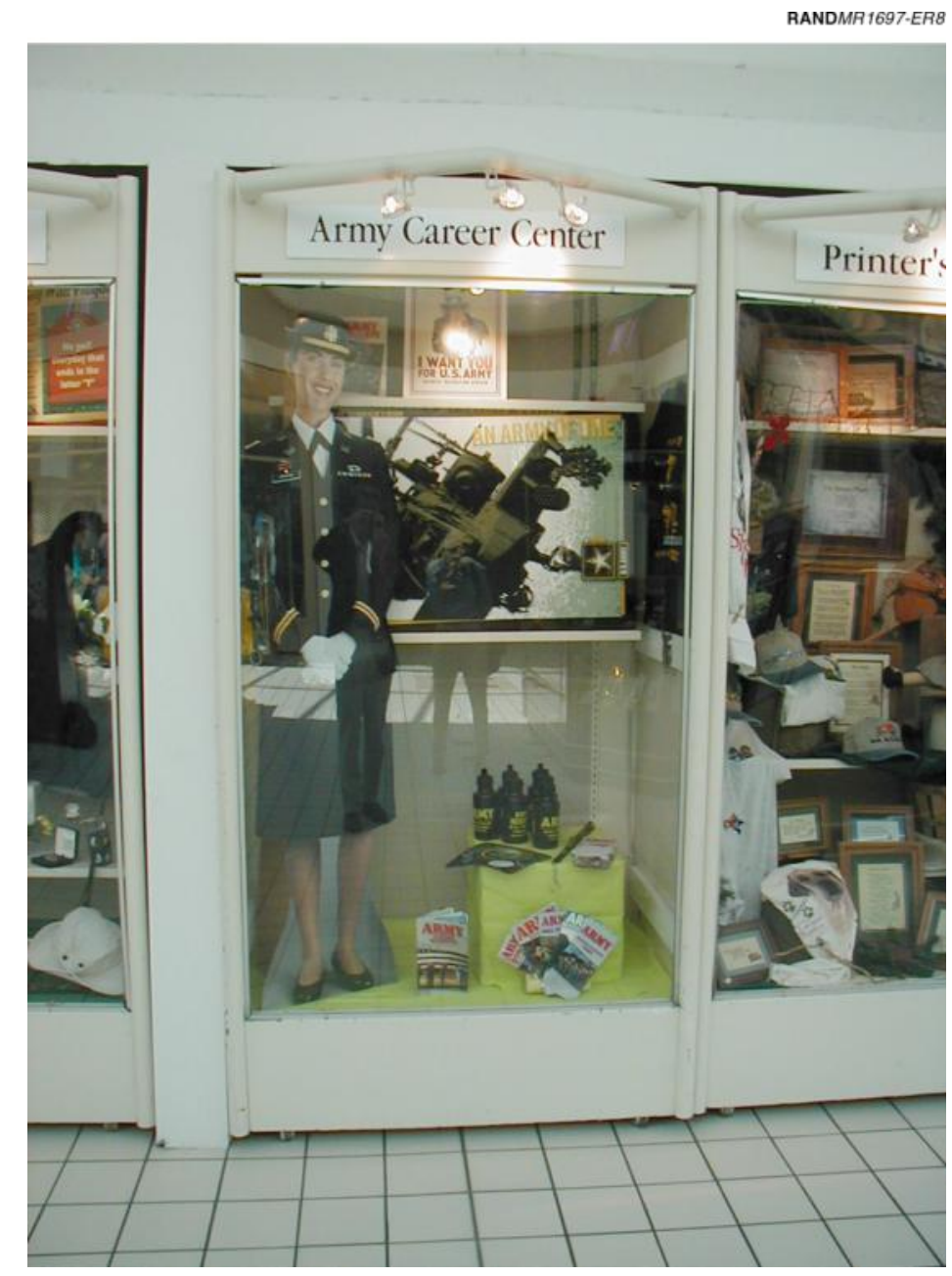

Figure ER.8-Recruiting Display in the Mall

In the mall, some distance from the station itself, was a display case exhibiting Army paraphernalia as an advertisement for the recruiting station. The space was provided by the mall as part of the station lease, as was signage to help visitors find the station. 


\section{JOINT RECRUITING STATION AT TIMES SQUARE, NEW YORK CITY}

The following photographs, taken in February 2001, show the joint recruiting station in Times Square, New York City. Located literally in the middle of Times Square and with a unique design, the station is in many ways a showcase for the armed services. (Chapter Five provides additional details on the station and its location.) 


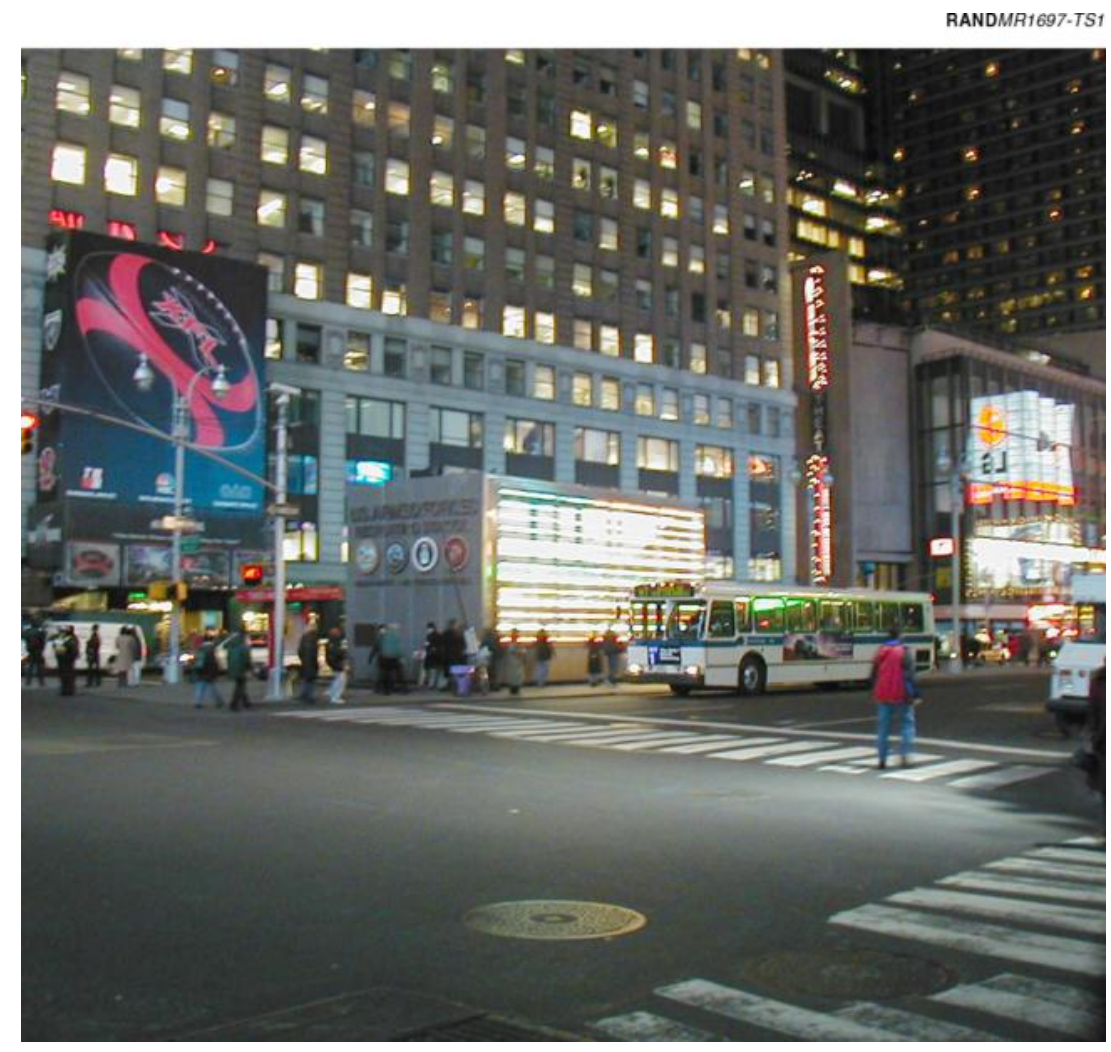

Figure TS.1-Times Square Station Exterior

The exterior of the station at night, looking from across the street. Although difficult to see in this picture, the American flag is prominently displayed on the side of the station, in neon lights (in keeping with the neon-advertising theme of Times Square). The services' seals help identify the station (shown here and in Figure TS.2). 


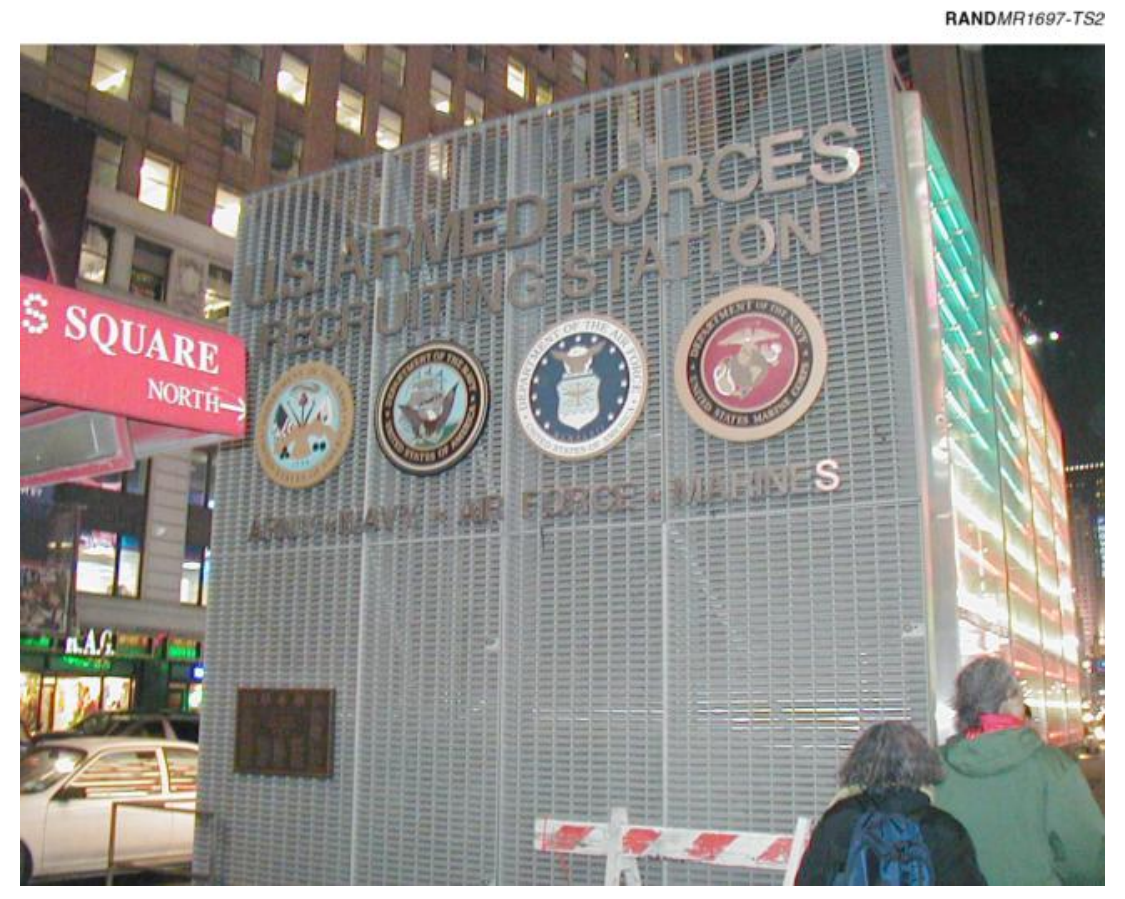

Figure TS.2-A View of the Exterior, Looking North

A major challenge for the station is to make itself visible in the visually overstimulating Times Square area. Note also that the station is actually located on an island in the middle of the street. Nonetheless, the station receives a very high volume of foot traffic, because of the routinely high volume of pedestrian foot traffic in the Times Square area, the high population density in New York City, and the presence of a recruiting station in Times Square for decades. As a result, its existence and location are well known to the local residents, and they seek it out. 


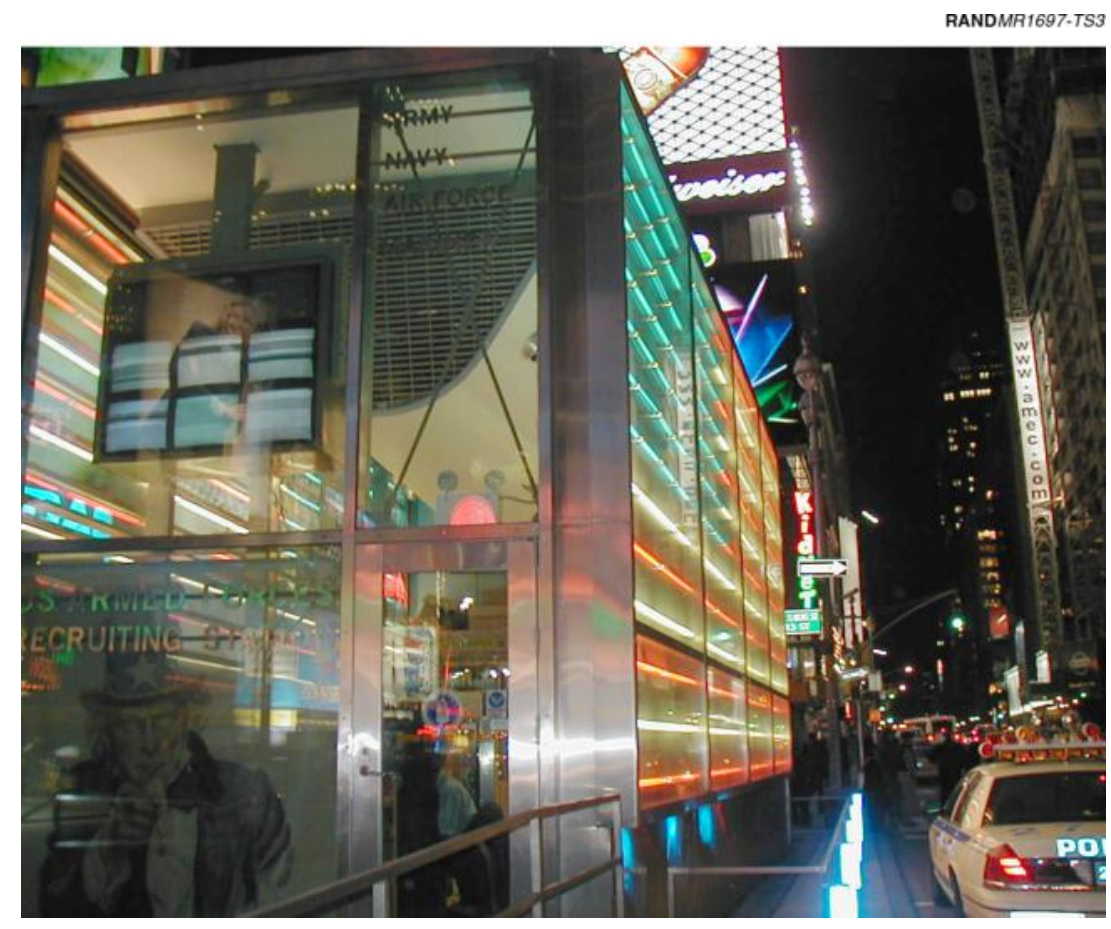

Figure TS.3-A View of the Exterior, Looking South

The entrance to the station can be seen here. The television monitors were installed to display advertising videos for the services. The services, via the Joint Recruiting Facilities Committee, are considering various improvements to make the videos more noticeable and more visible. 


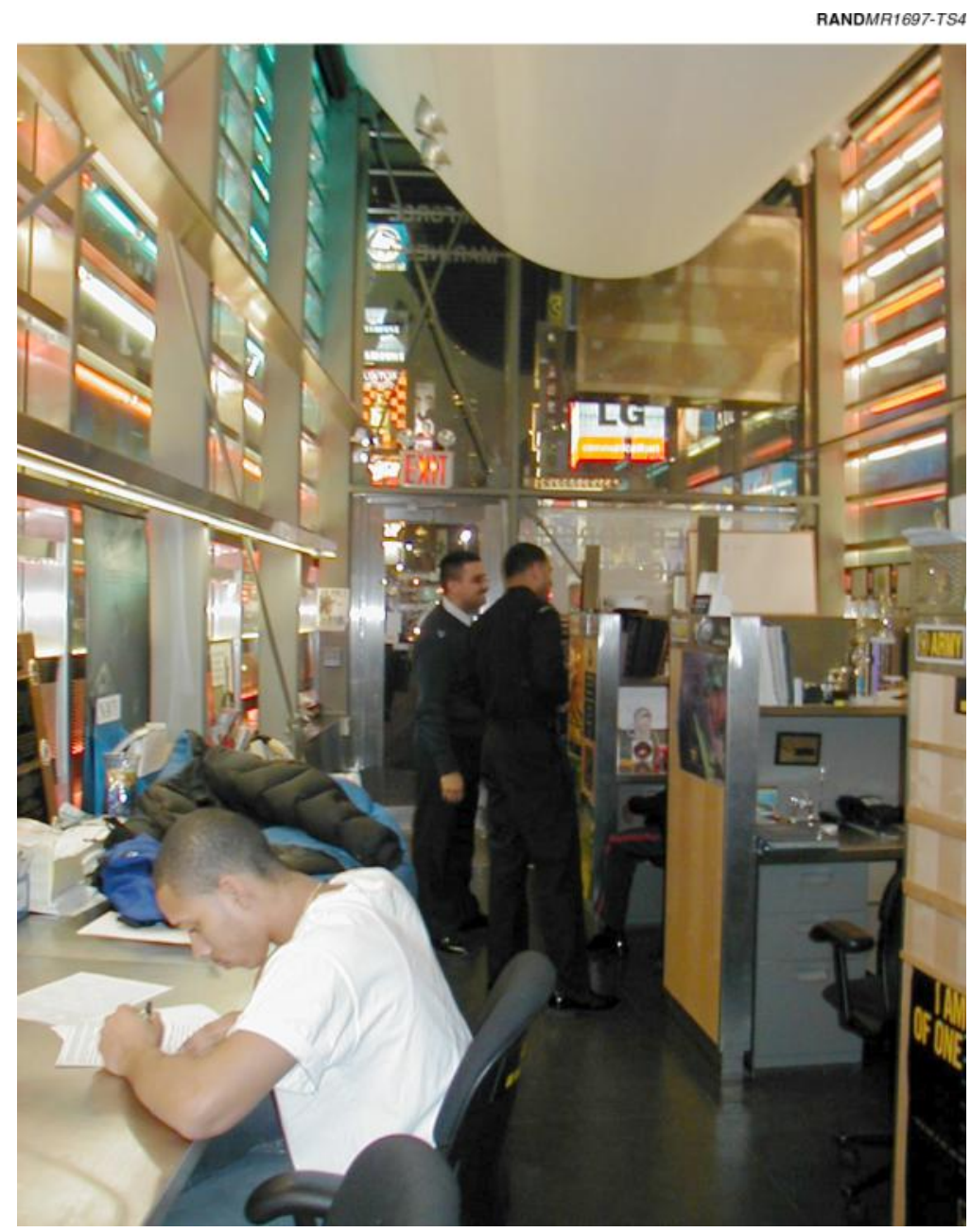

Figure TS.4-The Interior of the Station

The interior of the station is small due simply to the site's space constraints. 


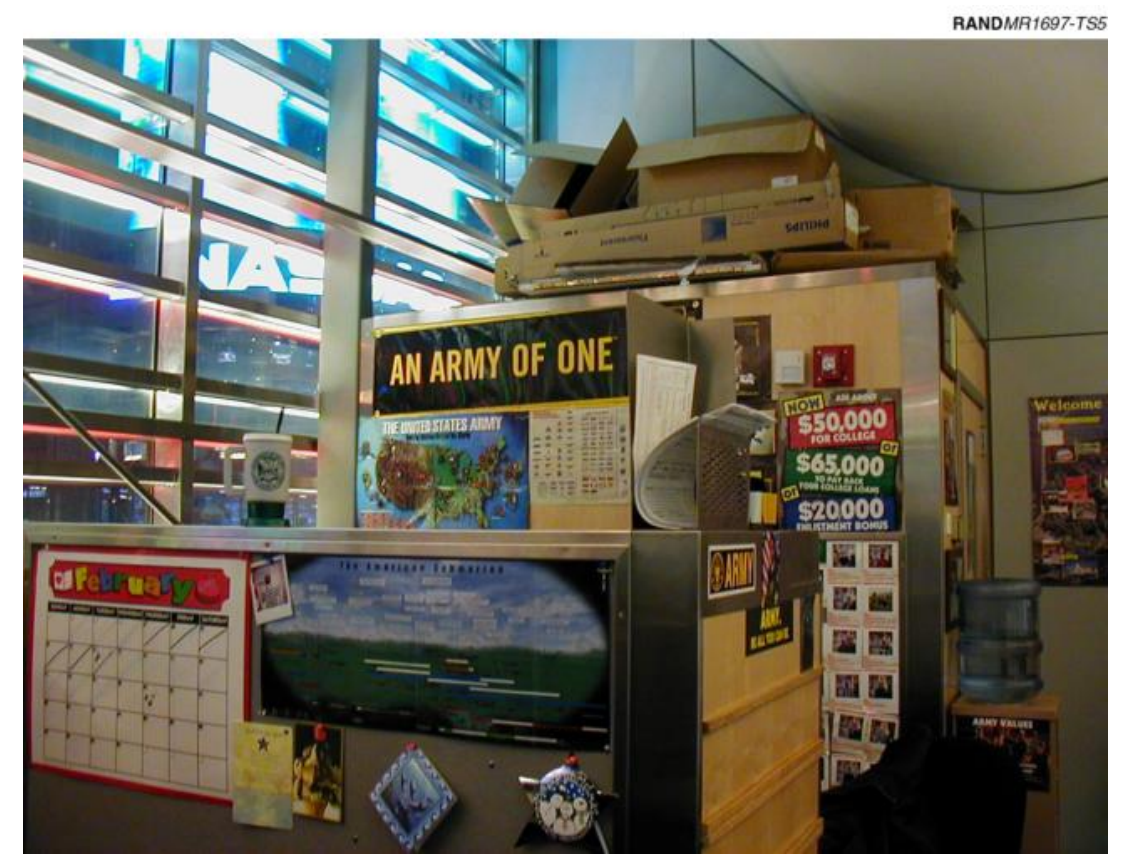

Figure TS.5-A Recruiter's Cubicle in the Station

An example of a recruiter's cubicle inside the station. 


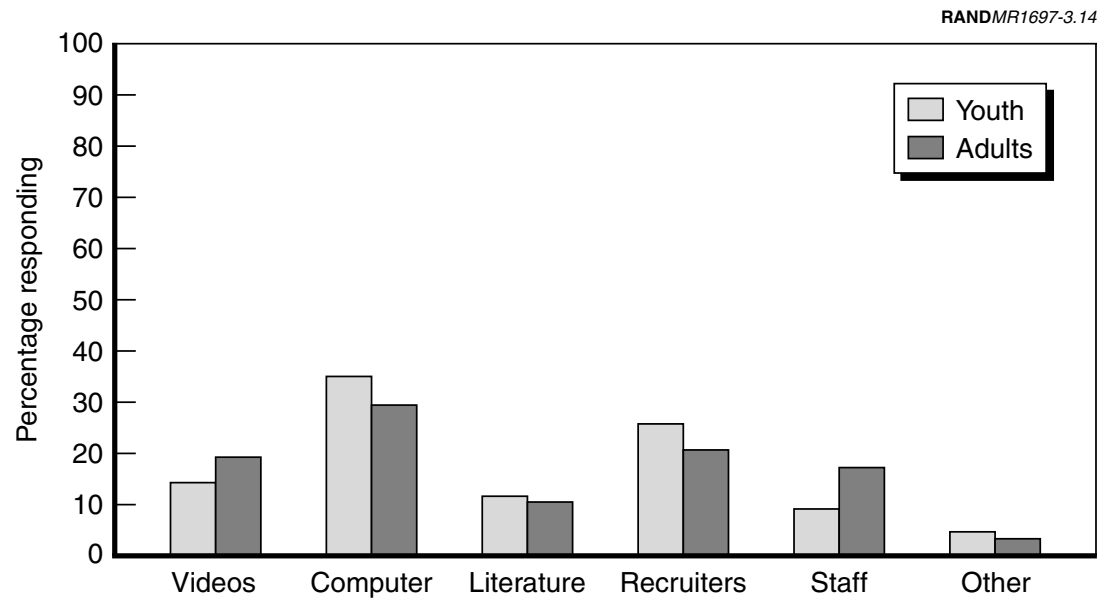

Figure 3.14-Answers to the Prompt "'The best feature of the Military Career Center was ...' (pick one)"

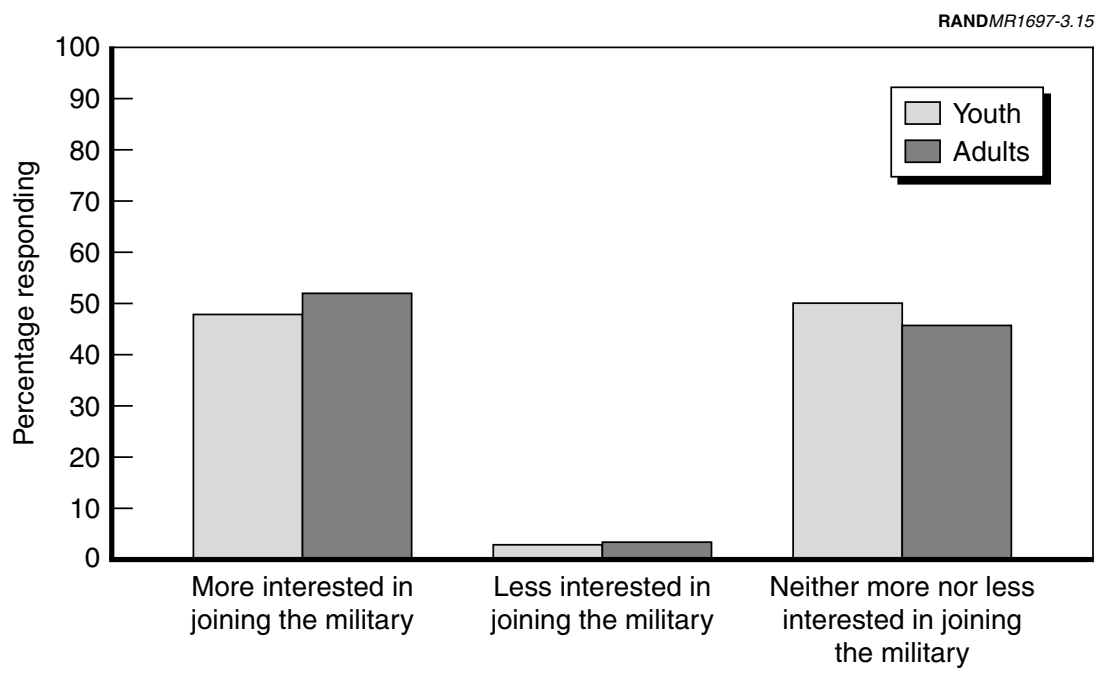

Figure 3.15-Answers to the Prompt “"After visiting the Career Center, I am ...' (pick one)" 
Finally, Table 3.5 contains respondents' write-in "suggestions to improve the Career Center." The comments related to staffing the lobby with military personnel were all made by active-duty or prior military personnel. None of the youth filling out the survey made such comments. In contrast, all the comments related to playing music, making the computers louder, and making the station more exciting were made by recruit-age youth.

\section{CONCLUSIONS}

As an experimental prototype of the marketing-enhanced recruiting station concept, the performance results from the Potomac Mills station should be viewed with both interest and caution: interest, because the data provide some useful insights into what a marketing-enhanced station might achieve; caution, because this is only one possible realization of the concept in one location operating under one set of recruiting policies and procedures. Making generalizations about other locations or modifications to the concept from these results is difficult. However, these results are suggestive in a number of ways.

Conclusion: Recruiters, working a standard workweek of Monday through Friday, are not present in the station during the periods of peak visitor traffic.

Although the majority of visits to the station occur on Thursday and Friday evenings and on the weekends, recruiters staff the station during standard business hours from Monday through Friday. Essentially, the recruiters staffed the Potomac Mills station staff just as they would any other recruiting station, without regard to the uniqueness of its location.

The Army did try a different approach when the station first opened, by not putting their recruiters on mission and by having them screen and then refer prospects to other stations. In essence, the Army attempted to use the station as a lead-generation facility, and they did staff it on weekends for a period of time. The Army station commander at the time indicated that he felt they achieved little as a result of the weekend staffing. However, it is not clear whether, had the entire station been staffed on weekends and had such staffing been made 
Table 3.5

\section{Survey Participant Write-In Suggestions for Station Improvement}

\section{Staff-Related Comments:}

- Staff it with military personnel, preferably military personnel on TDY from an active unit! This center was staffed by two civilians!

- Have someone at the front desk who is in the military or somewhat interested in the military or was once a military member.

- Not very welcoming and does not seem very useful. Someone in uniform behind desk might help.

- Staff could have been more friendly ... was not very informative.

Recruiter-Related Comments:

- I like that this Career Center has recruiters from all branches.

- Add a National Guard specialist.

Ambience-Related Comments:

- Be a little less quiet, maybe play music.

- Have some music to make it sound like more fun, exciting. Very quiet in here.

○ None. It's great but louder speakers would be nice.

Computer-Related Comments:

○ Make the sound on the computers louder and put more information on them.

- Areas where you could sit down at a PC and log on to military web sites.

- Like the CD ROMs to carry with you.

Literature-Related Comments:

$\circ \quad$ More pamphlets and written documents advertising the military and all their benefits (and pros and cons about the military and FAQs). Also steps on how to get in the military.

- Needs a water fountain and a lot more pamphlets for our perusal while we wait.

- More brochures.

- More literature.

Miscellaneous Comments:

- More images of military personnel in action on the walls (via TV screen at minimum); you need to "draw” them in visually; today's youth are "visual"!

○ Excellent concept. Stay with the hi-tech focus to catch prospects' attention-lots of action video-interactive kiosks are great!! Possibly add models of planes, ships, and tanks.

- Open other centers around the country. I think this is a cost-effective idea of recruiting from all services in one place.

- Put the hours of business on the answering machine since no one answers the phone.

- Label or title pictures/photos on the walls. Display a few items of military equipment.

- They could have each person fill out a preliminary questionnaire when they first walk in to tailor the experience to individual needs.

known to the visiting public, it would have made a difference in terms of recruit contract generation. 
That is, it is entirely possible that weekend visitors are more interested in simply learning more about the military and not in talking to recruiters, so that providing knowledgeable civilian staff, literature, and useful computer kiosks is sufficient on the weekends. However, it is equally possible that a different station design, different station operation or recruiter-motivation policies, or simply additional publicity would make the weekends the most productive time of station operation for recruiters.

In any case, it is clear that recruiters currently staff the station when the least number of station and mall visitors are present. More research involving the active participation of the recruiting commands is required to determine whether this is a rational or suboptimal way to staff the station.

Conclusion: Station visitors are overwhelmingly local, even though the station is located in a regional mall.

The initial concern that all of the nonlocal visitors in a regional mall would detract from the effectiveness of the recruiting station has not turned out to be true in this particular case. Station visitors are predominantly local, in spite of the general mall-visitor demographics.

Unlike standard recruiting stations, the Potomac Mills station visitors are from a wider local area in Northern Virginia. But this is not a negative result. It simply means that recruiting commands need to modify their operating procedures to appropriately handle visitors who live in nearby recruiting territories. Indeed, that the mall attracts a large number of visitors from a wide area is desirable, causing the marketing-enhanced features of the recruiting station to reach a wider audience, thereby promoting the military and military careers to a larger audience and, hence, increasing the return on station investment.

Conclusion: Locating the station in a high-foot-traffic location can result in a significant number of walk-in visitors.

The Potomac Mills station has attracted and continues to attract a significant number of walk-in visitors, particularly in comparison to standard recruiting stations. These visitors are a combination of youth and adults, those seriously interested in military careers, and those literally just browsing, having walked in from the mall. The 
demographics of the visitors (versus the mall-shopper demographics) are oriented toward those the military services would be interested in recruiting.

The volume of walk-in traffic was achieved without additional displays by any of the services or any other type of special advertising or station promotion. Similarly, the volume was achieved without optimizing the video displays or the sound in the station; indeed, station administrators frequently had videos and sound turned off or down during our visits. Hence, it is not known what level of foot traffic, particularly youth foot traffic, could be achieved by using the video screens and the speakers to their fullest potential.

In addition, because this is a single installation, it is not possible to distinguish how much of the foot traffic was attracted by the design of the station and how much by its location in the mall. Only additional research at additional sites would be able to determine which aspects of the station (e.g., location in a mall, the particular location within the mall, and various aspects of the station design and layout) attract walk-in visitors and which aspects attract the desired demographic of recruit-age and eligible youth.

Conclusion: More generally, recruiting commands and organizations have not exploited the location and the marketing aspects of the station.

What is clear from the operation of the prototype marketingenhanced recruiting station thus far is that it does not neatly fit within the current organization of the recruiting commands. As we described earlier in this report, generally speaking, the commands are divided into two groups: recruiting and advertising. The former are most fundamentally concerned with generating the requisite number of contracts for a given period of time, within which recruiting stations have their place, but generally only in the sense of functioning as recruiters' offices as recruiters quest for contracts. The latter tend to be concerned with national advertising campaigns and other types of large-scale advertising and public-relations events.

The marketing-enhanced recruiting station lies at the intersection of these two groups, requiring (1) the advertising part of the organization to promote the station, create and implement special events at the station, and incorporate new materials within the station (videos, 
web sites, etc.) and (2) the recruiting part of the organization to conduct the recruiting, including training recruiters in how to operate within this new type of recruiting station and recruiting environment. However, station performance can be maximized only if the recruiting part of the organization learns how to effectively leverage the advertising and marketing aspects of the new station and the advertising part brings its expertise and capabilities to the new station or stations.

Conclusion: Station design and operation could be further optimized to appeal to youth.

Survey results from recruit-age youth were generally positive about the station, although the comments made about the station being too quiet, not playing music, etc., reflect an ambience that may not be as enticing to today's youth as it could be. Similarly, simple observation of youth at the computer kiosks shows that the computers do not hold a visitor's interest for very long. The average kiosk user stays at a computer for only a minute or two. In contrast, video games and arcades, as well as other forms of entertainment, can hold youths' attention for hours and result in repeated visits. Basic market and design research would likely yield a host of station enhancements that would entice youth to enter the station, prolong their visit, and return periodically.

Conclusion: In general, station visitors are favorably impressed by the prototype MERS, they find it useful for learning about military careers, and many say it increases their interest in joining the military.

Surveys of station visitors indicated that the current prototype is perceived as "welcoming" by a majority of visitors, as well as "educational." Comments about the station are almost invariably favorable, either as a result of the survey or in informal interactions with visitors. Over 90 percent of the visitors found the station very interesting or somewhat interesting.

An important challenge is to modify future MERS design and operation so that the majority of visitors find the station very interesting. Given the range of military occupations, equipment, and missions, there is ample material to engage and impress any visitor to the station. 


\section{POTOMAC MILLS RECRUITING STATION PRODUCTION AND COST-EFFECTIVENESS}

Visitors are generally favorably impressed with the Potomac Mills Mall MERS, and there is some evidence that indicates the MERS to be effective at the goals of enticing mall visitors into the station and then interesting over half of those in some facet of the station or of military service. However, it is also important to evaluate the station in terms of how cost-effective it is in contract production, lead generation, and advertising. Assessing cost-effectiveness requires quantifying both the cost of the station and these various station outcomes and comparing the cost per outcome to that of alternatives. Each of these tasks is mildly difficult to very difficult in certain ways. A few caveats are important to keep in mind.

First, as a prototype, Potomac Mills station was built under significant time pressures, incurring costs that would not be associated with future, equivalent stations. As a result, the costs of Potomac Mills station itself do not reflect the likely costs of future marketingenhanced recruiting stations. Indeed, while Potomac Mills cost almost $\$ 900,000$, the U.S. Army Corps of Engineers estimates that future, equivalent stations would cost less than half that. (Complete cost breakdowns and estimates are provided in the "Potomac Mills Construction and Operating Costs" section below.)

Second, we cannot directly quantify some of the outcomes for the station, such as equivalent advertising impressions. ${ }^{1}$ The difficulty

\footnotetext{
${ }^{1}$ In the advertising sense, an impression is one individual being exposed to one advertisement.
} 
stems from the dual use of the station for both recruiting and marketing. The recruiting outcomes are relatively easy to measure; the marketing and advertising outcomes are not. We provide some bounds for the effects of advertising. However, the nature of subject makes the advertising benefits of the station inherently hard to measure and to quantify, as discussed in the "Considering Advertising and Marketing as Part of Station Cost-Effectiveness" section of this chapter.

Third, given the difficulty of measuring some aspects of station performance and the lack of direct equivalents, it is equally difficult to provide either an overall cost-effectiveness evaluation or definitive comparisons to meaningful alternatives.

Despite these difficulties, in this chapter we provide the most thorough cost-effectiveness comparison possible for the Potomac Mills MERS on contract-generation performance, lead-generation performance, and advertising performance. In doing so, we offer ranges rather than single numbers and describe all of our assumptions in detail in order to provide the reader with the maximum amount of information with which to reach a conclusion.

\section{CONTRACT-GENERATION PERFORMANCE}

One clearly quantifiable aspect of the Potomac Mills station's performance is recruit contract generation. ${ }^{2}$ From the services' reports, recruiters in Potomac Mills generated 138 contracts in calendar year 2001 (Table 4.1).

\footnotetext{
${ }^{2}$ The number of contracts can be quantified easily; however, we did not attempt to identify and quantify the root cause of each contract (that is, whether a contract was the result of a walk-in, a recruiter's prospecting efforts, etc.). While collecting such data is theoretically possible, the data would have been difficult to impossible to interpret and use, since the reason an individual enlists generally cannot be ascribed to one, simple reason or cause. (For example, how does one count an individual who walked in to the station and enlisted without immediate recruiter encouragement, but who had also been contacted previously by a recruiter? Or, conversely, how does one count an individual who had walked in to the station, collected literature and information, but had not joined until subsequently contacted by a recruiter? Which is more relevant/deciding, the first contact or the contact that results in the signing of a contract?)
} 


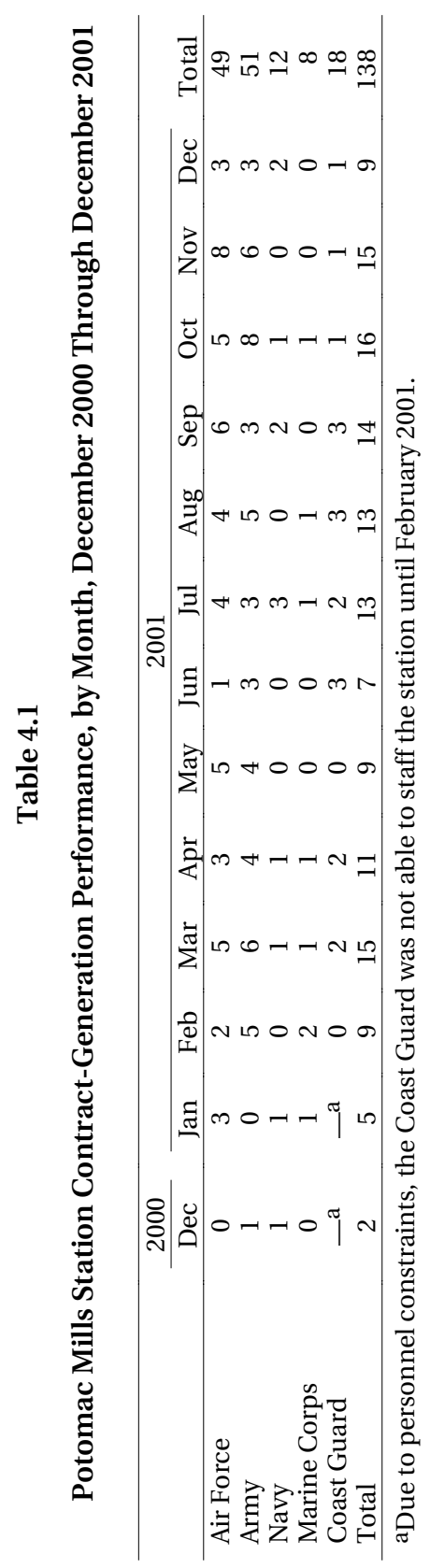


Figure 4.1 shows the average contract-generation performance per recruiter per quarter by service for the first year of operation. The lack of overall trend underscores the sensitivity of station production to individual recruiter and service operating procedures. For example, the Army showed flat performance until recruiters were put on mission/goal, at which time there was an "up-tick" in contract generation. In comparison, the Air Force had a slow start in adjusting to the station, but then showed steady improvement. The Coast Guard, too, showed steady improvement until the fourth quarter of fiscal year 2001 (FY01), when the recruiters rotated. In contrast, the Marine Corps had little interest at the start of the station, assigning only a part-time recruiter, and that interest seems to have subsequently waned even further. The trend reflects this waning.

The obvious question to ask is, Do the enhanced features improve station performance? To test whether the station is experiencing increased (or decreased) contract production, it is relatively simple to compare the performance of this station with equivalents-in this

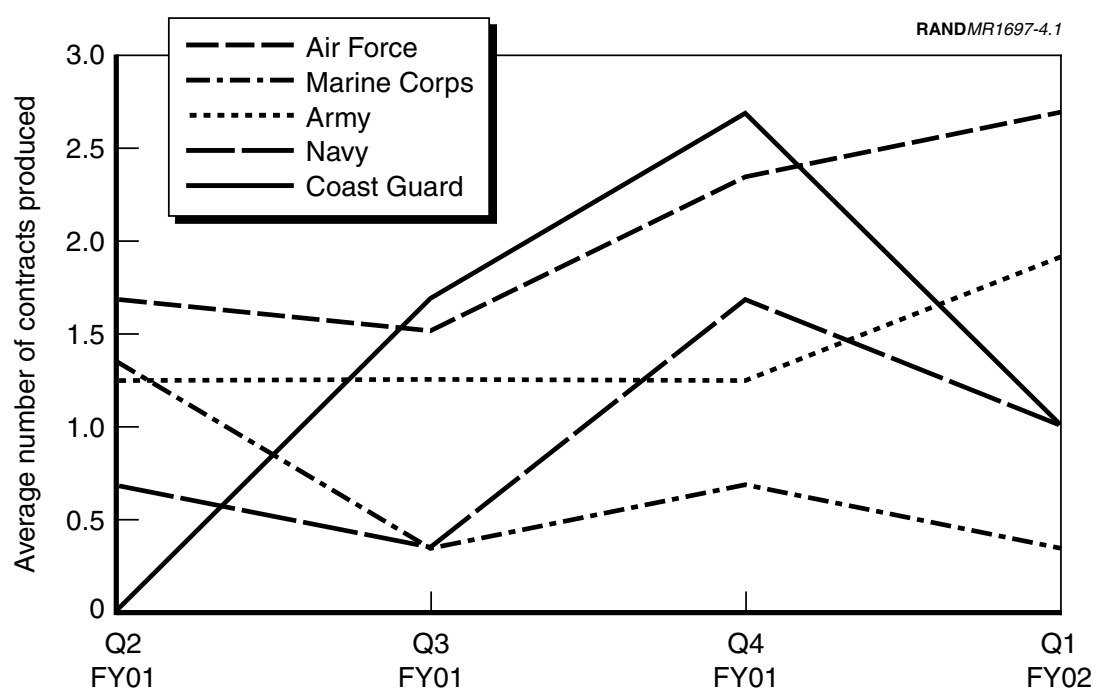

Figure 4.1-Average Contract Production for Potomac Mills Recruiters, per Recruiter per Quarter by Service 
case, similar production stations. However, it is much more difficult to attribute differences in performance to any particular cause. Such a comparison must be interpreted with caution, for at least two reasons:

- Any observed differences may or may not be due to the effect of the marketing-enhanced recruiting station itself. Because only one station was constructed, it is impossible to disentangle the effect of the marketing-enhanced features of the station from other factors unique to the station, such as geographic location and individual recruiters. For example, it is possible that the recruiters at Potomac Mills are either more or less naturally talented at recruiting than the comparison group. If so, then any difference observed could be due solely to this factor and have nothing to do with the station itself.

- It may also be true that no differences are observed between the contract production in Potomac Mills and that in the comparison stations, even though the station itself is contributing to improved recruiting. This evening-out could occur because the recruiters operate under a quota system and their incentive is to meet the quota but not to significantly exceed it. That is, even if the station is bringing in more-interested, more-qualified applicants, the recruiters may logically and naturally compensate by reducing their effort.

Unfortunately, with only one station, there is no way to tell, statistically, what the real cause of the observed performance is. Furthermore, it is important to remember that the mission of this station was both marketing and recruiting. Evaluating the contractgeneration performance attempts only to quantify station performance for one of these two important dimensions.

Table 4.2 compares the average number of contracts per recruiter per month for Potomac Mills versus the average number of accessions per recruiter per month for each service. For the purposes of this comparison, we discarded data for December and January for Potomac Mills to allow for start-up effects, and the service data are based on second-quarter FY01 accession data and the number of production recruiters for September 2000. We can see from the table 
Table 4.2

Potomac Mills Accession Rates Versus Each Service's Average

\begin{tabular}{lcc}
\hline & \multicolumn{2}{c}{$\begin{array}{c}\text { Average Production per Recruiter } \\
\text { per Montha }\end{array}$} \\
\cline { 2 - 3 } Service & Potomac Mills & Overall Service \\
\hline Army & 1.3 & 1.2 \\
Navy & 0.5 & 0.8 \\
Air Force & 1.9 & 2.6 \\
Marine Corps & 1.0 & 0.8 \\
Coast Guard & 1.0 & Unknown \\
\hline aRounded to the nearest tenth. & \multicolumn{2}{c}{}
\end{tabular}

that the average production in Potomac Mills has slightly lagged the overall service average for the Navy and Air Force but has slightly exceeded the service average for the Army and Marine Corps.

More-detailed comparisons between the quarterly contractgeneration performance at Potomac Mills by service and overall service averages revealed neither general trends nor any evidence that recruiters at the Potomac Mills station are systematically over- or underperforming relative to their peers nationwide.

We further compared the performance of Potomac Mills in calendar year 2001, by service, to counties in Virginia that most closely matched the demographics and performance of Prince William and Stafford Counties in calendar years 1999 and 2000. At lease three reasons can be given for using this "match-first, then-compare" methodology. First, it is well known that propensity to enlist (i.e., an individual's likelihood of signing up) and, hence, station contract enlistment performance (i.e., the number of enlistments a station gets), varies with demographics; therefore, matching on demographics helps to ensure, to the extent possible, that we are comparing areas with roughly equal enlistment propensity. Second, we matched past contract performance, both in terms of high-quality enlistments and total number of contracts, to attempt to match historical recruiter performance as much as possible. Third, we looked at differences between contract performance in the counties of interest and that in the comparison counties to control for time trends. The resulting comparison, then, does not look at overall recruiting increases or declines over the period of interest; rather, it looks at whether Potomac Mills station recruiting was better or worse than 
equivalent recruiting territories in the same region of the country with similar demographics.

The result is that matching by county only further reduces the difference in performance between the Potomac Mills recruiters and their local peers. Thus, there is no evidence to conclude that the Potomac Mills station is performing any differently, in terms of average recruiter production, than the equivalent standard recruiting stations. However, this should not be surprising, since the Potomac Mills recruiters were managed and given incentives exactly the same as their peers.

\section{LEAD-GENERATION PERFORMANCE}

For the first three months of station operation, Potomac Mills recruiters were asked to judge whether the walk-ins to their offices within the station were of sufficient interest to them-i.e., whether the station was attracting potentially qualified walk-ins. After all, it is counterproductive to burden recruiters with fielding queries from unqualified applicants. Recruiters determined that about 10 percent of station visitors were of such quality, or an estimated 250 good enlisted leads, which translates to about 1,000 good leads per year generated by the station and its location. This number is significantly higher than what almost any other station in the country generates (perhaps with the exception of the Times Square station in New York City). In addition, the station also attracts possible officer candidates.

\section{POTOMAC MILLS CONSTRUCTION AND OPERATING COSTS}

As described later in this chapter (Table 4.3), the construction costs of this particular station were significantly higher than what would be incurred in future marketing-enhanced stations. First, an accelerated construction schedule caused the costs to be inflated by over $\$ 150,000$. Second, the design of this station entailed constructing an entirely new second floor in the space, which significantly increased the basic construction costs and could be eliminated from any follow-on MERS. Third, because this station was the first of its kind, it incurred engineering design costs and other costs that would be 
mitigated or eliminated in follow-on stations. Rough estimates by members of the U.S. Army Corps of Engineers indicate that a followon, single-story MERS of similar functionality and capacity could be constructed for about half the cost of the Potomac Mills station.

With respect to annual operating costs, the largest component of the recurring costs is rent. Rent is a function of the mall and the location within the mall. For the Potomac Mills station, the annual rent of $\$ 163,750$ reduces to $\$ 45$ per square foot, based on the 3,600-squarefoot footprint in the mall. When the total space of 4,500 square feet is taken into account, including the second floor, that cost further reduces to about $\$ 36$ per square foot per year.

In comparison, the average recruiting station costs about $\$ 17$ per square foot per year. At $\$ 36$ per square foot, Potomac Mills is in the upper 95th percentile of all recruiting stations nationwide. In addition, in its current design, Potomac Mills also allocates significantly more square footage to each recruiter (about 560 square feet if all eight desks in the station are assigned to recruiters, compared with an average of about 150 to 200 square feet per recruiter in a standard station), making the facility even more expensive on a per-recruiter basis than an average recruiting station.

\section{ENLISTMENT CONTRACT PRODUCTION COST- EFFECTIVENESS}

Ignoring the benefits of advertising and marketing for the moment, we first analyze just the cost-effectiveness of the production of contracts. Our approach is to determine how many contracts a MERS must generate to be on a par with the average cost per contract from a standard station-clearly a conservative approach: If the MERS can be made cost-effective solely on the basis of enlistment contract production, then any advertising and marketing effectiveness only increases the station's overall cost-effectiveness.

The most conservative assumption in this first approach is that recruiters in the station perform no better on average than their peers in standard stations, which reduces to matching the MERS cost per recruiter to the cost per recruiter of a standard station. 
Given that these stations are purposely designed to be at the higher end of the cost scale, it is unreasonable to equate them with the average station. Rather, the MERS, if implemented, will likely make up a small fraction of the total number of recruiting stations. Thus, we use the 90th percentile of cost per square foot of existing recruiting stations, or $\$ 25$ per square foot, for comparison purposes.

Under the assumption that a standard recruiting station in the future will allocate about 200 square feet per recruiter, the annual rental cost of a station at the 90th percentile will be about $\$ 5,000$ per recruiter per year ( $\$ 25$ per square foot times 200 square feet). Considering only the rent for the Potomac Mills station $(\$ 163,750$ per year, Table 4.3), it would take 33 average-performing recruiters to break

Table 4.3

Potomac Mills Construction and Annual Operating Costs

\begin{tabular}{lr}
\hline Construction (Fixed) Costs & \\
\hline Original buildout cost & $\$ 541,691$ \\
Accelerated schedule & $\$ 151,451$ \\
Miscellaneous electrical equipment & $\$ 24,000$ \\
Telephone hardware & $\$ 20,483$ \\
Kiosk construction/installation & $\$ 8,255$ \\
Test room/administrator computers & $\$ 7,500$ \\
Computer tech support & $\$ 2,000$ \\
Total construction cost: & $\$ 755,380$ \\
& \\
One-time engineering labor/design & $\$ 104,312$ \\
Video loop tape and setup & $\$ 9,000$ \\
Exercise equipment & $\$ 9,000$ \\
Office equipment/supplies & $\$ 1,600$ \\
Plants & $\$ 1,000$ \\
Service flags/banners & $\$ 500$ \\
Total fixed cost: & $\$ 880,792$ \\
\hline Annual Operating (Recurring) Costs & \\
\hline Rent & $\$ 163,750$ \\
Basic telephone service & $\$ 19,200$ \\
Telephone long-distance toll charges & $\$ 18,000$ \\
Janitorial & $\$ 15,400$ \\
Kiosk maintenance & $\$ 12,000$ \\
Furniture rental & $\$ 8,020$ \\
Electricity & $\$ 7,200$ \\
Cable/internet & $\$ 6,912$ \\
Miscellaneous electrical equipment support & $\$ 1,472$ \\
Trash removal & $\$ 450$ \\
Total annual operating (recurring) cost: & $\$ 252,404$ \\
\hline
\end{tabular}

SOURCE: Data were provided by the U.S. Army Corps of Engineers. 
even on a contract-production basis ( $\$ 163,750$ divided by $\$ 5,000$ is just under 33). If the recurring costs of civilian station administrators and janitorial services are included, the number of recruiters required to reach contract-production cost-effectiveness could be as high as 70 recruiters.

As mentioned, such a calculation ignores the advertising aspects of the station, which, as will be discussed below, have the potential to be quite cost-effective compared with traditional advertising media. Even so, it is at least theoretically possible to modify the MERS implementation to make it cost competitive with standard stations just in terms of contract production.

\section{Approaches to Improving Contract-Production Cost- Effectiveness}

The cost-effectiveness of a recruiting station can be improved in three ways: (1) decrease the rental and construction costs, (2) increase contract-generation effectiveness, and (3) mitigate operating costs through revenue generation. The services have concentrated on the first option-decreasing operating costs-as the primary means of improving recruiting station cost-effectiveness. That Potomac Mills is expensive in the operating-cost dimension has been the leading source of criticism of the MERS concept. Mall rents are high and will remain so.

With regard to the second option-increasing contract-generation effectiveness-it appears that the services expected the Potomac Mills station in and of itself to potentially increase contract production. However, as has been discussed, even though the station seems to have increased the supply of potential recruits, recruiter contractgeneration performance has been about average; hence, the station as staffed and operated will not achieve contract-production costeffectiveness.

One possible solution is to increase station staffing. If 33 average contract-production recruiters were assigned to the station (without increasing the station square footage), the station could achieve costeffectiveness on just a contract-production basis. Seemingly impossible prima facie, assigning that many recruiters to the station could be achieved under a couple of conditions: (1) If the surrounding area 
was dense enough to support 30 recruiters in one location and (2) if the usual staffing and operating paradigms for the stations were modified appropriately.

The current paradigm is that every recruiter must have his or her own desk and office space. However, in today's cell phone-laptop computer environment, it is quite possible that recruiters can operate in a completely self-contained manner, needing to come in to the recruiting station only to meet prospects and conduct other types of necessary in-station business, such as completing paperwork and having discussions and meetings with supervisors.

One way to modify the MERS concept to accommodate such a paradigm change would be to convert the second floor into hoteling stations for recruiters. ${ }^{3}$ For example, the second floor could be converted to eight hoteling stations to accommodate 32 recruiters, who would spend an average of two hours per day in the station. Then, if each of the eight existing cubicles in four offices were apportioned so that each service had a station commander with his or her own cubicle and the other office cubicle was used on a rotating basis for recruiters meeting with prospects, a station like Potomac Mills could accommodate a total of 36 recruiters. More-aggressive implementation or greater facilities could increase this number even further.

Such an operating paradigm would require a number of changes to current assumptions and procedures, including the following:

- Recruiters would have to be capable, both technologically and managerially, of operating independently, which could require some additional equipment (e.g., a laptop compatible with the hoteling station) and perhaps a change in recruiter selection and supervision.

\footnotetext{
${ }^{3}$ Hoteling is a concept being embraced by the commercial world for employees who do not need permanent offices, such as sales representatives. A hoteling station is a special location at which employees, when they do come in to the office, can plug in their laptop and have a small workspace. The hoteling stations are not permanently assigned but are used on a first-come, first-served basis. If employees spend an average of only 10 hours a week (say, two hours per day) in the office, then eight such stations can accommodate 32 employees. See, for example, "Hoteling Variation Works for Employees on the Go," Los Angeles Times, August 7, 2000, p. C7.
} 
- As mentioned previously, the station would have to be located in a relatively dense urban area so that none of the recruiters would have to commute too far to his or her territory.

- Conversely, given that he or she would not have to come in to the station frequently, the distance from recruiting territory to station could be greater than with existing stations and territories.

This paradigm may seem far-fetched to current recruiting commanders; however, discussions in 2002 with a civilian recruiter for the Army's experimental civilian recruiter program revealed that such recruiters operated without any fixed office. The particular civilian recruiter interviewed operated out of his car, yet with all the requisite equipment (cell phone, laptop, etc.) needed to effectively recruit. As the civilian recruiter said, “I don't need an office. I need to be where the recruits are." No technical reason prevents active-duty recruiters from operating in a similar fashion, with hoteling stations in a larger recruiting station such as a MERS so that they could periodically "drop in" to conduct business and maintain contacts with their recruiting peers and supervisors.

The third option-mitigating costs through revenue generation-is made possible by the unique location and staffing of marketingenhanced recruiting stations. The idea is simple: The station is in a retail location; it could sell some merchandise. Indeed, when the Potomac Mills station opened, many of the visitors, not understanding that it was a recruiting station, came in to inquire about purchasing some of the recruiting giveaways that were displayed (e.g., mouse pads, posters, pens).

Given that Potomac Mills is staffed by civilian administrators, it is conceivable that a portion of the lobby could be used to display merchandise for sale. Indeed, one approach would be to incorporate the retail operation as part of the commercial contract for staffing the station with civilian administrators. The retail operation could serve a twofold purpose: (1) The profits could be used to defray the costs of staffing the station with civilian administrators (and perhaps other costs as well) and (2) with the right merchandise, presumably military-related, it could attract additional station visitors, who might subsequently contribute to the station's recruiting mission. 


\section{CONSIDERING ADVERTISING AND MARKETING AS PART OF STATION COST-EFFECTIVENESS}

As a "marketing-enhanced" recruiting station, one of the purposes of the station is to promote and advertise the military services and military careers. In this section, we seek to show that the cost of "advertising" via such stations (neither accounting for the recruiting performance of the station nor adjusting for those costs) is at least of a similar order of magnitude as the standard media, which the services already use. But how to assess the effect of such advertising on recruiting and station cost-effectiveness is not as straightforward as evaluating the cost-effectiveness of enlisted contract production. The difficulty occurs for many reasons, including the following:

- "Advertising" at Potomac Mills is fundamentally different from other standard advertising media, such as television, radio, and print advertising.

- All advertising-effectiveness evaluations suffer from difficulties inherent in determining whether the advertising has been seen by a member of the public and whether the advertising had any real impact.

Comparisons of the effectiveness of advertising are generally reduced to calculating the number of potential viewers of the advertisement. For example, in print media, such effectiveness is the cost per 1,000 subscribers; in television and radio, it is the cost per 1,000 estimated viewers or listeners. Clearly, these are imperfect measures, but they are the most concrete (since trying to measure the advertisement's effect on the subscriber/viewer/listener is both difficult and questionable). Table 4.4 provides the cost per 1,000 subscribers/viewers/ listeners for newspaper, television, and radio advertising for 1997 through 2001.4

To make a cost comparison to the Potomac Mills recruiting station, it is necessary to estimate the number of visitors to the mall, and then

${ }^{4}$ Data source: The Television Bureau of Advertising Online at www.tvb.org, accessed January 19, 2003. 
Table 4.4

Advertising Costs for Traditional Media

\begin{tabular}{lccc}
\hline & \multicolumn{3}{c}{ Average Cost per 1,000 } \\
& Subscribers/Households/Listeners \\
\cline { 2 - 4 } Year & $\$ 52.77$ & $\$ 17.30$ & Radio $^{\mathrm{c}}$ \\
\hline 1997 & $\$ 58.42$ & $\$ 18.08$ & $\$ 35.23$ \\
1998 & $\$ 59.62$ & $\$ 20.99$ & $\$ 37.74^{\mathrm{d}}$ \\
1999 & $\$ 66.57$ & $\$ 24.55$ & $\$ 39.62^{\mathrm{d}}$ \\
2000 & $\$ 69.79 \mathrm{~d}$ & $\$ 26.97$ & $\$ 41.61^{\mathrm{d}}$ \\
2001 & Televisionb & \\
SOURCE: & Data are from The Television Bureau of Advertising \\
Online at www.tvb.org, accessed January 19, 2003. & \\
aOne-half-page ad in daily newspaper. & & \\
bPrime-time 30-second commercial in top-100 markets. \\
cRounded to the nearest tenth. \\
dEstimated using the lesser of the average increase in cost for \\
previous five years or 5 percent.
\end{tabular}

to make cost comparisons to traditional media by defining the appropriate cost basis of the station. Two estimates for visitors to Potomac Mills in 1999 were 22 million ${ }^{5}$ and 24.2 million. ${ }^{6}$ Assuming a 3 -percent increase in visitors per year, which is consistent with the historical performance of the mall, would result in estimates of 23.3 to 25.7 million visitors in 2001. Table 4.5 uses a number of cost bases:

- Full costs for first year of operation of the Potomac Mills station, including all actual construction costs plus actual operating costs in FY01: $\$ 1,383,196 .^{7}$

- Estimated actual operating costs in future years: $\$ 422,404 .^{8}$

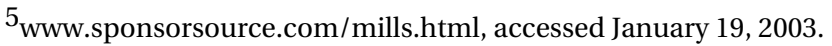

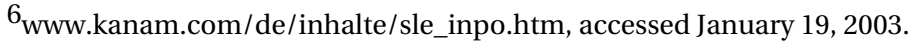

7 Total FY01 costs are $\$ 880,792$ for construction costs (Table 4.3) plus $\$ 252,404$ for annual operating costs (Table 4.3), plus $\$ 250,000$ for the station administrator contract.

${ }^{8}$ Total future-year costs are $\$ 252,404$ for annual operating costs (Table 4.3 ) plus $\$ 170,000$ for station administrator contract (administrator costs reduced as a result of contract competition). 
Table 4.5

Advertising Costs for Marketing-Enhanced Recruiting Stations

\begin{tabular}{lcccc}
\hline & \multicolumn{4}{c}{ Average Cost per 1,000 Mall Visitors } \\
\cline { 2 - 5 } & $\begin{array}{c}\text { Potomac } \\
\text { Mills, 1st Year }\end{array}$ & $\begin{array}{c}\text { Potomac Mills, } \\
\text { Future Years }\end{array}$ & $\begin{array}{c}\text { New MERS, } \\
1 \text { st Year }\end{array}$ & $\begin{array}{c}\text { New MERS, } \\
\text { Future Years }\end{array}$ \\
\hline $\begin{array}{c}\text { Cost } \\
\text { Number of mall } \\
\text { visitors }\end{array}$ & $\$ 1,383,196$ & $\$ 422,404$ & $\$ 800,000$ & $\$ 400,000$ \\
$\begin{array}{c}\text { Cost/1,000 } \\
\text { visitors }\end{array}$ & 24 million & 24 million & 24 million & 24 million \\
\hline
\end{tabular}

- Likely full costs for a follow-on station to Potomac Mills for the first year of operation: $\$ 800,000 .^{9}$

- Likely operating costs for a follow-on station to Potomac Mills for future years: $\$ 400,000 .{ }^{10}$

From a comparison of the results in Tables 4.4 and 4.5, we can draw two conclusions. First, even in its first year of operation, with all the costs incurred for this first-of-its-kind station, the advertising cost per 1,000 mall visitors is comparable with the costs of radio and newspaper advertising. Second, in later years at Potomac Mills, assuming the construction costs are amortized in the first year, the advertising cost per 1,000 mall visitors for this station is less than even television advertising. And, for follow-on stations, which would be less expensive to construct and similarly expensive to operate, the cost comparison is even more favorable for the MERS. If the costs of construction are amortized over five years (rather than one year, as in Table 4.5), then the cost per 1,000 mall visitors is just under $\$ 25.00$

\footnotetext{
$9^{9}$ Total annual costs for the first year of operation of a follow-on station are $\$ 400,000$ for construction costs (roughly half the cost of Potomac Mills) plus $\$ 250,000$ for annual operating costs (same as for Potomac Mills) plus $\$ 150,000$ for station administrator contract (reduced costs, similar to Potomac Mills, due to improved contract competition).

${ }^{10}$ Total annual costs for the subsequent operation of a follow-on station are $\$ 250,000$ for annual operating costs (same as for Potomac Mills) plus $\$ 150,000$ for the station administrator contract (reduced costs, similar to those for Potomac Mills, due to improved contract competition).
} 
for Potomac Mills and \$20.00 for follow-on marketing-enhanced recruiting stations.

Some might argue that using the total number of mall visitors in a year is incorrect, because not all mall visitors will pass by the recruiting station. Of course, a similar criticism can be made about newspaper advertising, in which a subscriber may never read the section of the paper that has the advertisement or of television viewers who may get up for a snack during commercials. However, the advertising industry has studied consumer behavior. Advertising in print and broadcast media can be carefully targeted by demographics, so the services can and do target their media placement toward the desired youth demographic. Even so, if the number of mall visitors is halved (for a conservative estimate), to 12 million, as a rough estimate of the number of visitors that pass by the station, the resulting cost per 1,000 visitors when the construction costs are amortized over five years is still equivalent to radio advertising and less than newspaper advertising.

Note that this discussion is not meant to definitively demonstrate that the Potomac Mills MERS is a cheaper alternative than traditional advertising media. To do so would take significantly more study, and it may not be true. Rather, it is to show that the cost of "advertising" via such stations is at least of a similar order of magnitude as standard media, which the services already use.

As a combined recruiting and advertising venue, a MERS is not unjustifiably expensive. The reason for its potential advertising costeffectiveness as a medium is its permanence. It is not just in one print run of a newspaper or one 30-second television spot. Rather, it is in a mall 365 days a year and thus can spread its costs across a large annual number of mall visitors.

Of course, as was discussed initially in this section, this analysis does not address the effectiveness of such advertising. However, with additional study, it is reasonable to believe that advertising in the mall via the marketing-enhanced recruiting station could be more effective than traditional media because it has the potential for immediacy, interactivity, etc. Therefore, appropriately implemented, the MERS may be able to provide advertising that is both cheaper and more effective than traditional print and broadcast media. 


\section{CONCLUSIONS}

Conclusion: The station is attracting a large number of walk-in visitors, of which a good fraction is judged "high quality." However, the station recruiters are producing only up to their contract mission/goals.

As described in Chapter Three, the station is attracting a large number of both youth and adult influencers. Of the walk-in youth, the recruiters judged 10 percent to be of good quality and, hence, worth pursuing. This walk-in foot traffic is significantly larger than what most standard recruiting stations get.

In spite of the increased walk-in foot traffic, the station recruiters are producing contracts at basically the same rate as their peers in similar locations.

Conclusion: Whether marketing-enhanced recruiting stations can produce contracts at a greater rate than standard stations under alternative operating procedures, recruiting policies, and/or recruiter incentives, is an open question.

Without innovation and experimentation by the services and their recruiting commands, it is impossible to determine whether the MERS concept can enable increased production over standard stations. As we discuss further in Chapter Six, all that we can conclude thus far is that standard operation of the Potomac Mills MERS results in standard output. What is required is innovation in the way the station is staffed and operated to see if the combination of location, design, and operating procedures will result in greater output.

Conclusion: Options for structuring the station are available that have the potential to achieve cost equivalence to standard recruiting stations in recruit-contract generation.

For contract generation, the station can be made more cost-effective either by lowering the cost of the station or by increasing the output. While follow-on marketing-enhanced recruiting stations are expected to cost about half what Potomac Mills did, those costs would still be higher than those of traditional stations. One strategy for reducing the operating cost of the station would be to sell appropriate, 
military-related items in the lobby. Such a strategy could be used to offset the costs of staffing the station with civilian administrators while also attracting a greater volume of foot traffic into the station. Alternatively, or in conjunction with this strategy, a greater number of recruiters could be assigned to the station, perhaps using a hoteling arrangement, to minimize office-space costs while maximizing contract generation for the station.

Conclusion: The cost of annual operation of the station in relation to the cost of various forms of national advertising is similar enough that it could result in a cost-effective means of advertising to a large audience.

Its permanence in a location with a high volume of visitors gives the marketing-enhanced recruiting station the potential to be as costeffective as other forms of traditional advertising. Furthermore, advertising via the MERS could be more effective than traditional media because the MERS has the potential for immediacy and interactivity, among other positive advertising characteristics. Therefore, DoD and the services could reasonably expect the MERS to provide advertising that is both cheaper and more effective than traditional print and broadcast media.

Conclusion: Appropriately implemented, the marketing-enhanced recruiting station could be cost-effective.

"Appropriately implemented" means that the MERS is optimized for both advertising and recruiting. As this chapter has discussed, it is possible to implement changes to the concept so that some operating costs are mitigated or eliminated, follow-on stations are built for half the cost of the Potomac Mills station, contract production is increased, and the station is fully used for advertising. Under a combination of some or all of these changes, the marketing-enhanced recruiting station has the potential to be a cost-effective alternative for some recruiting stations and for some advertising. 
Chapter Five

QUALITATIVE COMPARISONS WITH SIMILAR RECRUITING STATIONS

Across the country, several dozen recruiting stations are located in malls; however, no thorough study of these existing operations has been undertaken. ${ }^{1}$ That these mall-based recruiting stations have not been studied is unfortunate, because they may provide a valuable source of lessons learned for marketing-enhanced recruiting stations in particular and mall-based recruiting in general. These recruiting stations do not greatly resemble the Potomac Mills installation. Nonetheless, much may be learned from these preexisting stations about selecting malls and retail space within the mall, recruiter use of the retail space, contracting relations with mall management, and the quality of walk-in traffic at the various malls.

To augment the quantitative analyses of the Potomac Mills MERS just discussed in Chapters Three and Four, we examine here the services' experience with operating some of the mall recruiting stations. We identified several mall-based stations in coordination with the Army Corps of Engineers and selected the following as case studies:

- Eagle Ridge Mall (Lake Wales, Florida): Army Recruitment Center.

- Minnesota Mall of America (Minneapolis-St. Paul, Minnesota): Minnesota Army National Guard Recruitment Center.

${ }^{1}$ Indeed, it is difficult to even generate a list of such mall-based stations; that type of information is not maintained in a central database. 
- Westmoreland Mall (Greensburg, Pennsylvania): Joint Recruitment Center.

- Galleria Mall (Johnstown, Pennsylvania): Joint Recruitment Center.

We also visited the Times Square Joint Recruiting Station in New York City.

In this chapter, we present findings from the case studies. It is important to note that this was a sample chosen for convenience: The operations we identified are not representative of all mall-based stations. We visited two facilities (Eagle Ridge Mall and Times Square) and contacted others (Mall of America, Westmoreland Mall, Galleria Mall) by phone for semi-structured interviews.

\section{EAGLE RIDGE MALL}

The Eagle Ridge Mall is situated between Orlando and Tampa, Florida. Opened in 1996, it houses some 90 stores and has Dillard's, J.C. Penney, and Sears as its anchor tenants. According to the mall's marketing department, the closest competition is some 40 miles away, which makes its situation similar to that of Potomac Mills.

\section{Description of the Recruiting Station}

Opened in December 2000, this Army recruiting station replaces the Army's Winter Haven station. Unlike the other malls addressed in this chapter, the Eagle Ridge Mall station is a "quality-enhanced recruiting station" (see Figures ER.1 through ER.8 in the color-photograph insert), meaning that the quality of the furnishings has been upgraded relative to standard recruiting station furnishings. In this regard, the station is similar to the Potomac Mills MERS, although without most of the "marketing enhancements" of that station.

The Eagle Ridge station is reasonably well situated within the mall. It is near the food court but far away from any of the three anchors. The tiles and wall coverings resemble those of the Potomac Mills station, and the station has a television for videos built into the wall facing a window. The office of the station commander is in the front of the station. A large window permits complete visibility into his of- 
fice and visibility from his office into the mall, the entrance to the recruiting station, and the station itself. Unlike the Potomac Mills station, all the recruiters in the Eagle Ridge station are located in cubicles in the center of the station and are visible when a visitor walks by the station. The station also has a separate conference room in the back.

\section{Evaluating the Recruiters' Experience}

The Eagle Ridge Mall is new and has not achieved a prominent market position; however, the station commander argued that a station here is a good investment for the Army: This mall will become more established and, in the interim, mall management has been very cooperative with the Army and the station. The walk-in traffic has been slow, which the station commander attributed to the lack of advertising that has surrounded the move to Eagle Ridge. ${ }^{2}$ The commander cautioned against using the data reported to U.S. Army Recruiting Command (USAREC; Form 760) as a measure of the walk-in traffic, because recruiters are given incentives to claim "walk-in"/ "call-in" as "face-to-face" prospecting to appear more productive. Thus, figures reported on Form 760 are likely to underrepresent walk-in traffic at the station.

The station commander and other recruiters and commanders contacted for this study reported that being in the mall has several positive aspects. Potential enlistees are more willing to come to the station simply because it is located in the mall. As a consequence, no-show rates for appointments are lower than the recruiters' experience in the old Winter Haven station. Parents also inquire about opportunities within the station, but these numbers have been low because of the community's lack of familiarity with the new station. The mall also has had a positive effect on recruiter morale. But the commander cautioned that the mall placement has some downsides as well: Recruiters are comfortable at the mall and have become less motivated to go out into the field; they thus require continual motivation to leave the station.

\footnotetext{
${ }^{2}$ The station commander pointed out that even though the Winter Haven station did not have much appeal for bringing people into the station, it nonetheless had an established (if small) walk-in market.
} 
The station commander acknowledged that, whereas in Winter Haven the recruiters made their mission eight months in a row, since moving to Eagle Ridge their productivity has declined. However, he maintained that this drop in productivity was unrelated to their new location per se. Rather, he claimed that it is a result of the move and of personnel changes that occurred during the same period. The move itself precipitated a loss of focus among recruiters in December. The station also lost two of its most effective recruiters. Compounding this loss of experienced personnel, the new, replacement recruiters failed recruiting school the first time and had to repeat, delaying their arrival at the station.

Given the somewhat regional nature of the mall, it was initially thought that there could be complications with potential recruits who reside in other stations' territories coming to the mall and into the station. The station commander, himself an aggressive recruiter, discounted this complication, and he was unconcerned about the potential source of friction the overlap might cause with other station commanders. He suggested that if boundary crossing became a significant problem, station boundaries could be redrawn.

In this station, the recruiters are making some effort to make use of the entire mall space. For example, because the station is not located immediately near the various anchors and, while close, is not immediately in the traffic path to the food court, the station is using a display window elsewhere in the mall to raise awareness of its presence (see Figure ER.8 in color-photograph insert). The station is also planning an "Armed Forces Day," during which the Army will bring in pieces of equipment and vehicles and place them throughout the mall. In addition, the commander also identified mall employees as part of the station's target audience, as did others contacted for this study. At the time of this writing, the station had enlisted five mall employees since opening.

\section{Mall Management}

The management of the Eagle Ridge Mall has been proactive and helpful in promoting the Army recruiting station. For example, mall management is providing support for the above-noted Armed Forces Day by purchasing community advertising. The mall management 
also provides, free of charge, signage within the mall that directs patrons to the station. And the mall provides the above-mentioned display case to the station, as well as to the other tenants.

In contrast to the experience of other stations we contacted, recruiters are allowed to actively recruit in the mall. The store is also not required to keep the main mall hours. Additionally, the recruiters feel free to leave the station open and unattended for periods of time. (The station commander noted that, in contrast to the Mall of America experience discussed below, there is nothing vulnerable to pilferage in the Eagle Ridge Mall station, because the recruiters use laptops, which are locked up.)

Reflecting upon the very positive relationship with the mall management, the station commander attributed the mall's active support of the recruiting station to the newness of this mall and its desire to foster positive business outcomes for the station and other stores, thereby ensuring the success of the mall. The station commander felt that the more-established malls would have little or no incentive to provide the type of support and assistance that has been offered to the Eagle Ridge station.

\section{MALL OF AMERICA}

Opened in 1992 and located on a 78-acre parcel less than 2 miles from Twin Cities International Airport in Minnesota, the Mall of America is a retail mall that is so enormous that it houses more than 520 stores, has a 7 -acre theme park, employs more than 12,000 people, and has a total traffic of 35 to 42 million visits per year, over 1.5 times that of the Potomac Mills Mall. One of the most-visited destinations in the United States, this mall draws more visitors per year than Disney World, Graceland, and the Grand Canyon combined. Its proximity to the airport has enabled the mall to market itself to international travelers. Moreover, the Mall of America can be reached by 28 million people who live within a day's drive. Thus, the marketing efforts of the mall are aimed at regional, national, and international audiences. ${ }^{3}$

\footnotetext{
${ }^{3}$ This section draws on the Mall of America web site at www.mallofamerica.com.
} 


\section{Description of the Recruiting Station}

The Minnesota Army National Guard operated a station in the Mall of America from 1994 to the summer of $1999 .{ }^{4}$ The retail space had a basically square layout, with a $10 \times 10 \mathrm{ft}$ kiosk in the middle of the store, equipped with phones, a seating area, and a computer (until it was stolen)..$^{5}$ One or two Minnesota Army National Guard personnel staffed the kiosk, distributing recruiting and informational materials. The station made use of television and seasonal displays to attract foot traffic.

\section{Evaluating the Recruiters' Experience}

The cost of leasing the station at the Mall of America was approximately \$82,000 a year, for which the Minnesota Army National Guard did not receive budget increases to support. At the peak of the station's operations, the Minnesota Army National Guard had three fulltime recruiters and from two to five part-time recruiters assigned to the station.

According to Major Loidolt, the store received "a lot of walk-in traffic," and in this sense the store was successful. Initially, the mall recruiters were not assigned high school students; instead, it was expected that the mall recruiters could meet their mission off of foot traffic (e.g., in prior-service recruits and high school graduates). However, the recruiters were unable to meet their mission with foot traffic alone.

Part of the problem with meeting mission just from the foot traffic is that walk-ins received at the Mall of America station were not suitable for the Minnesota Army National Guard mission: over half of the visitors were not from Minnesota and so were ineligible. Although the state residency requirement would not be a problem for the active-duty component, it is a problem with the Minnesota

\footnotetext{
${ }^{4}$ This section is based on conversations with Major Neal Loidolt, Recruiting and Retention Manager for the Minnesota Army National Guard.

${ }^{5}$ Theft is an issue that underscores an important problem at the recruiting center: The station's alleged understaffing, together with the mall's requirements that the station keep the same hours of operation as the mall, made the station vulnerable to theft whenever recruiters had to briefly leave the station.
} 
Army National Guard's mission because no system is in place to recognize lead generation for other guard missions for other states.

Moreover, recruits did not join the Guard at the Mall of America facility. Those who were interested would sign up with a recruiter for a follow-up appointment, typically at their homes or any other convenient place. Since 75 percent of the Minnesota Army National Guard's prime market comes from outside the metropolitan areas, those homes could represent substantial travel time. A related complication was that the recruiter would often have to go to the young person's home to solicit parental consent. According to Major Loidolt, Minnesota obtains 70 percent of enlistments from high school students, which requires parental consent. Rather than risk a no-show by requesting that the parents come to the mall, the recruiter would go to the youth's home to meet the parents to obtain consent. These two factors implied that recruiters were often out of the office and on the road.

Major Loidolt discussed some of the lessons learned from the Mall of America experience. First, had the Minnesota Army National Guard station been staffed in a way that supported unmissioned recruiters, such recruiters would have staffed the Mall of America and would have used it primarily as a public-relations/community-awareness effort. Major Loidolt maintained that, without the availability of manpower to have unmissioned recruiters, the Minnesota Army National Guard required a lower-scale operation such as that at strip-mall locations. He cited strip malls as potential space, since they are less expensive and more flexible (particularly with respect to hours of operation) than retail mall space.

In the final analysis, when production was the criteria, operating in the Mall of America was prohibitively expensive. Each recruit obtained was very expensive compared with recruits produced by other types of recruiting efforts, such as standard stations. However, Major Loidolt remains positive about the concept of mall-based recruiting generally and said the Army National Guard would like to revisit it in the future. The major suggested two criteria to guide such future efforts: (1) The location needs to be in a high-visibility/high-traffic area and (2) the station needs to be located within a mall that is more oriented toward its target market (i.e., a more rural or youth-oriented mall). 


\section{Mall Management}

Analysis of operations at this station identified the relationship with the mall management as an important contributing factor in the station's operational difficulties. In Major Loidolt's view, the management was very restrictive. With the exception of using the restroom or shopping, the recruiters and equipment were required to be contained within the store itself. Recruiters could not go into the mall to encourage youths to come in on a low-traffic day. Major Loidolt felt that this restriction hampered the station's ability to get leads in the door. He elaborated that, in his experience, the youths who have decided to enlist have already approached the recruiter. The rest of the target market must be informed about the various benefits. In his view, this segment of the market will not simply walk in without some sort of engagement/encouragement.

Another concern with mall policy was similar to that at Potomac Mills: the requirement that the station maintain the same operating hours as the mall. This policy did not recognize that recruiting stations have a different pattern of traffic and that recruiters often need to travel to appointments, nor did the policy recognize that office hours can be different from retail hours.

The mall also restricted the Minnesota Army National Guard from leveraging the mall space in more creative ways. On one occasion, the Guard sought to bring its medical units to offer services such as free blood-pressure screening, but was prohibited from doing so by the mall's lease agreement. On another occasion, the Guard wanted to bring in various simulators and demonstration weapon systems, but these too closely approximated real weapon systems and were disallowed by the lease agreement.

\section{WESTMORELAND MALL}

The Westmoreland Mall is located in Greensburg, Pennsylvania. The largest mall in Westmoreland County and the third-largest mall in the metropolitan Pittsburgh area, the Westmoreland Mall houses some 170 stores, occupies approximately 1,275,090 square feet, and is anchored by Sears, J.C. Penney, Bon Ton, and Kaufmann's. According to the Army Corps of Engineers, this mall is not seen as a major destination mall, as is the Mall of America. However, this view 
differs from that of the local recruiters, who see Westmoreland as the biggest mall in the area. ${ }^{6}$

\section{Description of the Recruiting Station}

The recruiting station in the Westmoreland Mall is located on the lower level, adjacent to the Bon Ton department store. It houses separate offices for all four services, which were previously located in the now-defunct Greengate Mall. (The Army also recruits for the Army Reserve Component.) The interior layout of the recruiting station has the Air Force and Navy located on the left side of a long corridor, and the Army and Marine Corps located on the right side of the corridor. The corridor has a door-sized entryway with a roll-up gate and the armed forces recruitment signage overhead. The entrance has been described as not particularly inviting or attractive to passersby. ${ }^{7}$

\section{Evaluating the Recruiters' Experience ${ }^{8}$}

Conversations with the services in this station suggest that each uses the mall space differently. The Army has taken substantial effort to use the space creatively: It is trying to get advertisements in the food court, and it has on occasion brought a HMMWV into the mall to generate public interest. The Navy also distributes literature in the food court. Recruiters from several services report going out into the mall to speak to people, even though they technically have to observe a lease line that does not allow such activity. Recruiters explained that their target audience includes mall employees as well as mall customers. One recruiter remarked that "You can't actually recruit in the mall as stores don't want us to recruit their employees ... [but] there are ways around this."

\footnotetext{
${ }^{6}$ This section draws on conversations with the Army Corps of Engineers, as well as on a "Fact Sheet" on the Westmoreland Mall published by Jones Lang LaSalle, 2000.

${ }^{7}$ Information for this section was obtained from a personal communication with Rodger Reynolds of the U.S. Army Corps of Engineers. We also spoke with the Army station commander and with recruiters from the Navy and Marines. (We were unable, after several tries, to speak with the Air Force representation.)

${ }^{8}$ This section draws on interviews with the Army station commander and with recruiters from the Navy and Marines. The Air Force could not be reached, despite numerous calls.
} 
The services concurred that the walk-in traffic here is much improved in this location relative to that in the Greensburg, Penn., mall station, but each service reported a different experience with walk-in traffic and with the ability to convert these walk-ins to contracts. The Navy reported getting about two walk-ins per week (which it claims is an enormous increase over the rate at the previous station), a majority of which meet qualifications. These walk-ins make up nearly one-third of its contracts. The Army was less positive about the contribution of walk-ins to meeting mission. The Army and Navy indicated that the location of the mall with respect to generating walk-in traffic is as good as it could be, without being located in the premium food-court area.

\section{Mall Management}

Recruiters said that the mall management is flexible with respect to mall hours, permitting the services to keep separate hours from the mall's. The station has a separate back door, which lets it operate outside of standard operating hours. Statements from recruiters also suggest that the mall is somewhat lenient about enforcing the ban on prospecting in the mall.

\section{GALLERIA MALL}

The Galleria Mall is located in the east of the city of Johnstown in Richland Township, Pennsylvania. The mall is a $Y$-shaped structure that currently occupies approximately 767,000 square feet in a large, flat area. It has Bon Ton, Sears, and J.C. Penney as its anchors. WalMart occupies one of the outer parcels, but it is not connected to the mall itself. A number of other major chain stores make up the mall, which is well situated as the only retail activity that is accessible without excessive driving and the only mall in a 40-mile radius, much like Potomac Mills and Eagle Ridge. As of July 1999, this mall had a 93-percent occupancy rate. ${ }^{9}$

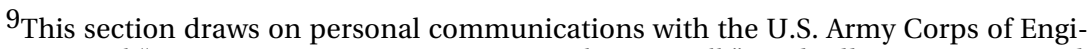
neers and "CBL \& Associates Acquires Pennsylvania Mall," Nashville Business Journal, July 2, 1999, available at nashville.bcentral.com/nashville/stories/1999/06/28/daily25. html.
} 


\section{Description of the Recruiting Station ${ }^{10}$}

The recruiting station is located where the two branches of the $Y$ intersect, on the lower level. The station itself is shaped like an inverted $L$, with the Navy occupying the top portion. The other services cascade down the long arm, the Army occupying the farthestmost space. This unusual shape could, in principle, expose the different services to different traffic patterns. The Navy is situated across from Champs, a major sporting-goods store; the Army is located nearest to J.C. Penney. The Navy's entrance is somewhat obscured by a stairway (and elevator) that permits foot traffic between the mall's first and second floors. The Navy store is the first recruiting office seen by traffic descending the stairwell or elevator. Each of the services has a separate entrance with a distinctive glass door, rather than the barrier-free overhead door that typifies the other stores in the mall.

\section{Evaluating the Recruiters' Experience ${ }^{11}$}

The views expressed by the different services heavily reflected their different physical positions within the mall. The Army expressed concern because it is situated near J.C. Penney, which reportedly does not draw the Army's target demographic. The Army claims that it receives four to five walk-in leads per month. However, these leads do not generally qualify, either because of low educational achievement, low AFQT scores, or law violations. In the Army's view, this facility draws more walk-ins relative to other locations, yet the walkin traffic does not substantially contribute to making mission.

Despite the Navy's better location for foot traffic, it claimed that it receives only four walk-in leads per month, and those are during good recruiting periods. Some months may go by without any walk-in leads. The Navy also expressed concern about the quality of walk-in leads, because most fail to qualify as a result of criminal records and

\footnotetext{
${ }^{10}$ This section draws on information obtained from personal communications with the U.S. Army Corps of Engineers.

${ }^{11}$ This section is based on information obtained during semi-structured interviews with the Army Station Commander and with recruiters from the Navy and Marines. The Air Force could not be contacted, despite several efforts.
} 
poor AFQT scores. Nonetheless, the Navy recruiter was generally satisfied with the Navy's location, with its station design, and with the mall traffic patterns. However, the Navy recruiter noted that while this is the best place to be in the area, in the only mall in a 40mile radius, the overall foot traffic in this mall is low.

The Marines report a much higher figure for walk-ins relative to the Army and Navy: one or two per day. However, like the other services, the Marines also find that the quality of this foot traffic is low, with only one in five qualifying. (The Marines here also sign Reserve contracts.)

One of the positive aspects identified by all services is that the mall location itself is good for recruiter morale. It provides the recruiter a space in which to decompress when things are going particularly poorly. The services also value being colocated, which both encourages competitiveness across the services and allows the services to catch each other's "leftovers." The Navy and Marines expressed considerable satisfaction with their particular locations in the mall, given that they could not be on the food court.

All services identified one aspect of the station as a problem: No common area is available in which recruits and their parents can wait. The recruiters identified several negative scenarios in this regard. First, sometimes, if a recruiter is late and there is no place to wait until the recruiter gets there, the lead may simply leave or wander down to speak with a different service. Moreover, there is no place for the parents (or other influencers or significant others) to wait, which the recruiters feel does not foster a positive feeling about the experience. According to recruiters, there is not even a mall bench in the vicinity of the stores.

Of the three services that we could contact, only the Army has taken advantage of the mall's overall space by bringing in a HMMWV and some Reserve unit equipment. The Army has also set up displays in the mall. While the mall has not charged the Army yet, the Army understands that it may do so in the future. (But the Army does not expect that these fees will be so great that it would be deterred from making future plans.) None of the services contacted leaves literature in the food court, as the recruiters did in the Westmoreland Mall. Recruiters reported that they recruit from mall employees and 
try to engage youths in the mall, despite a management ban on such activity.

\section{Mall Management}

As just mentioned, the mall has permitted the Army to bring in equipment for promotions. As well, it does not require that the services keep mall hours (the station is closed on Sunday). Moreover, the Army explained that the services are permitted to leave literature, with the proviso that they sign up for this in advance-a requirement for all mall occupants. The Navy, conversely, commented upon the fact that it is not permitted to place racks containing promotional literature around the mall. (Of course these views are not necessarily contradictory. Putting up racks in the mall is not the same as holding a scheduled promotion.) One source of dissatisfaction expressed by the recruiters is the mall's strict prohibition on prospecting in the mall.

\section{TIMES SQUARE}

The Times Square station is situated on a "pie-slice-shaped" piece of the sidewalk between 7th Avenue and Broadway at 45th Street, in New York City. This station first opened in May 1946 and has attained landmark status among the local population, who know it as the "Booth" or the "Shack." This station was the nation's first joint recruiting station and has been the most successful station in the nation. In 1998, the original structure was demolished and the new facility was constructed. In addition to being located at one of the busiest locations in the country, it is situated at a major subway stop.

\section{Description of the Recruiting Station}

The new facility itself is a small, aluminum structure with two 35-foot fluorescent flags spanning the entire area of the two larger outer walls (see Figures TS.1 through TS.5 in the color-photograph insert). Above the entrance, a sign indicates that the facility is a "U.S. Armed Forces Recruiting Station"; however, the sign is hard to read. A larger and much more visible sign on the rear (south) wall indicates that the structure is a recruiting station. On the same face as the entrance 
(north) is an 18-foot-high video screen segmented into several smaller screens. In the opinion of the recruiters, this video detracts from the front signage. Because the station is quite small, each of the four services (the Coast Guard is not present in this station) has a small cubicle (see Figure TS.5) and contacts have limited space in which to wait and to conduct business. ${ }^{12}$

\section{Evaluating the Recruiters' Experience}

Most of the recruiters ${ }^{13}$ noted that the foot traffic at this station is substantial, because of this station's location. However, in the opinion of the recruiters, the overall quality of the visitors is also lower for the same reason. For example, visitors to the station include foreigners, veterans, and others who are drawn in by the architecture. The recruiters also indicated that the military aptitude and law violations among the walk-ins was a particular problem at this station. The landmark status of the station means that people with an interest in enlistment come from far away to visit this station, apparently unaware of stations nearer to them. Consequently, their follow-up tends to take place closer to home rather than at the station. Such potential recruits, if enlisted, would not count toward the Times Square station's mission.

Despite its historical position and large signage, this structure's identity as a recruiting station escaped a good number of people, according to the recruiters. To communicate the function of the facility, the recruiters reportedly stand outside the station in uniform to prospect when traffic is low. The recruiters also claim to take advantage of the subway station near the facility to prospect.

\footnotetext{
${ }^{12}$ This section draws on information available in Kathleen Welker, "Caldera Rededicates New Times Square Recruiting Station," Army LINK News, September 7, 1999; "Mayor Giuliani and Army Secretary Louis Caldera Rededicate Times Square Armed Forces Recruitment Station,” Press Release No. 341-99, September 7, 1999; "Mayor Giuliani and Defense Secretary Cohen Visit Times Square Armed Forces Recruitment Station," Press Release No. 317-98, July 6, 1998; "Times Square Recruiting Station," DoD News Briefing, July 6, 1998.

${ }^{13}$ The Army recruiter was unable to meet with us and thus is not included here.
} 
All of the services are on-mission, and all but the Navy are assigned high school lists. The Navy is expected to meet mission from foot traffic alone, which it does.

\section{CONCLUSIONS}

Drawing from the recruiters' experiences across these very different facilities, several themes emerge that may be helpful in considering the future of mall-based recruiting.

Conclusion: Whether the services are selecting a mall or a place within the mall, location matters.

These case studies cannot shed much light on the optimal placement of recruiting stations in malls. However, some considerations did emerge from this research:

- Malls without a competitor within a reasonable distance (40-50 miles) may be desirable, all else being equal.

- Malls that are a major tourist destination may be unattractive, because visitors to the station may not actually enlist there.

- Care must be taken to ensure that the mall demographics are the right demographics. (The Mall of America is a good example of a mall with demographics not conducive to the mission of the recruiting station located there.)

- Foot traffic to a recruiting station can vary significantly with location within the mall.

- If the recruiter must follow up with a visit to a potential recruit's home, allowances must be made for the recruiter's driving time and time away must be considered before a service signs a potentially restrictive lease agreement (see next conclusion).

Conclusion: Mall management and the contract with the mall are important considerations when choosing the mall in which to locate a recruiting station. The contract (lease agreement) is what defines the rights of the services and the management that enforces the contract. 
When selecting malls for recruiting stations, services should consider explicitly how cooperative-indeed, supportive of-mall management will be with recruiters, the recruiting station, military promotions, and station operations in the mall. As these interviews demonstrate, the contractual and operational relationships among existing stations and the several malls vary widely. In negotiations with the mall management, services must ascertain whether their recruiters will be able to conduct promotional activities, have the right to leverage and attract foot traffic (through advertisements elsewhere in the mall and in the food court), and know the hours that the station may keep. Locating a station in a mall that severely restricts station and recruiter operations may be worse than locating the station somewhere other than a mall.

Conclusion: Within the mall, an obvious trade-off is between cost and location, particularly a location with significant youth foot traffic, such as food courts and movie theaters.

Given that the services may decide not to locate near the food court because of high costs, there are other ways of leveraging the mall space to attract foot traffic, such as signage and displays. Again, the cooperation and support of mall management is important. If the siting of the station in the mall and/or the contractual restrictions placed on the recruiting station do not allow the station to leverage the mall's foot traffic, then the result is likely to be unnecessarily expensive office space.

Conclusion: Some consideration should be paid to the quality rather than the quantity of walk-ins.

Nearly all services in nearly all facilities contacted during this research made a point of stressing quality over quantity. Alternatively, for mall-based stations, recruiting commands might explore ways for visitors to self-screen, either through readily available literature and/or interactive kiosks, thereby reducing the burden on the station's recruiters. Similarly, in mall-based stations that employ civilian administrators, the administrators may be able to assist in screening visitors so that recruiters can concentrate on the mostpromising prospects.

Conclusion: A more qualitative consideration, which is difficult to address empirically but which has wide concurrence, is that mall- 
based recruiting enhances recruiter morale and also decreases noshow rates.

In particular, the mall-based location reportedly makes it easier for follow-up appointments with individuals contacted outside the mall: The mall has a centrality that out-of-the-way locations, which are often hard to find, lack. However, at least one station commander also found that recruiters may become too comfortable in the mall and become complacent.

Conclusion: Some of the recruiters and commanders contacted were exceptionally creative in leveraging the mall atmosphere for their mission.

Services should consolidate some of these leveraging strategies so that other station commanders can use them. In fact, the services should codify and put into operation the most-successful strategies so that they can be easily and consistently applied. Furthermore, given that there are some 20 to 30 recruiting stations already operating in malls, and that some of them have been operating for several decades, it may be worthwhile to explore systematically the lessons learned by these operations.

Ultimately, how robust these anecdotal findings are is open to question. However, our preliminary efforts suggest that mall stations may be worth exploring if the interest in establishing recruiting stations in high-visibility retail areas persists. 

Chapter Six

DISCUSSION AND RECOMMENDATIONS

The information we have gathered on the Potomac Mills MERS and on other mall stations provides useful comparisons about size, station layout, recruiting style, mall management, and other important aspects of stations located in retail malls. The aspects that appeared successful at one station but unsuccessful at another raise more questions than they answer. These questions should be viewed as a basis for additional studies on MERS and on mall recruiting in general.

However, insofar as conclusions can be drawn, in this chapter we provide observations and conclusions about marketing-enhanced recruiting stations. First, we take another look at the recruiting process in general and in relation to the Potomac Mills MERS in particular. Then, we provide recommendations for the future disposition of the subject MERS.

\section{WHAT HAVE WE LEARNED FROM THE PROTOTYPE MARKETING-ENHANCED RECRUITING STATION?}

Our observations from both the prototype MERS and the other mallbased stations, as well as from the quantitative data we collected at Potomac Mills, lead us to a number of observations and conclusions about marketing-enhanced recruiting stations:

- The marketing-enhanced recruiting station concept, appropriately implemented, has the potential to be a cost-effective alternative for some recruiting stations and for some types of advertising when the station's potential recruiting and advertising 
benefits are fully exploited. Furthermore, as this report has discussed, follow-on marketing-enhanced stations can be implemented at a significantly lower cost than that of Potomac Mills as a result both of reduced construction costs and of mitigated operating costs.

- To date, the Potomac Mills station has not demonstrated increased enlistment-contract production over that of equivalent (i.e., standard) stations. Two factors, discussed in more detail in Chapter Two, account for this outcome:

- Potomac Mills station recruiters were required to operate under the standard mission/quota system, a practice that probably stifled station operational innovation and that may have driven station contract production toward the norm. ${ }^{1}$

- The existing Woodbridge recruiting station, located just across the mall parking lot, was not closed. For most of the services, it maintained responsibility for most or all of the surrounding territory.

- Potomac Mills station recruiters performed similarly to their peers in a standard recruiting station, making the station seem less than cost-effective in recruit contract generation than standard recruiting stations. However, this conclusion ignores the marketing and advertising aspects of the station, which, as this report addressed in more detail in Chapter Four, have the potential to make the MERS platform a very cost-effective combined recruiting-and-advertising venue.

- Because recruiters and recruiting commands did not experiment with adapting their recruiting or operational procedures to the new mall and MERS environment, we were not able to evaluate what drives station performance or whether alternative operating procedures would have attracted even more or higher-quality walk-ins or increased contract production. For example:

\footnotetext{
${ }^{1}$ Army production was the exception. Initially, the Army operated the station as a lead-generating facility. It has since reverted to staffing and operating Potomac Mills as a standard production facility.
} 
- Recruiters generally kept standard weekday working hours, even though most station visitors came on the weekends and Thursday and Friday nights.

- The services did not hold any special events at the station, nor did they otherwise provide any type of marketing or advertising to exploit the station location.

- Our survey indicated that the prototype MERS is effective at attracting local recruit-age youth and adult influencers. This success comes despite less-than-optimal use of the enhanced station features and no innovation by the services in developing marketing materials or events. For example:

- The station attracted over 8,000 visitors in its first year of operation, of which approximately half were of recruit age, or an average of 10 recruit-age visitors and 10 adult influencers per day.

- Recruiters judged that about 10 percent of the youth visitors resulted in quality leads, or an average of about one lead per day.

- Our survey also indicated that the visitors were favorably impressed by the station and that they found it useful for learning about military careers. A significant number said the station increased their interest in joining the military. The station thus seems to fulfill its purpose as an effective marketing and advertising medium.

- An overwhelming majority of active-duty recruiters believe that placing recruiting stations in large, enclosed malls would help recruiting. In the 2000 Military Recruiter Survey (U.S. DoD, 2002), 93 percent of active-duty recruiters felt that well-designed recruiting stations in malls would reflect positively on the military, generate new leads, and help them recruit. Almost 70 percent of active-duty recruiters said that they would prefer a recruiting station in a large mall to their current station location. And, more than 80 percent of active-duty recruiters believe that teenagers would visit such a station and that it would positively impress key influencers. 
Taken together, these lessons provide reasonable evidence for concluding that combining marketing functions with recruiting stations merits further study and experimentation.

\section{DISCUSSION OF THE RECRUITING PROCESS'S ROLE IN EVALUATING MERS}

As mentioned in Chapter One, the recruiting system can be described as (1) the operational and management policies and procedures of the recruiting commands, (2) the actual facilities and equipment provided to the recruiters, and (3) other operating parameters, such as the number and distribution of recruiters themselves. Relevant to this evaluation is that operational policies and procedures do indeed affect whether certain types of facilities and equipment are appropriate and/or effective for military recruiting, just as the availability or unavailability of some types of equipment can dictate changes in policy and procedures. New technology may require changes in policies and procedures and, perhaps more important, in the very recruiting process itself.

Thus, the question of whether the concept of MERS is good is a relative one. It is relative to the rest of the recruiting process, of which MERS facilities can be only one part. That is, MERS' effectiveness is governed in part by the rest of the recruiting system, and that effectiveness can be enhanced or degraded as a result of changes to the rest of the system.

As discussed in Chapter One, even if the MERS was able to increase the supply of youth, and there is some evidence that it did, the factors that influence recruiter performance and ultimately drive contract production are equally important, if not more so. In the following two subsections, we look at two such factors: incentives and changes to the recruiting process that must accompany new "hardware."

\section{“Made Mission, Gone Fishin"”}

What is most relevant to the evaluation of the Potomac Mills prototype MERS is that the new type of station was operated using standard recruiting and operational procedures. Hence, it should not be 
surprising that, at least in terms of contract generation, the Potomac Mills station performed much as did any other station.

In particular, a fundamental issue with the MERS is that few positive incentives are given for recruiters to support the purely marketing aspects of the station or to exceed their production goals. Moreover, recruiters may even be motivated to avoid exceeding their goals, since regularly doing so may result in increased quotas or failure to meet a future quota. Thus, in evaluating production at Potomac Mills, it is important to recognize that an increase in supply (that is, visitors to the station) is necessary but not sufficient for increasing station contract production. Changes in the demand factors (that is, how the recruiters allocate their time and effort) are also vitally important.

In the face of increased enlistment prospects, a recruiter has a number of choices. From the service's perspective, the desired choice is for the recruiter to maintain the same level of effort as before the increase in supply and thereby generate greater numbers of contracts. However, from the recruiter's perspective, a desirable approach may be to invest the minimum amount of effort necessary to continue to meet the existing mission/goal. Such an approach may be justified on the grounds that when supply shrinks, the recruiter will have to invest more time to continue to make mission/goal. Therefore, easing off during times of higher supply is seen as a deserved return on the extra effort previously invested or that will have to be invested in the future. Also, from the recruiter's perspective, it has the benefit of not driving future increases in mission/goal and of allowing the recruiter to save leads and hot prospects in case there is a downturn in supply. Indeed, given that recruiters are concerned about the long hours they must devote to their jobs (GAO, 1998, p. 3), it may be perfectly rational for increases in supply to result in decreased effort.

We provide the above discussion to underscore that an increase in supply does not necessarily directly translate into an increase in production. As another example, Polich, Dertouzos, and Press (1986) found that, when a recruiting resource such as advertising is increased, enlistments do not increase to the full market potential. They found that enlistments increased to only about 70 percent of what was expected, unless the recruiter quotas (goals, missions) were 
increased simultaneously. They concluded that, as the market expands, the recruiter's job is made easier, so the recruiter puts forth less effort.

This result is succinctly captured in the recruiter saying, "Made mission, gone fishin."”

\section{Improvement Requires More Than New Hardware}

Cordeiro et al. (2001) concluded in their paper on modeling time utilization of Army recruiters that "[a]lthough prospecting would be a simple matter if applicants simply walked into the station, most recruiters find that they must actively and aggressively pursue the 'leads' they have obtained through one of the means previously described.” However, experience with the Potomac Mills MERS may indicate that getting recruits to walk into a recruiting station is not enough. Recruiter incentives and the recruiting process must be reoriented to maximize the performance of the marketing-enhanced recruiting station.

As discussed in Chapters Two, Three, and Five, station operating and management policies are as important as design. Just as warfare campaigns are won when hardware is optimally integrated and operated using appropriate operational doctrine, training, and leadership, changes in the location and appearance of a recruiting station in the absence of updated operational doctrine should not be expected to result in dramatic increases in recruit contract generation.

An even more fundamental question is raised by this lack of expectation: What is the purpose, and hence what are the key measures of performance, of a marketing-enhanced recruiting station? That is, optimal employment of the marketing-enhanced recruiting station requires revisiting the basic tenets underlying the employment of recruiting stations. Is a recruiting station

- oriented toward short-term mission/goal or long-term market and awareness?

- intended to market and raise awareness of military service and the services themselves or meant to produce recruit contracts cheaply? 
- meant to be part of a larger network of recruiters and stations and/or to service a large region, or simply to stand alone and/or service a small, local territory?

Potomac Mills has largely been operated by the services as just another recruiting station. Such a contract-production orientation has limited the station, and it misses a major potential focus of such a station: marketing and advertising.

\section{RECOMMENDATIONS}

Much more thought and experimentation are required to define the most effective operating model for the MERS. The information from Potomac Mills and the other mall recruiting stations raises more questions and hypotheses about why various station aspects do or do not work in MERS. Experimentation will take concerted effort and may require a dedicated organization outside of the recruiting commands. The obvious analogy is the use of the Joint Forces Command for spearheading force transformation rather than individual services' operational commands.

We suggest that the Potomac Mills marketing-enhanced recruiting station should be converted from a standard production recruiting station into an experimental facility for learning how to market and to recruit today's youth in a commercial environment. DoD has invested almost a million dollars in a unique facility that, thus far, has not been employed to its full potential. As a standard recruiting station, Potomac Mills is untenably expensive. As a combined advertising platform and recruiting station, the Potomac Mills MERS has the potential to be cost-effective. But, as a test bed for new advertisements, marketing strategies, and recruiting procedures and techniques, Potomac Mills is invaluable. With a view toward MERS' being used as such a test bed, we present the following recommendations:

Recommendation No. 1: Use the Potomac Mills Station for Market Experimentation. The Potomac Mills marketing-enhanced recruiting station is unique among stations. It is in a commercial location with a high volume of foot traffic. It has facilities for displaying 
commercials and web sites to a broad cross section of the public. It even has built-in capabilities to remotely study station visitors and passersby to determine the effectiveness of the various marketing, promotional, and recruiting techniques.

As a result, the Potomac Mills station should be thought of as an ongoing experiment and a platform for testing and evaluating new recruiting methods, rather than as the final manifestation of a specific MERS-type station. Such experimentation can serve both as a way of learning to exploit the strengths of the MERS, thus maximizing MERS' production, and as a way to discover new, more widely applicable methods of recruiting.

In the process of conducting this research, we approached various recruiting commands about using the station to perform marketing and recruiting tests. We were interested in understanding what aspects of the station attracted visitors and affected station performance. For example, which types of special promotions and marketing techniques would attract various types of station visitors; how variants of staffing and recruiting methods would affect station production; how visitors would use the station under various conditions; and, most important, how these factors would relate to the conversion of casual visitors into serious prospects. To date, no service or recruiting command has used the station for this purpose.

Examples of the types of experiments we had in mind include the following:

- Evaluating whether displays of military equipment attract visitors.

- Determining whether staffing the station lobby with active-duty personnel helps attract and/or convert youth.

- Understanding whether new types of promotions, such as the military-related video games currently being distributed and played on the Web, might attract visitors.

- Learning how varying the ambience of the station, such as lighting changes, music type and volume changes, changes to the promotions on the monitors, etc., would or would not attract various visitor demographics. 
- Evaluating how hosting unique special events, such as a reception in the lobby for local school counselors, teachers, principals, etc., could contribute to the long-term marketing and recruiting success of the station.

These types of experiments and evaluations are commonplace in the commercial world. The military has a facility in place now to conduct such evaluations and should take advantage of it.

Recommendation No. 2: Use Potomac Mills to Determine How to Optimize the MERS Concept. In addition to using the facility to test individual marketing and recruiting techniques, the Potomac Mills station should be used to learn how to optimize the marketingenhanced concept. As we have discussed previously, the services' approach to date has been to expect hardware changes-the way a station is designed and sited-to translate automatically into increased contracts without concomitant changes in management of recruiters' incentives or station operation. Various operational changes should be implemented and tested at Potomac Mills in order to learn how to optimally operate such a station. Examples of possible operational changes include the following:

- Varying how civilian administrators are used, to learn how they are best employed. For example, virtually every recruiter and recruiting commander is convinced that nothing can replace a recruiter sitting "knee to knee" with a potential recruit, particularly insofar as doing so converts that potential recruit into an enlistee. As a result, civilian administrators were restricted from most activities within Potomac Mills. However, it is possible that an expanded role for the civilian administrators could make the recruiters more efficient and/or improve the performance of the station.

- Evaluating changes in the way recruiters use the station and operate from it. For example, the second floor of the station could be converted to hoteling stations and the number of recruiters attached to the station increased significantly. Via Potomac Mills, such new models of recruiting-station use could be evaluated and optimized. It is possible that such changes, successfully tested and implemented, could make a marketing-enhanced re- 
cruiting station such as Potomac Mills more cost-effective than standard stations on a purely contract-production basis.

- Understanding how station design and operation contribute to converting casual visitors to military recruits. For example, the location of the Potomac Mills station within the mall encourages casual walk-in visitors, whom recruiters might initially find less than serious about military service. However, it is possible that changes in the design and operation of the station would either encourage or discourage casual walk-in visitors to get more serious about joining the military and/or return to the station. Examples might include making more or different types of literature available in different parts of the MERS lobby and displaying educational videos, as opposed to advertisements, on the monitors.

- Modifying station operation to make it more efficient at collecting leads and helping walk-ins to self-screen. One of the criticisms of recruiters in mall-based stations is that recruiters end up spending time on walk-ins who are not qualified or are of low quality. The station design and operation could be modified so that visitors are given the necessary information to enable them to self-screen.

- Upgrading certain parts of the facility, such as the computer kiosk, to optimize their attractiveness to youth.

Recommendation No. 3: Consider Giving the Station to One Service to Experiment with and Operate. As this report describes, some of the complexity in operating Potomac Mills stems from the colocation of multiple services in a joint facility, in which the services share common areas (such as a lobby) and/or recruiters of different services are expected to cooperate in the operation of the station.

The experience to date in the Potomac Mills station is that recruiters prefer to forgo the use of certain station amenities rather than risk being perceived as unfairly using/exploiting those amenities to the detriment of the other services. For example, recruiters do not take advantage of the lobby area, which has become almost a "no-man's- 
land," largely unused and unexploited. In a similar vein, as we discussed in Chapter Two, the "jointness" of the station means that there is no one station commander, which a standard station, such as that in the Eagle Ridge Mall, would have; hence, no one is truly in charge of the station on either a day-to-day or a long-term basis.

Thus, one approach to facilitating innovation and experimentation within Potomac Mills would be to turn it over completely to one service for an extended period of time. Given that the Woodbridge station was never closed, this change can be made in such a way that the effect on the other services' recruiting efforts would be minimized. That one service would then have free rein to experiment with the staffing, operation, and management of the station, with the goal of figuring out how to maximize the use of a MERS in a large commercial mall.

Recommendation No. 4: Once the MERS Concept Has Been Refined, Conduct Broader, Formal Experiments to Ensure Its Widespread Applicability. Originally envisioned as an experimental test of a concept that DoD would construct 30 of around the country and conduct performance evaluations on using a formal, statistical methodology, the marketing-enhanced recruiting station awaits formal concept testing. As mentioned in Chapter One, such testing has been used and continues to be used in specific areas of military recruiting: the Army's Enlistment Bonus Experiment in the early 1980s (Polich, Dertouzos, and Press, 1986), the Educational Assistance Test Program in 1981 (Fernandez, 1982), and the Advertising Mix Test (Carroll, 1987).

Once sufficient experimentation at Potomac Mills has been conducted so that the MERS concept has been optimized and fully proven in that one location, a larger set of stations should be constructed and formally evaluated. Such an evaluation will provide more-definitive evidence that the MERS works in all locations and under a variety of conditions. In particular, it would be possible to evaluate a number of station variants at the same time to determine which combinations of features are widely applicable and are most effective. 


\section{MINING FOR DIAMONDS}

Recommending putting recruiting stations in malls should be like telling prospectors to go into the mines to look for diamonds. And such a mining metaphor is particularly apt for military recruiting: It is not an accident that recruiters refer to the process of looking for new recruits as prospecting.

Using the mining metaphor, the question we set out to answer is whether the additional yield in these retail "mines," versus existing strip mall-based "mining," is worth the increased cost of operations. What we have found is that the mine shows distinct promise but that the operators have not yet learned how to maximize the quantity of diamonds extracted. Hence, before deciding to abandon the mine, the operators should first learn to optimize the mining operation. It is only through experimentation and innovation that the mine will achieve its highest yield. 
Appendix RAND MILITARY CAREER CENTER EVALUATION

RAND is a non-profit organization conducting research about military recruiting. Your participation in this survey, your responses, and your personal information will be kept strictly confidential. It will not be released to any recruiter or anyone outside of RAND.

\section{Tell Us What You Think About Military Recruiting}

If you are interested in participating in an interview about military recruiting, please send us your name and contact information. This information will be kept strictly confidential. RAND will not give it to anyone, including the Department of Defense or any military recruiters. Participants chosen for the study will receive $\$ 25$.

Name

Address

City

State

Zip

Day Phone

Evening Phone

Email Address 
1. Gender (check one)

$\square$ Male

$\square$ Female

2. Age (check one)

$\square$ Under 18 years old

$\square$ 18-24 years old

$\square$ 25-34 years old

$\square$ Over 34 years old

3. Race/Ethnicity (check one) ㄱ Caucasian

$\square$ African American

$\square$ Asian

$\checkmark$ Hispanic

$\neg$ Other

4. I am currently: (check one)

$\square$ In school

ᄀ Not in school
5. Marital Status (check one)

$\neg$ Single

$\square$ Married

$\checkmark$ Married with children

6. I have: (check all that apply)

$\checkmark$ A high school degree or GED

$\checkmark$ Completed some college

$\neg$ A college degree

7. Military Experience (check all that apply) $\checkmark$ I have never been in the military

$\square$ An immediate family member (parent, brother or sister) is/was in the military

$\checkmark$ A relative in my family (uncle, cousin, etc.) is/was in the military

$\neg$ One of my friends joined the military

$\checkmark$ I was previously in the military

$\square$ Other

\section{Please tell us what you think of the Potomac Mills Military Career Center}

\section{I found the Military Career Center (check any that apply):}

$\square$ exciting $\square$ welcoming $\square$ hi-tech $\square$ educational $\checkmark$ boring $\square$ other

2. The Military Career Center was useful for (check all that apply):

- Learning about:

$\checkmark$ military career opportunities

$\square$ educational benefits

$\square$ other career benefits

- Contacting:

$\square$ military recruiters

$\square$ others interested in a military career

$\checkmark$ military web sites

- $\square$ The Center was not useful to me 


\section{The Military Career Center was (pick one):}

$\square$ very interesting $\square$ somewhat interesting

$\square$ somewhat uninteresting $\square$ very uninteresting

4. What brought you into the Military Career Center? (check all that apply):

$\square$ referred $\square$ just walking by $\square$ browsing

$\checkmark$ curious about military $\square$ other

5. After visiting the Career Center, I am (pick only one):

$\square$ more/less/ $\square$ neither more nor less interested in joining the military

6. The best feature of the Military Career Center was (pick one):

$\square$ videos $\square$ computers $\square$ recruiters $\square$ literature

$\square$ staff $\square$ other

7. How did you find out about the Military Career Center? (check all that apply):

- I heard about it from:

$\square$ school $\square$ friends $\square$ parents

$\square$ other relative

- I saw it:

$\square$ just walking by $\square$ in an advertisement

$\square$ on the internet $\square$ in the paper

8. Other than this Center, have you ever visited a military recruiting office before? (pick one):

$\checkmark$ yes-once $\square$ yes-more than once $\square$ no

9. Have you ever been contacted by a recruiter before? (pick one):

$\checkmark$ yes-once $\square$ yes-more than once $\square$ no 
If Yes, which service? (check all that apply):

$\square$ Army $\square$ Air Force $\square$ Navy $\square$ Marine Corps $\square$ Coast Guard Suggestions to improve the Career Center:

Please return this in the postage-paid envelope or mail it to:

RAND

1700 Main St., P.O. Box 2138

Santa Monica, CA 90407-2138

THANK YOU FOR YOUR HELP! 


\section{BIBLIOGRAPHY}

Anton, M., and L. Earnest, "Courting Teenagers at the Mall: The Block at Orange Is, by Design, a Magnet for the Young, but Getting Adults to Go There Too Can Be Tricky," Los Angeles Times, October 27, 2000, p. A1.

Asch, B. J., Navy Recruiter Productivity and the Freeman Plan, Santa Monica, Calif.: RAND, R-3713-FMP, 1990.

Asch, B. J., M. R. Kilburn, and J. A. Klerman, Attracting College-Bound Youth into the Military: Toward the Development of New Recruiting Policy Options, Santa Monica, Calif.: RAND, MR-984OSD, 1999.

Asch, B. J., and B. R. Orvis, Recent Recruiting Trends and Their Implications: Preliminary Analysis and Recommendations, Santa Monica, Calif.: RAND, MR-549-A/OSD, 1994.

Carroll, V. P., DoD Advertising Mix Test, Philadelphia, Penn.: Wharton Center for Applied Research, July 1987.

"CBL \& Associates Acquires Pennsylvania Mall," Nashville Business Journal, July 2, 1999. Available at nashville.bcentral.com/ nashville/stories/1999/06/28/daily25.html.

Cordeiro, J. D., M. A. Friend, J. O. Miller, K. W. Bauer, Jr., and J. M. Kloeber, "Using Simulation to Model Time Utilization of Army Recruiters," Military Operations Research, Vol. 6, 2001, pp. 59-68.

Dahlman, C., "Assessing the Environment: Interviews with DoD Recruiters," Santa Monica, Calif.: unpublished RAND research. 
Dertouzos, J. N., Recruiter Incentives and Enlistment Supply, Santa Monica, Calif.: RAND, R-3065-MIL, 1985.

Fernandez, R. L., Enlistment Effects and Policy Implications of the Educational Assistance Test Program, Santa Monica, Calif.: RAND, R-2935-MRAL, September 1982.

General Accounting Office, Military Recruiting: DOD Could Improve Its Recruiter Selection and Incentive Systems, Washington, D.C.: GAO/NSIAD-98-58, January 1998.

"Hoteling Variation Works for Employees on the Go," Los Angeles Times, August 7, 2000, p. C7.

Johnson, Greg, "Malls Are Becoming Walled Ad Sites," Los Angeles Times, June 2, 2001, p. C2.

Jones Lang LaSalle, "Fact Sheet” on the Westmoreland Mall, 2000.

"Mayor Giuliani and Army Secretary Louis Caldera Rededicate Times Square Armed Forces Recruitment Station," Press Release No. 341-99, September 7, 1999, as accessed at http://www.ci.nyc.ny. us/html/om/html/99b/pr341-99.html on July 28, 2003.

"Mayor Giuliani and Defense Secretary Cohen Visit Times Square Armed Forces Recruitment Station," Press Release No. 317-98, July 6, 1998, as accessed at http://www.ci.nyc.ny.us/html/om/html/ 98b/pr317-89.html on July 28, 2003.

The Mills, Potomac Mills Marketing Program 2000, Prince William, Va., 2000.

The Mills, Potomac Mills Annual Marketing Program 2001, Prince William, Va., 2001.

Orvis, B. R., and B. J. Asch, Military Recruiting: Trends, Outlook, and Implications, Santa Monica, Calif.: RAND, MR-902-A/OSD, 2001.

Orvis, B. R., N. Sastry, and L. L. McDonald, Military Recruiting Outlook: Recent Trends in Enlistment Propensity and Conversion of Potential Enlisted Supply, Santa Monica, Calif.: RAND, MR-677A/OSD, 1996. 
Polich, J. M., J. N. Dertouzos, and S. J. Press, The Enlistment Bonus Experiment, Santa Monica, Calif.: RAND, R-3353-FMP, April 1986.

The Television Bureau of Advertising Online at www.tvb.org, accessed January 19, 2003.

Thomas, J. R., Reengineering DoD Recruiting, Santa Monica, Calif.: RAND, IP-165, 1997.

“Times Square Recruiting Station,” DoD News Briefing, July 6, 1998.

U.S. Department of Commerce, Bureau of the Census, 1990 Census of Population and Housing, Summary Tape file 3A. Accessed at http://venus.census.gov/cdrom/lookup.

U.S. Department of Defense, 2000 Military Recruiter Survey, Tabulations of Responses, Volumes 1 and 2, Washington, D.C.: Defense Human Resources Activity, Joint Advertising, Market Research and Studies, August 2002.

Welker, Kathleen, “Caldera Rededicates New Times Square Recruiting Station," Army LINK News, September 7, 1999.

Wilson, M. J., et al., 2000 Military Recruiter Survey: An Overview, Arlington, Va.: Defense Human Resources Activity, JMARS Report No. 2002-001, 2002 (DTIC Report No. ADA 408153). 
